Clusterização de dados utilizando técnicas de redes complexas e computação bioinspirada 



\section{Clusterização de dados utilizando técnicas de redes complexas e computação bioinspirada}

Tatyana Bitencourt Soares de Oliveira

Orientador: Prof. Dr. Zhao Liang

Dissertação apresentada ao Instituto de Ciências Matemáticas e de Computação - ICMC/USP, como parte dos requisitos para obtenção do título de Mestre em Ciências de Computação e Matemática Computacional.

USP - São Carlos

Janeiro/2008 



\section{Agradecimentos}

Quando um trabalho chega à conclusão, sempre existem inúmeras pessoas as quais queremos agradecer. Às vezes essas pessoas não têm idéia de sua importância na execução de um trabalho, e precisam de um agradecimento mais explícito.

Agradeço inicialmente à Deus, pela fé e serenidade proporcionados nos momentos mais necessários.

Agradeço à minha família, meu porto seguro. Em especial, obrigada à minha mãe Ingrid, pelo incentivo constante, ao meu pai Silvio, pelo apoio incondicional, e ao meu irmão Crystian, pela alegria contagiante. Um obrigada especial também à minha tia Sigried e minha prima Areane, pela presença constante.

Obrigada ao professor Zhao, meu orientador, pela direção e pela dedicação nesses dois anos de trabalho.

Obrigada ao meu amigo, companheiro e amor, Eduardo, pelo apoio e compreensão em todos os momentos.

Obrigada aos amigos, próximos ou distantes, sempre com palavras de conforto e apoio nas horas mais difíceis.

Obrigada aos professores e funcionários do ICMC/USP, que de uma forma ou de outra contribuíram para a realização desse trabalho.

Obrigada à CAPES, pelo apoio financeiro a esse trabalho.

A todos que contribuíram de alguma forma para essa realização, esse é o meu agradecimento. 



\begin{abstract}
A
Clusterização de dados em grupos oferece uma maneira de entender e extrair informações relevantes de grandes conjuntos de dados. A abordagem em relação a aspectos como a representação dos dados e medida de similaridade entre clusters, e a necessidade de ajuste de parâmetros iniciais são as principais diferenças entre os algoritmos de clusterização, influenciando na qualidade da divisão dos clusters. O uso cada vez mais comum de grandes conjuntos de dados aliado à possibilidade de melhoria das técnicas já existentes tornam a clusterização de dados uma área de pesquisa que permite inovações em diferentes campos. Nesse trabalho é feita uma revisão dos métodos de clusterização já existentes, e é descrito um novo método de clusterização de dados baseado na identificação de comunidades em redes complexas e modelos computacionais inspirados biologicamente. A técnica de clusterização proposta é composta por duas etapas: formação da rede usando os dados de entrada; e particionamento dessa rede para obtenção dos clusters. Nessa última etapa, a técnica de otimização por nuvens de partículas é utilizada a fim de identificar os clusters na rede, resultando em um algoritmo de clusterização hierárquico divisivo. Resultados experimentais revelaram como características do método proposto a capacidade de detecção de clusters de formas arbitrárias e a representação de clusters com diferentes níveis de refinamento.
\end{abstract}



Ata clustering is an important technique to understand and to extract relevant information in large datasets. Data representation and similarity measure adopted, and the need to adjust initial parameters, are the main differences among clustering algorithms, interfering on clusters quality. The crescent use of large datasets and the possibility to improve existing techniques make data clustering a research area that allows innovation in different fields. In this work is made a review of existing data clustering methods, and it is proposed a new data clustering technique based on community dectection on complex networks and bioinspired models. The proposed technique is composed by two steps: network formation to represent input data; and network partitioning to identify clusters. In the last step, particle swarm optimization technique is used to detect clusters, resulting in an hierarchical clustering algorithm. Experimental results reveal two main features of the algorithm: the ability to detect clusters in arbitrary shapes and the ability to generate clusters with different refinement degrees. 



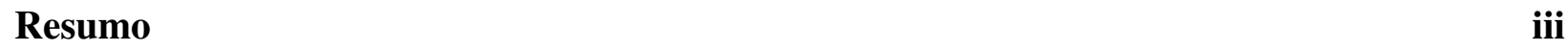

$\begin{array}{lll}\text { Abstract } & \text { v }\end{array}$

1 Introdução $\quad 1$

1.1 Motivação . . . . . . . . . . . . . . . . . . . . 4

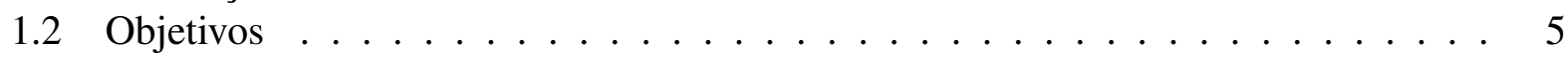

1.3 Estrutura do documento . . . . . . . . . . . . . . 6

2 Clusterização de dados $\quad 7$

2.1 Etapas do processo de clusterização . . . . . . . . . . . . . . . . 8

2.2 Medidas de similaridade . . . . . . . . . . . . . . . . . . . 9 9

2.2.1 Similaridade entre dados . . . . . . . . . . . . . . . . . . . . 9

2.2.2 Similaridade entre clusters . . . . . . . . . . . . . . . . 11

2.3 Técnicas de clusterização de dados . . . . . . . . . . . . . . . . . . . . 12

2.3.1 Algoritmos de clusterização por particionamento . . . . . . . . . . . . 12

2.3.2 Redes Auto-Organizáveis - SOM . . . . . . . . . . . . . . . . 14

2.3.3 Algoritmos de clusterização por densidade . . . . . . . . . . . . . . 15

2.3.4 Algoritmos de clusterização hierárquica . . . . . . . . . . . . . . . . 16

2.3.5 Algoritmos de clusterização baseados em grafo . . . . . . . . . . . . . . . 18

2.4 Validação . . . . . . . . . . . . . . . . . . . . . . 24

2.4 .1 Índice Davies-Bouldin . . . . . . . . . . . . . . . . 25

2.4 .2 Índice Rand Corrigido . . . . . . . . . . . . . . . . . . . . 26

2.5 Considerações Finais . . . . . . . . . . . . . . . . . . 26

3 Detecção de comunidades em redes complexas 29

3.1 Edge Betweenness . . . . . . . . . . . . . . . . . . . . . 32

3.2 Partícula Browniana . . . . . . . . . . . . . . . . . 34

3.2.1 Exemplos de comunidades locais e globais . . . . . . . . . . . 36

3.2 .2 Índice de dissimilaridade . . . . . . . . . . . . . . . . . . . . . . . . . . . . . . 37

3.3 Modularidade e estrutura de comunidades . . . . . . . . . . . . . . . . . . . . . . . . . . . . . . . . . .

3.4 Considerações Finais . . . . . . . . . . . . . . . . . . . 40 
4 Técnicas de Computação Bioinspirada $4 \mathbf{4 1}$

4.1 Sistema de Colônia de Formigas . . . . . . . . . . . . . . . . . . . . . . 41

4.1.1 Colônia de Formigas e o Caixeiro Viajante . . . . . . . . . . . . . . . . . 43

4.2 Otimização por Nuvem de Partículas - PSO . . . . . . . . . . . . . . . . 45

4.2.1 Descrição do PSO clássico . . . . . . . . . . . . . . . . . . 45

4.2.2 PSO com velocidade adaptativa . . . . . . . . . . . . . . . 48

4.3 Aprendizado por Reforço . . . . . . . . . . . . . . . . . . . . . 50

4.3 .1 O Aprendizado . . . . . . . . . . . . . . . . 53

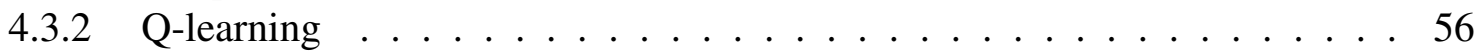

4.3 .3 Programação Neurodinâmica . . . . . . . . . . . . . . . . . . 58

4.4 Considerações Finais . . . . . . . . . . . . . . . . . . . . . . 59

5 Clusterização de dados e detecção de comunidades

5.1 Visão geral . . . . . . . . . . . . . . . . . . . . . . 62

5.2 Formação da rede . . . . . . . . . . . . . . . . . . . . . 62 . . . . . . . . . 63

5.3 Regra de atualização do ângulo . . . . . . . . . . . . . . . . . . 63

$5.3 .1 \quad$ Cálculo do peso $w_{i j} \ldots \ldots \ldots \ldots$. . . . . . . . . . 66

5.3.2 Taxa de atualização de ângulo e estabilidade do sistema . . . . . . . . . . . 69

5.4 Algoritmo de clusterização de dados . . . . . . . . . . . . . . . . . 71

5.4 .1 Exemplo de execução . . . . . . . . . . . . . . . . . . . . . . . . . . . . . . 73

5.5 Considerações Finais . . . . . . . . . . . . . . . . . . . . . 74

6 Experimentos $\quad \mathbf{7 7}$

6.1 Metodologia de avaliação . . . . . . . . . . . . . . . . . 77

6.2 Dados artificiais . . . . . . . . . . . . . . . . . 78

6.2 .1 Redes artificiais . . . . . . . . . . . . . . . . . 78

6.2 .2 Conjunto de dados artificiais . . . . . . . . . . . . . . . . . . 79

6.3 Dados reais . . . . . . . . . . . . . . . . . 80

6.3 .1 Redes complexas reais . . . . . . . . . . . . . . . 82

6.3 .2 Conjuntos de dados reais . . . . . . . . . . . . . . 83

6.4 Considerações Finais . . . . . . . . . . . . . . . . . . . 85

$\begin{array}{lll} & \text { Conclusão } & \mathbf{8 7}\end{array}$

7.1 Contribuições . . . . . . . . . . . . . . . . . . . . 88

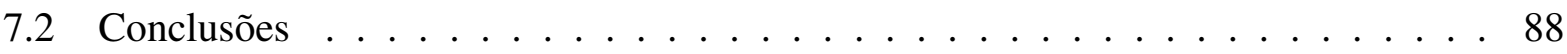

7.3 Trabalhos Futuros . . . . . . . . . . . . . . . . . . 89 


\section{Lista de Figuras}

1.1 Clusterização de um conjunto de dados (a) dados originais; (b) divisão em dois clusters; (c) divisão em três clusters e (d) divisão em cinco clusters. Cada cluster é representado por uma cor diferente. . . . . . . . . . . . . . . . 1

1.2 Exemplos de clusters de diferentes formas e tamanhos (Karypis et al., 1999) . . . . 2

2.1 Etapas do processo de clusterização . . . . . . . . . . . . . . . . . . 8

2.2 Ilustração do cálculo da distância de Minkowski (Jain \& Dubes, 1988) . . . . . . . 10

2.3 Em um algoritmo que leva em conta apenas a proximidade entre elementos dos dois clusters, os clusters em (a) seriam unidos por estarem mais próximos em detrimento dos clusters em $(\mathrm{b}) . \ldots \ldots \ldots \ldots$. . . . . . . . . . . . 11

2.4 Em um algoritmo que leva em conta apenas a interconectividade entre elementos dos dois clusters, os clusters verde e azul seriam unidos e não os clusters azul e vermelho. . . . . . . . . . . . . . . . . . 12

2.5 Saída gerada por algoritmo de clusterização hierárquica . . . . . . . . . . . . . 16

2.6 Construção do dendrograma nos algoritmos de clusterização hierárquica . . . . . . 17

2.7 Etapas do algoritmo Chameleon . . . . . . . . . . . . . . . . . 20

2.8 Construção de grafos a partir dos k-vizinhos mais próximos: (a) dados originais, (b)1-, (c)2-, (d)3-vizinhos mais próximos . . . . . . . . . . . . . 21

2.9 Divisão em duas partições pelo algoritmo de particionamento de grafos multinível. Em (a) o algoritmo identifica regiões esparsas; em (b) o algoritmo identifica a conexão entre os clusters. (Karypis et al., 1999) . . . . . . . . . . . . . . . .

3.1 Exemplo de rede randômica com 8 vértices. (a) Quando $p=0$ o grafo gerado não possui arestas; (b) Quando $p=0.1$ poucas arestas são adicionadas contribuindo para a formação de árvores; (c) A adição de mais arestas, $\operatorname{com} p=0.3$, possibilita a formação de ciclos no grafo; (d) Para $p=0.8$, o grafo gerado aproxima-se de um grafo completo. . . . . . . . . . . . . . . . . . .

3.2 Processo de alteração de uma fração $p$ de arestas de uma rede regular formada por 20 vértices. Para determinados valores de $p$, a rede criada é uma rede de pequeno-mundo. Conforme o valor de $p$ aproxima-se de 1, grande parte das arestas é modificada, resultando em uma rede randômica (Albert \& Barabasi, 2002). . . . . 30

3.3 Rede Livre de Escala, formada por 200 vértices e 199 arestas, com a presença de "hubs" (vértices com grande número de arestas incidentes). Vértices em diferentes cores possuem maior grau k: vermelho $\rightarrow k=33$; azul $\rightarrow k=12$ e verde $\rightarrow$ $k=11($ Strogatz, 2001). . . . . . . . . . . . . . . . 31 
3.4 Rede com estrutura de comunidade, formada por três comunidades. . . . . . . . . . 32

3.5 Saída gerada por algoritmo de detecção de comunidades . . . . . . . . . . . . . . 32

3.6 Divisão de comunidades da rede de interações do clube de caratê de (Zachary, 1977). Originalmente os dados são divididos em duas comunidades representadas pelas diferentes cores, enquanto a divisão dada pelo algoritmo de (Zhou, 2003b) é dada pela localização espacial dos nós. . . . . . . . . . . . . . . . . . . 36

3.7 Divisão de comunidades da rede de interações do campeonato de futebol americano de (Girvan \& Newman, 2002) dada pelo algoritmo de (Zhou, 2003b) . . . . . 37

4.1 Formigas reais em busca por alimento: (a) formigas seguem um caminho de seu ninho à fonte de alimento (b)um obstáculo é colocado no caminho e as formigas devem decidir qual caminho seguir (c)a quantidade de feromônio no menor caminho é maior e mais formigas seguem por ele. . . . . . . . . . . . . . . . 42

4.2 Influência da quantidade de formigas na busca pelo menor caminho . . . . . . . . . 44

4.3 Convergência das partículas para o mínimo global da função de Raistrigin . . . . . . 48

4.4 Influência de $\alpha$ na definição do coeficiente de velocidade $c_{\alpha}(\phi)$. Para qualquer valor de $\alpha, c_{\alpha}(\phi)=1$ se $\phi=1$. Para $\alpha=0, c_{\alpha}(\phi) \equiv 1$. Para $0<\alpha<\infty$, $0<c_{\alpha}(\phi)<1$ se $0<\phi<1$. Para $\alpha=\infty, c_{\alpha}(\phi)=0$ se $0<\phi<1 . \ldots . . .50$

4.5 Diagrama da interação entre o sistema de aprendizado e seu ambiente. . . . . . . . 52

4.6 Interpretação do Q-valor (Haykin, 1999) . . . . . . . . . . . . . . . . . . . . 55

4.7 Utilização de rede neural para aproximação da função valor $V^{*}$ (Haykin, 1999) . . 58

5.1 As setas indicam o valor do ângulo de um nó $v_{i}$, da rede artificial da Figura 5.2, e seus vizinhos. As cores indicam o cluster ao qual o nó pertence. (a) Inicialmente os ângulos dos nós movimentam-se aleatoriamente. (b) Após algumas iterações, nós de um mesmo cluster entram em "acordo" e tendem a ter ângulos similares. . . 64

5.2 Rede artificial original. Nós de diferentes cores pertencem à diferentes clusters. . . 64

5.3 Evolução do processo de atualização de ângulos. Nas primeira iterações, os ângulos encontram-se desordenados. Após algumas iterações, os ângulos dos vértices dividem-se em grupos estáveis.

5.4 Evolução do processo de atualização de ângulos dos nós da rede artificial da Figura 5.2. A divisão de ângulos dos vértices que pertencem originalmente aos clusters em azul e verde não é tão clara, diferente do que acontece na execução mostrada na Figura 5.3. . . . . . . . . . . . . . . . . . . . . .

5.5 (a) Conjunto de dados original (b) Estrutura E1, baixo nível de refinamento, dividindo os dados em 2 clusters; (c) Estrutura E2, maior nível de refinamento, dividindo os dados em 4 clusters. . . . . . . . . . . . . . . . . . . . . .

5.6 Interações entre o vértice $v_{0}$ e seus vizinhos, após a modelagem do conjunto de dados em uma rede, onde o peso nas arestas indica a distância euclidiana entre os vértices. A cor de cada vértice indica a qual cluster ele pertence originalmente, de acordo com a estrutura $E 2$ apresentada na Figura 5.5(c).

5.7 Relação entre o peso do vértice $v_{j}$ na atualização do ângulo de $v_{0}$ e a variação de $\alpha$. A cor da série indica o cluster ao qual o vértice pertence originalmente na estrutura $E 2$. Conforme o valor de $\alpha$ aumenta, a influência de vizinhos mais distantes na atualização do ângulo de $v_{0}$ diminui mais acentuadamente do que a influência de vizinhos mais próximos. 
5.8 Influência de $S N\left(v_{0}, v_{j}\right)$ no cálculo do peso final $w_{0, j}$ de cada vizinho de $v_{0}$. A cor da série indica o cluster ao qual o vértice pertence originalmente na estrutura $E 2$. É possível notar que os vizinhos que não pertencem ao mesmo cluster de $v_{0}$ são os que possuem o menor peso. . . . . . . . . . . . . . . . .

5.9 (a) O agrupamento de nós de um mesmo cluster é indicado pelo desvio padrão dos ângulos de $v_{i}$ e seus vizinhos; (b) Decrescimento da taxa de atualização dos ângulos à medida em que estes começam a agrupar-se.

5.10 Influência da escolha de $\beta$ na eficiência do algoritmo. (a) Quando $\beta=0.5$ o sistema atinge a estabilidade com os ângulos formando um único grupo; (b) Quando $\beta=50$, a atualização dos ângulos é muito lenta, resultando em nenhum agrupamento dos ângulos; (c) Quando $\beta=5$, o sistema atinge a estabilidade quando os ângulos de nós de um mesmo cluster encontram-se agrupados. . . . . . . . . . . . 72

5.11 Divisão do cluster $C 1$ através da regra de atualização de ângulos. O cluster é dividido na posição em que ocorreu a maior diferença entre ângulos. . . . . . . . . . 74

5.12 O cluster $C 2$ apresenta a maior diferença entre ângulos, após a aplicação da regra de atualização de ângulos a todos os clusters de CSet. . . . . . . . . . . . . . .

5.13 Os três clusters em CSet correspondem às comunidades da rede original. A partir desse ponto, a divisão dos clusters não revela qualquer estrutura de comunidades da rede original. . . . . . . . . . . . . . . . . . .

6.1 Relação entre o índice CR e a probabilidade de conectar vértices de comunidades diferentes, dada por $\mathrm{Pl}$, em rede artificial formada por 4 comunidades com 32 vértices cada. . . . . . . . . . . . . . . . . . . 79

6.2 Conjunto de dados com 2123 pontos. . . . . . . . . . . . . . . . . . 80

6.3 Resultado da clusterização dos dados da Figura 6.2, $\operatorname{com} \alpha=0.4$. (a) Divisão do conjunto de dados em 2 clusters. (b) Estrutura $E 1$, formada por 3 clusters. . . . . . 80

6.4 Resultado da clusterização dos dados da Figura 6.2, com $\alpha=0.5$. (a) Divisão do conjunto de dados em 2 clusters. (b) Divisão dos dados em 3 clusters, onde a estrutura $E 1$ não é mais identificada. (c) Divisão dos dados em 4 clusters. (d) Divisão dos dados em 5 clusters. (e) Estrutura E2, formada por 6 clusters. . . . . .

6.5 Evolução do processo de atualização dos ângulos para a rede social de (Lusseau et al., 2003). As duas comunidades reais podem ser identificadas pelos agrupamentos presentes na série temporal. . . . . . . . . . . . . . . . . . . 82

6.6 Dendrograma do resultado da simulação para a rede social de (Lusseau et al., 2003). O dendrograma revela a divisão dos dados nas duas comunidades originais, indicadas pelos itens em verde (41 elementos) e itens em vermelho (21 elementos).

6.7 Estrutura de comunidades encontrada pelo algoritmo proposto no conjunto de dados de (Girvan \& Newman, 2002). Os nós são coloridos de acordo com as comunidades reais, e a localização espacial indica as comunidades identificadas pelo algoritmo. O algoritmo apresenta média de $C R=0.8017$, tendo melhores resultados de $C R$ quando a partição tem exatemente 12 grupos. Grande parte dos nós classificados erradamente pelo algoritmo trata-se de nós instáveis.

6.8 Dendrograma do resultado da simulação para a estrutura $E 1$ do conjunto de dados golub. A linha pontilhada corta o dendrograma em dois clusters, representando dois tipos de leucemia: $A L L$ (itens em vermelho) and $A M L$ (itens em azul). . . . . . 



\section{Lista de Tabelas}

2.1 Cálculo das distâncias de acordo com as três variações da distância de Minkowski . 11

5.1 Proporção de vértices em comum entre $v_{0}$ e seus vizinhos $\left(S N\left(v_{0}, v_{j}\right)\right) \ldots$. . . 68

6.1 Resultados da simulação para o conjunto de dados IRIS (3 clusters originais) . . . . 84

6.2 Número de elementos dos clusters das duas estruturas conhecidas do conjunto de dados GOLUB (Golub et al., 1999) . . . . . . . . . . . . . . . . . 85

6.3 Resultados da simulação para o conjunto de dados GOLUB - E1 (2 clusters originais) 85

6.4 Resultados da simulação para o conjunto de dados GOLUB - E2 (3 clusters originais) 85 
A clusterização de dados em grupos pode oferecer uma maneira de entender e extrair informações relevantes de grandes conjuntos de dados. A idéia é que dados de um mesmo grupo tenham mais características em comum entre si do que com dados de outro grupo.

A principal diferença entre classificação e clusterização de dados é que na primeira os dados devem ser atribuídos a grupos já conhecidos previamente, enquanto a segunda deve "descobrir" esses grupos. A Figura 1.1 mostra um conjunto de dados antes da clusterização (Figura 1.1 (a)) e maneiras diferentes de separá-los em grupos, onde cada cor corresponde a um grupo: na Figura 1.1 (b) os dados são separados em dois clusters; na Figura 1.1 (c) em três clusters e na Figura 1.1 (d) em cinco clusters.

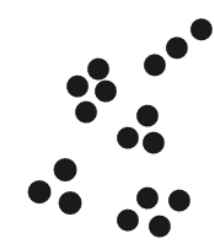

(a) Dados iniciais

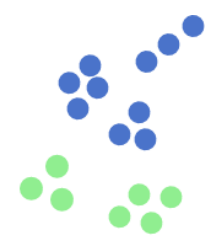

(b) Dois clusters

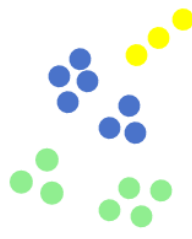

(c) Três clusters

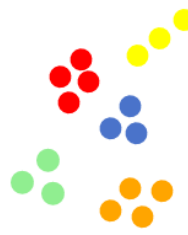

(c) Cinco clusters

Figura 1.1: Clusterização de um conjunto de dados (a) dados originais; (b) divisão em dois clusters; (c) divisão em três clusters e (d) divisão em cinco clusters. Cada cluster é representado por uma cor diferente.

O problema de clusterização de dados é relevante para as mais diversas áreas de pesquisa, como aprendizado de máquina (Mitchell, 1997), mineração de dados (Tan et al., 2005) e reconhecimento de padrões (Bishop, 2006). Entre as aplicações realizadas nessas áreas encontram-se bioinformá- 
tica (Jiang et al., 2004; Golub et al., 1999), classificação de documentos da Web (Boley et al., 1999) e segmentação de imagens (Celenk, 1990), entre outras.

Diversos fatores devem ser levados em consideração por um algoritmo de clusterização de dados: a representação dos dados, como mensurar a similaridade entre dados e entre clusters, como avaliar a qualidade do resultado gerado pelo algoritmo (Jain et al., 1999), entre outros. A abordagem dada a cada um desses fatores e os parâmetros a serem ajustados inicialmente são as principais diferenças entre os algoritmos de clusterização, influenciando na qualidade da divisão dos clusters.

Grupos de dados de diferentes formas, densidades e tamanhos estão presentes em diferentes conjuntos de dados. A restrição de alguns desses atributos pode levar a uma distribuição errada dos dados. Alguns algoritmos clássicos de clusterização são incapazes de detectar clusters como os da Figura 1.2, de tamanhos diferentes (Figura 1.2 (a)) e formas côncavas (Figura 1.2 (b)). Um exemplo é o algoritmo $K$-Médias ${ }^{1}$ que restringe-se a identificação de clusters de forma elipsoidal. Algoritmos que utilizam centros como representantes de cada cluster, e a similaridade entre os clusters é calculada de acordo com a similaridade entre os centros, têm dificuldades em identificar clusters de formas e tamanhos variados. Enquanto isso, alguns algoritmos capazes de detectar clusters de formas variadas são altamente sensíveis a ruídos ou acabam unindo clusters de maneira equivocada.

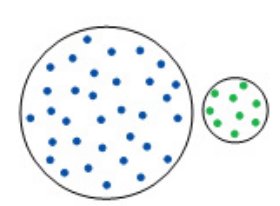

(a)

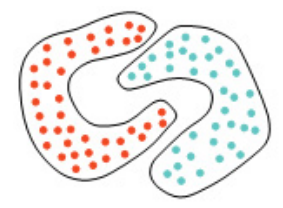

(b)

Figura 1.2: Exemplos de clusters de diferentes formas e tamanhos (Karypis et al., 1999)

Além da detecção de clusters de formas arbitrárias, a produção de uma estrutura hierárquica de clusters é uma característica desejada dos algoritmos de clusterização, pois produz diversas possibilidades de partição de um mesmo conjunto de dados. Essa hierarquia pode ser representada por uma árvore, onde as folhas representam o conjunto de dados, e à medida que a altura da árvore cresce os dados são agrupados em clusters. Cada nível dessa árvore corresponde a uma partição do conjunto de dados, onde a última partição é formada por um cluster com todos os dados e representada pela raiz da árvore. Em alguns métodos hierárquicos tradicionais, cada cluster é representado por um centróide (i.e. um ponto especial que traduz toda disposição dos dados no cluster), e a similaridade entre dois clusters é medida através da similaridade entre esses centróides. Essa abordagem encontra dificuldades quando dados de um certo cluster estão mais próximos do centro de outro cluster do que do centro de seu próprio cluster. Esta situação ocorre em muitos clusters naturais. Por exemplo, se há uma grande variação no tamanho dos clusters, como na Figura 1.2 (a), ou quando a forma dos clusters é côncava, como na Figura 1.2 (b).

\footnotetext{
${ }^{1}$ descrito em detalhes no capítulo 2
} 
Algoritmos baseados em grafos são capazes de identificar clusters de formas variadas e os representam de maneira hierárquica. Um exemplo dessa classe é o algoritmo Chameleon (Karypis et al., 1999). O Chameleon modela os dados em um grafo esparso, onde os nós representam os dados e as arestas representam a similaridade entre os nós, através do conceito de $K$-vizinhos mais próximos (k-nearest neighbor - KNN). O processo de clusterização dá-se em duas etapas: na primeira, o grafo é particionado em inúmeros subgrafos por um algoritmo de particionamento de grafos; na segunda etapa, os subgrafos são sucessivamente agrupados de maneira hierárquica, encontrando assim os clusters finais. Devido a representação em grafo dos dados, o algoritmo Chameleon busca a estrutura topológica entre os dados de entrada. Conseqüentemente, é capaz de identificar, até certo nível, formas de clusters variadas.

A segunda área contemplada nesse projeto é chamada Redes Complexas. As redes complexas estão presentes em muitas relações existentes em nosso planeta, como por exemplo a Internet, redes sociais entre indivíduos, cadeias alimentares e redes de interação entre proteínas, entre outros. Em 1998, (Watts \& Strogatz, 1998) descobriram que a média de caminhos mais curtos pode ser dramaticamente reduzida por alteração aleatória de poucas ligações de uma rede regular. A rede resultante é chamada de Rede de Pequeno Mundo (Small-World Network). Em 1999, Barabási e Albert (Barabasi \& Albert, 1999) descobriram que muitas redes complexas reais têm a distribuição de grau para os vértices que obedece a lei de potência (power law): $P(k) \sim k^{-\gamma}$, onde $k$ é o número de ligações de um vértice escolhido aleatoriamente e $\gamma$ é o expoente de escala. Essa distribuição heterogênea revela a existência de um pequeno grupo de vértices que possuem um grande número de ligações, dando origem às Redes Livre de Escala (Scale-free Networks). Enquanto isso as Redes Aleatórias (Random Networks), apresentam uma distribuição de grau homogênea, resultando na ausência de vértices dominantes.

A partir dessas descobertas, muitas pesquisas continuam sendo feitas e a área de redes complexas é atualmente bem definida. Um campo de pesquisa dessa área que vem sendo estudado por pesquisadores é a detecção de comunidades em redes complexas. Uma propriedade partilhada por muitas redes é a presença de comunidades: conjuntos de nós que possuem densa conexão entre si e baixa conexão entre grupos. Diversos algoritmos foram desenvolvidos para identificar comunidades em redes complexas, três desses abordados nesse trabalho. O método de detecção de comunidades desenvolvido por (Newman \& Girvan, 2004) é baseado no conceito de betweenness de cada aresta (quantidade total de menores caminhos que passam pela determinada aresta) da rede. A cada passo, a aresta de maior betweenness é removida, dividindo a rede em comunidades. O segundo método de identificação de comunidades é baseado no conceito de movimento browniano para calcular a distância entre os nós da rede. A partir da distância é calculado um índice de dissimilaridade entre os nós, usado na divisão da rede. Esse método foi desenvolvido por (Zhou, 2003b) e estendido posteriormente em (Zhou, 2003a). O terceiro método foi desenvolvido por (Newman, 2004b) e sugere um algoritmo que otimize o valor da modularidade, medida usada para qualificar determinada partição da rede em comunidades. 
Outra área de pesquisa discutida insipira-se em modelos biológicos para resolver problemas de otimização. Técnicas inteligentes têm sido aplicadas com sucesso em problemas de biologia molecular, computação e mecânica, e têm a vantagem de precisarem de pouca informação para encontrar a solução do problema. Colônia de formigas, inteligência coletiva e aprendizado por reforço são as técnicas bioinspiradas abordadas nesse trabalho.

A técnica de otimização por nuvem de partículas, ou Particle Swarm Optimization - PSO, foi desenvolvida por (Kennedy \& Eberhart, 1995) e inspira-se no comportamento de um bando de pássaros. Em linhas gerais, o PSO é formado por uma população de partículas que exploram o espaço de busca de maneira inicialmente aleatória. À medida que algumas partículas encontram uma parte do espaço de busca mais promissora, são seguidas pelas demais partículas que ajudam na exploração do espaço. Entretanto, as partículas ainda têm a possibilidade de explorar novas regiões e encontrar soluções melhores para o problema.

\subsection{Motivação}

A quantidade de algoritmos de clusterização é grande, mas muitos apresentam dificuldades em alguns aspectos. Por isso acredita-se existir um campo fértil para exploração de novas técnicas capazes de suprir e/ou amenizar as dificuldades encontradas em outros algoritmos de clusterização.

O processo utilizado por algoritmos de clusterização baseados em grafos consiste em representar um conjunto de dados em um grafo, e particioná-lo em subgrafos, onde cada subgrafo corresponde a um cluster. Para isso é necessário adotar uma medida de similaridade (distância) no processo de agrupamento, o que pode fazer com que o algoritmo apresente alguma dificuldade em determinar clusters de formas variadas. Em outras palavras, algoritmos baseados em grafos, como por exemplo Chameleon, não são completamente livre da medida de similaridade física na fase de partição de grafos. Enquanto isso, algoritmos de detecção de comunidade como (Newman \& Girvan, 2004), não utilizam qualquer medida de distância entre os dados de entrada, apenas a medida topológica do grafo. Por isso, acredita-se que a detecção de comunidades em redes que modelam a similaridade (distância) entre nós pode produzir bons resultados.

A teoria dos grafos considera principalmente grafos formados por poucos vértices, além de buscar soluções exatas para os problemas. Quando os grafos possuem um grande número de vértices, a busca por soluções ótimas torna-se inviável. Por outro lado, a área de redes complexas trata redes grandes, que modelam sistemas reais formados por milhares de nós. Ela apresenta alta robustez e eficiência ao abordar redes de larga escala porque não busca a solução ótima, e sim uma solução satisfatória. Esse trabalho considera os termos "grafo" e "rede" intercambiáveis.

Outro aspecto interessante é o fato de que o problema de identificação de comunidades pode ser visto como um problema de otimização, onde deve-se maximizar a quantidade de arestas entre nós de uma mesma comunidade e minimizar arestas entre nós de comunidades diferentes. Tal 
característica permite a aplicação de técnicas adaptativas baseadas em sistemas biológicos para detectar comunidades em redes.

Além disso, um mesmo conjunto de dados pode apresentar mais de uma divisão relevante dos dados, com diferentes graus de refinamento. Técnicas de clusterização que buscam uma única partição dos dados não conseguem identificar as demais partições relevantes. Na área de bioinformática, por exemplo, a identificação de subgrupos em um conjunto de dados é uma tarefa importante, auxiliando na descoberta de novos subgrupos de doenças. Assim, um algoritmo de clusterização capaz de detectar clusters com diferentes graus de refinamento torna-se muito importante nessa área.

\subsection{Objetivos}

O uso cada vez mais comum de grandes conjuntos de dados aliado à possibilidade de melhoria das técnicas já existentes tornam a clusterização de dados uma área de pesquisa que permite inovações em diferentes campos. Como na clusterização de dados os clusters não são conhecidos $a$ priori, a ocorrência de grupos de formas arbitrárias é possível e sua detecção correta é importante para organização e análise desses dados. Assim, o estudo de suas características e a busca por técnicas mais robustas e eficientes para sua detecção representa um grande avanço para a área de clusterização de dados.

O objetivo desse trabalho é desenvolver uma nova técnica para clusterização de dados buscando diminuir ao máximo a dependência de parâmetros pré-definidos e possibilitar a detecção de clusters de formas, densidades e tamanhos variados. A nova abordagem visa também a identificação de clusters com diferentes graus de refinamento, oferencendo diferentes interpretações válidas do conjunto de dados.

O novo método de clusterização será baseado em grafos, modificando os seguintes aspectos: obter novas formas de modelar o conjunto de dados em um grafo e representar a similaridade entre os dados; particionar o grafo em clusters através de uma técnica de identificação de comunidades em redes complexas inspirada em modelos inteligentes.

A primeira etapa do algoritmo proposto consiste na modelagem dos dados em forma de um grafo. No algoritmo Chameleon, a modelagem dos dados é feita através do conceito de $K$-vizinhos mais próximos (K-nearest neighbors - $\mathrm{KNN}$ ), resultando em uma rede sem pesos. A modelagem proposta incorpora à rede as distâncias entre os dados como peso nas arestas. Uma vantagem obtida com essa modelagem é que a similaridade entre os dados é considerada em conjunto com a distância topológica descrita pela rede. Outro aspecto interessante é que a técnica pode ser aplicada tanto para redes com ou sem peso.

Na segunda etapa, o algoritmo irá particionar a rede modelada no passo anterior, identificando hierarquicamente os clusters que compõem o conjunto de dados. Nessa etapa, as áreas de redes complexas e computação bioinspirada são unidas, através de uma técnica inspirada biologicamente 
para detectar as comunidades existentes na rede. Cada nó da rede possui um ângulo inicial e, como na técnica de nuvem de partículas, através da interação entre os nós da rede os clusters são identificados. Assim, os nós agem como se fossem partículas, e se auto-organizam para formação do padrão desejado. Os clusters são identificados de acordo com o agrupamento dos nós com ângulos similares.

A identificação de clusters com diferentes graus de refinamento ocorre através da variação de um parâmetro $\alpha$ durante a etapa de particionamento da rede. Esse parâmetro é responsável por definir a importância que cada vizinho terá na atualização do ângulo de um nó, de acordo com distância (dissimilaridade) entre eles, como será descrito nos capítulos a seguir.

Resumidamente, a abordagem proposta procura satisfazer duas características interessantes a algoritmos de clusterização: a detecção de clusters com diferentes formas, tamanhos e densidades, e a identificação de clusters com diferentes graus de refinamento, em um mesmo conjunto de dados. Os experimentos realizados com dados reais e artificiais, buscam comprovar a eficiência do algoritmo na clusterização de dados com clusters arbitrários e/ou partições com diferentes níveis de refinamento.

\subsection{Estrutura do documento}

No Capítulo 2 são apresentados os conceitos e técnicas de clusterização de dados, bem como os fatores que influenciam na eficácia da clusterização dos dados. No Capítulo 3 é definido o conceito de redes complexas e são expostas algumas recentes técnicas para detecção de comunidades em tais redes. No Capítulo 4 são descritas algumas técnicas de otimização baseadas em sistemas biológicos. No Capítulo 5 a abordagem proposta para clusterização de dados é apresentada. Os resultados dos experimentos são apresentados no Capítulo 6, mostrando a capacidade do algoritmo proposto em atingir os requisitos estabelecidos. No Capítulo 7 são apresentadas as conclusões obtidas com a realização desse trabalho, os principais resultados alcançados, além de possíveis trabalhos futuros. 


\section{Clusterização de dados}

Clusterização é a divisão de dados, com base na similaridade entre eles, em grupos disjuntos chamados clusters. Isso significa que dados em um mesmo cluster são mais similares do que dados pertencentes a clusters diferentes. $\mathrm{O}$ ato de agrupar os dados representa uma ferramenta importante no aprendizado e compreensão a respeito dos mesmos. Pode ser definido também como um problema de aprendizado não-supervisionado, já que a estrutura dos dados e as propriedades que os tornam similares são desconhecidas. Como não existem rótulos iniciais, o objetivo da clusterização é encontrar uma organização válida e conveniente dos dados, ao invés de separá-los em categorias como acontece no reconhecimento de padrões e na classificação de dados (Jain \& Dubes, 1988).

A seguir são definidos alguns termos de uso recorrente durante o capítulo:

- Conjunto de dados $X=\left\{x_{1}, x_{2}, \ldots, x_{n}\right\}$ onde $n$ é o número de elementos;

- Um dado $x_{i}$ é formado por um vetor de $d$ atributos ou características: $x_{i}=\left(x_{i 1}, x_{i 2}, \ldots, x_{i d}\right)$. A representação do dado com $d$ atributos é feita em um espaço $d$-dimensional;

- Os dados são armazenados em uma matriz de dados $n \times d$;

- Medida de similaridade é usada para quantificar a semelhança entre dados ou clusters;

- Matriz de similaridade é uma matriz $n \times n$ que indica a semelhança entre dados. Analogamente, a matriz de dissimilaridade indica a diferença entre os dados.

- $P=\left\langle C_{1}, C_{2}, \ldots, C_{K}\right\rangle$ indica uma partição do conjunto de dados em $K$ clusters. 


\subsection{Etapas do processo de clusterização}

Diversos fatores devem ser levados em consideração para assegurar a eficiência da clusterização: coleta dos dados, seleção das variáveis, medidas de similaridade, algoritmo de clusterização, validação e análise dos resultados obtidos (Jain et al., 1999), como mostra a Figura 2.1.

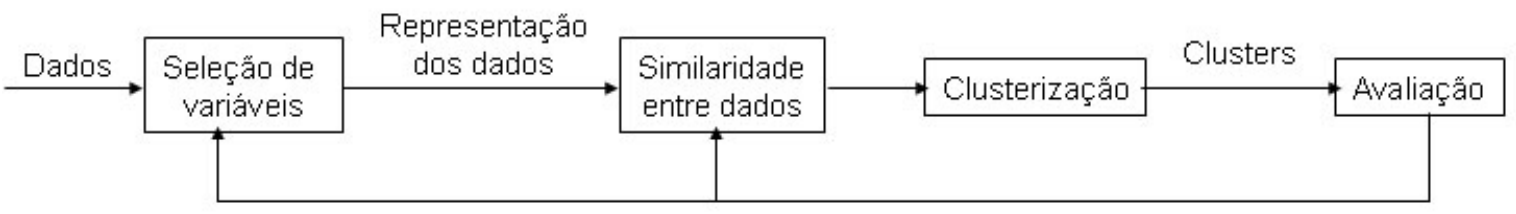

Figura 2.1: Etapas do processo de clusterização

A seguir são apresentadas as etapas que compõem o processo de clusterização:

\section{Pré-processamento e seleção de variáveis}

Etapa em que são identificadas as variáveis, ou atributos, mais relevantes do conjunto de dados inicial. Nessa etapa algumas variáveis podem ser eliminadas (por exemplo, quando todos os valores da variável são iguais) e os dados coletados são formatados de modo que o algoritmo de clusterização possa processá-los. Em um conjunto formado por $n$ dados, o resultado é uma matriz $n \times d$, onde $d$ é o número de atributos. Assim um dado corresponde a um ponto no espaço $d$-dimensional, e a tarefa de clusterização consiste em identificar conjuntos de dados próximos nesse espaço $d$-dimensional (Jain \& Dubes, 1988).

\section{Medidas de similaridade}

Para que a proximidade de dois dados, possa ser quantificada, é necessário adotar alguma medida de similaridade entre eles. Existem diversas maneiras de quantificar a similaridade, ou dissimilaridade, entre pares de dados e a escolha da medida de similaridade adequada é fundamental para a clusterização dos dados. Normalmente as medidas utilizadas representam a dissimilaridade entre dados. A maneira mais comum de calcular a dissimilaridade é através da distância Euclidiana, medida que será discutida juntamente com outros tipos de medidas de similaridade/dissimilaridade na Seção 2.2.

\section{Algoritmos de clusterização}

Nessa etapa define-se o modo de agrupamento dos dados, que pode ser realizado de diferentes maneiras. Os algoritmos de clusterização são classificados de acordo com as diferentes técnicas que empregam no agrupamento dos dados. Dentre esses algoritmos destacam-se os algoritmos de clusterização hierárquica e os algoritmos por particionamento, que serão discutidos na Seção 2.3. O resultado dessa etapa é a divisão do conjunto de dados inicial em clusters. Este trabalho focaliza esta etapa. 
4. Validação e análise dos resultados

Nessa etapa a qualidade dos clusters encontrados é avaliada, já que são desconhecidos inicialmente. Essa validação pode ser feita com base em índices estatísticos ou através da comparação com outros algoritmos. Além disso, a análise dos resultados pode levar à redefinição dos atributos escolhidos e/ou da medida de similaridade, definidos nas etapas anteriores. Os critérios adotados para validação dos resultados são descritos na Seção 2.4.

\subsection{Medidas de similaridade}

Muitos métodos de clusterização utilizam como ponto de partida uma matriz que reflete de maneira quantitativa a proximidade entre os elementos de um conjunto de dados. Essa proximidade pode representar a dissimilaridade, distância ou similaridade entre dois elementos. Quanto maior a similaridade, ou menor a dissimilaridade ou distância, entre dois elementos, mais próximos esses elementos encontram-se (Everitt et al., 2001). Essa matriz recebe o nome de matriz de similaridade ou matriz de proximidade.

As medidas de similaridade variam de acordo com a representação e escala dos atributos dos dados. Um atributo pode ter representação binária, discreta ou contínua. A escala indica o grau de importância de um atributo em relação aos demais. Por exemplo, um atributo pode indicar a porcentagem de aceitação de um produto no mercado (onde o valor do atributo varia de 0 a 100) ou indicar a distância entre duas cidades (onde o valor absoluto do atributo é relevante). Outros tipos de escalas são detalhados em (Jain \& Dubes, 1988).

A matriz de similaridade relaciona a proximidade entre dados do conjunto inicial. Entretanto, alguns algoritmos utilizam a união entre clusters, sendo necessário alguma forma para calcular a similaridade entre os clusters. Medidas para cálculo da similaridade entre dois dados e entre dois clusters são descritas a seguir.

\subsubsection{Similaridade entre dados}

A proximidade entre dois dados $x_{i}$ e $x_{j}$ é denotada por $d\left(x_{i}, x_{j}\right)$. Uma maneira de medir a similaridade entre atributos contínuos é através do cálculo da distância entre eles. Para que a distância seja considerada uma métrica deve satisfazer as seguintes condições:

- $d\left(x_{i}, x_{j}\right) \geq 0$

- $d\left(x_{i}, x_{j}\right)=0$, se e somente se $x_{i}=x_{j}$

- $d\left(x_{i}, x_{j}\right)=d\left(x_{j}, x_{i}\right)$

- $d\left(x_{i}, x_{l}\right) \leq d\left(x_{i}, x_{j}\right)+d\left(x_{j}, l\right)$ 
onde $x_{i}, x_{j}, x_{l} \in X$.

A distância mais utilizada no cálculo da similaridade entre dois dados é a distância de Minkowski. É calculada pela Equação 2.1, onde $d$ é o número de atributos do dado.

$$
d\left(x_{i}, x_{j}\right)=\sqrt[p]{\sum_{k=1}^{d}\left(\left|x_{i k}-x_{j k}\right|\right)^{p}}, p \geq 1
$$

Quando $p=2$ é calculada a distância euclidiana, representada na Equação 2.3. É a métrica mais utilizada quando os atributos possuem valores contínuos para avaliar a proximidade de dados representados em duas ou três dimensões. A variação do parâmetro $p$ define distâncias diferentes. As três variações mais comuns da distância de Minkowski são calculadas pelas Equações 2.2, 2.3 e 2.4 (Jain \& Dubes, 1988) e ilustradas na Figura 2.2.

- Distância de Manhattan, $p=1$

$$
d\left(x_{i}, x_{j}\right)=\sum_{k=1}^{d}\left(\left|x_{i k}-x_{j k}\right|\right)
$$

- Distância Euclidiana, $p=2$

$$
d\left(x_{i}, x_{j}\right)=\sqrt{\sum_{k=1}^{d}\left(\left|x_{i k}-x_{j k}\right|\right)^{2}}
$$

- Distância "sup", $p \rightarrow \infty$

$$
d\left(x_{i}, x_{j}\right)=\max _{1 \leq k \leq d}\left|x_{i k}-x_{j k}\right|
$$

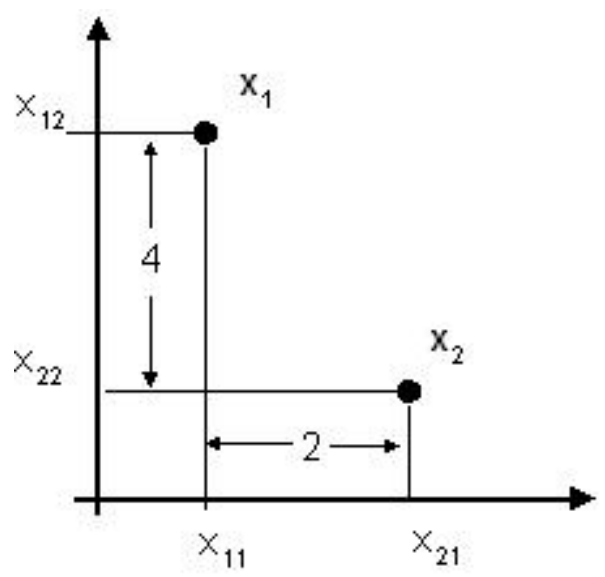

Figura 2.2: Ilustração do cálculo da distância de Minkowski (Jain \& Dubes, 1988)

O cálculo das distâncias de acordo com as três variações da distância de Minkowski no exemplo da Figura 2.2 é dado pela Tabela 2.2.1. 


\begin{tabular}{|c|c|}
\hline Distancia Euclidiana: & $\sqrt{4^{2}+2^{2}}=4.472$ \\
\hline Distancia de Manhattan: & $4+2=6$ \\
\hline Distancia "sup": & $\max \{4,2\}=4$ \\
\hline
\end{tabular}

Tabela 2.1: Cálculo das distâncias de acordo com as três variações da distância de Minkowski

Uma das desvantagens do uso da distância euclidiana é a possibilidade da dominância de um atributo sobre os demais. Uma das soluções para o problema consiste na normalização dos valores dos atributos de acordo com a sua variância e média. Entretanto a perda do valor absoluto pode não ser desejado em algumas aplicações.

\subsubsection{Similaridade entre clusters}

As medidas de similaridade descritas até o momento focalizam a proximidade entre dois dados e não entre grupos de dados. Entretanto em alguns algoritmos de clusterização é necessário unir dois clusters similares. Uma maneira de medir essa similaridade é calcular a distância entre todos os pares de pontos dos dois clusters, onde cada ponto pertence a um cluster diferente. Podem ser escolhidas a distância mínima entre todos os pares de dados (distância do vizinho mais próximo), a distância máxima (distância do vizinho mais distante) ou a média das distâncias entre os pares de dados (distância média) (Everitt et al., 2001).

$\mathrm{O}$ uso da proximidade como medida de similaridade entre clusters pode levar algoritmos a unirem clusters de maneira errada. Um exemplo é dado pela Figura 2.3. Considerando que seja usada a distância do vizinho mais próximo para medir a similaridade entre os clusters, sejam $d_{1}$ a distância entre os clusters da Figura 2.3(a) e $d_{2}$ a distância entre os clusters da Figura 2.3(b). Como a distância $d_{1}$ entre os elementos dos clusters da Figura 2.3(a) é pequena, a tendência é que o algoritmo una os dois clusters. Já os elementos dos clusters em Figura 2.3(b) possuem uma distância maior e provavelmente não seriam escolhidos pelo algoritmo para união.

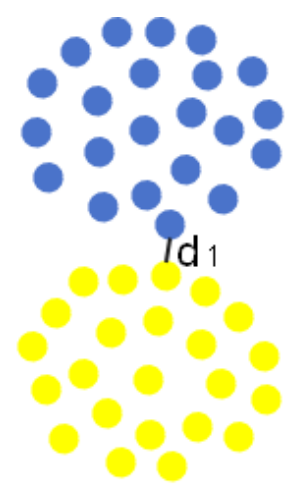

(a)

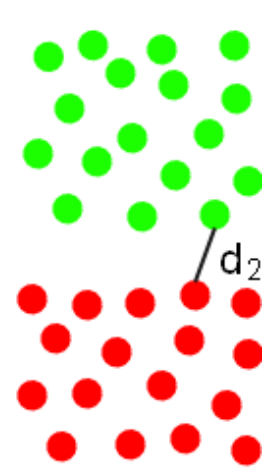

(b)

Figura 2.3: Em um algoritmo que leva em conta apenas a proximidade entre elementos dos dois clusters, os clusters em (a) seriam unidos por estarem mais próximos em detrimento dos clusters em (b). 
Outra maneira de medir a similaridade entre os clusters é o cálculo da interconectividade (agregação de similaridades) entre dois clusters. Nesse caso, dois dados $x_{i}$ e $x_{j}$ possuem uma conexão caso a similaridade entre eles exceda algum limite (essa similaridade entre dados pode ser obtida pelas medidas discutidas na Seção 2.2.1). A similaridade entre clusters é dada pela soma das conexões entre pares de dados, um dado de cada cluster. A idéia é que sub-clusters pertencentes a um mesmo cluster tenham alta interconectividade. Em geral, a interconectividade entre pares de clusters formados por muitos elementos é alta; por isso muitos algoritmos normalizam a similaridade entre clusters em relação a interconectividade entre os elementos de cada cluster (Karypis et al., 1999).

Um problema de algoritmos que utilizam apenas a interconectividade como medida de similaridade entre clusters é exemplificado na Figura 2.4. Supondo que a interconectividade entre os elementos dos clusters verde e azul seja maior que a interconectividade entre os elementos do cluster azul e vermelho, os clusters verde e azul seriam unidos de forma equivocada.

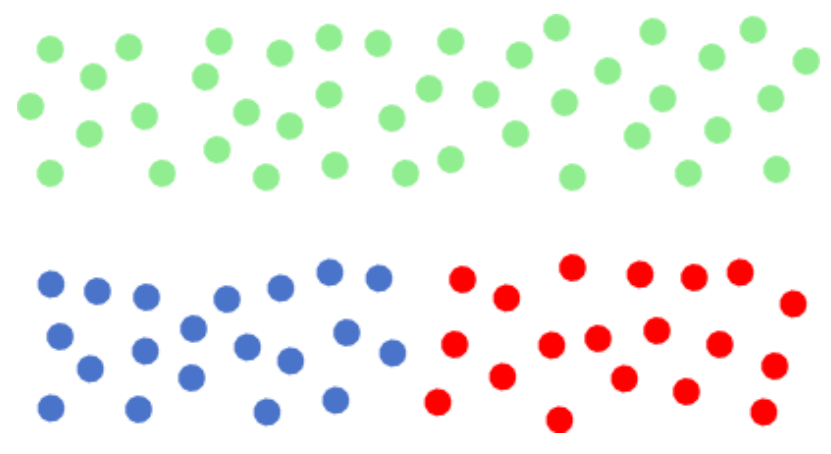

Figura 2.4: Em um algoritmo que leva em conta apenas a interconectividade entre elementos dos dois clusters, os clusters verde e azul seriam unidos e não os clusters azul e vermelho.

\subsection{Técnicas de clusterização de dados}

$\mathrm{Na}$ Seção 2.2 foram relacionadas algumas medidas para quantificar a similaridade entre dados. A matriz de similaridade que representa essa proximidade é a entrada para os algoritmos de clusterização. Os algoritmos utilizados na clusterização de dados podem ser classificados, por exemplo, de acordo com a abordagem utilizada na definição dos clusters: particionamento, redes auto-organizáveis, baseado em densidade, hierárquico e baseado em grafos. As características desses algoritmos são detalhadas nas subseções a seguir.

\subsubsection{Algoritmos de clusterização por particionamento}

Na clusterização por particionamento o conjunto de dados é dividido em um número determinado de clusters uma única vez. Outra alternativa é a dividir os dados gradualmente obtendo diversas partições dos dados; nesse caso a clusterização é hierárquica (descrita na Seção 2.3.4). O 
fato de gerar a partição uma única vez passa a ser uma vantagem quando a quantidade de dados é muito grande e a construção e armazenamento de todas as possibilidades de divisão resultantes da clusterização hierárquica tornam-se muito custosas. Essas restrições podem fazer com que a clusterização por particionamento seja ideal para alguns conjuntos de dados.

O problema de clusterização por particionamento pode ser definido formalmente como: Dado um conjunto de $n$ dados caracterizados por $d$ atributos cada, determine uma partição do conjunto inicial em $K$ clusters. A escolha do valor de $K$ depende do problema abordado e pode interferir na eficiência do algoritmo. O objetivo é maximizar a similaridade entre elementos de um mesmo cluster e minimizar a similaridade entre elementos de clusters diferentes, o que pode ser obtido com a otimização de uma função objetivo. A função objetivo pode expressar critérios diferentes a serem otimizados: um critério local forma os clusters a partir de informações estruturais dos dados, como por exemplo atribuir um dado e seus $k$ vizinhos mais próximos a um mesmo cluster; um critério global usa um elemento do conjunto de dados como representante de cada cluster e classifica os demais dados com base em sua similaridade com o dado representante (Jain \& Dubes, 1988). O uso de um critério global reduz o custo computacional da utilização de todos os dados no cálculo da distância entre os clusters.

Uma solução intuitiva para o problema é a listar todas as possíveis partições e escolher como resposta a partição que otimiza a função objetivo. Entretanto a geração de todas as possíveis combinações de $K$ clusters é computacionalmente inviável. Uma solução seria reduzir o espaço de busca, eliminando partições que não sejam interessantes. Outra alternativa é dividir inicialmente os dados em $K$ clusters e movê-los entre os clusters otimizando a função objetivo, como o algoritmo $K$-Médias apresentado a seguir.

\section{Algoritmo K-Médias}

O K-Médias é um dos algoritmos por paticionamento mais famosos, em que os dados são particionados em $K$ clusters, onde $K$ é definido previamente. Cada cluster é representado por um dado, chamado de centro do cluster. A função objetivo a ser minimizada pelo algoritmo é a função de erro quadrático, definida pela Equação 2.5, onde $c_{k}$ é o centro do cluster $k$. A função de erro quadrático busca minimizar a variação entre os dados em relação ao centro de cada cluster e é eficiente principalmente quando os clusters estão isolados (Jain et al., 1999). Os passos do algoritmo são descritos a seguir.

$$
E^{2}=\sum_{k=1}^{K} \sum\left(x_{i}-c_{k}\right)^{T}\left(x_{i}-c_{k}\right), x_{i} \in C_{k}
$$

1. Escolha a partição inicial formada por $K$ clusters.

A escolha da partição inicial envolve a definição de dois parâmetros: número de clusters, $K$, e centros iniciais, representado por $c(t)=\left\{c_{1}(t), c_{2}(t), \ldots, c_{K}(t)\right\}$ onde $t=0$ representa a primeira iteração do algoritmo. Para determinar $K$, é essencial o conhecimento a respeito 
dos dados do problema. Estudos que buscam facilitar a escolha do número de clusters podem ser encontrados em (Everitt et al., 2001). Outro parâmetro que deve ser escolhido inicialmente são os centros de cada cluster. Os centros podem ser escolhidos de maneira aleatória dentre os elementos do conjunto de dados inicial. A escolha errada da partição inicial pode levar o algoritmo a convergir para um mínimo local (Jain \& Dubes, 1988). Como trata-se de um algoritmo rápido, $O(n)$ (Jain et al., 1999), a saída geralmente é executá-lo várias vezes com diferentes números para $K$ e diferentes centros de clusters iniciais, e utilizar a melhor partição obtida.

2. Gere uma nova partição atribuindo cada dado ao cluster com o qual possui a maior semelhança.

A semelhança entre um dado e um cluster é calculada através da distância entre os dois: $\left\|x_{i}-c_{j}\right\|$, onde $i=\{1, \ldots, n\}$ e $j=\{1, \ldots, K\}$. O dado é adicionado ao cluster com o qual tiver a menor distância. Ao fim desse passo, os $n$ objetos estão distribuídos entre os $K$ clusters.

3. Atualize os centros dos $K$ clusters.

Os $K$ centros são recalculados para representarem adequadamente cada cluster, de acordo com a Equação 2.6, onde $c_{k}$ corresponde ao centro do cluster, $n_{k}$ é o número de elementos do cluster e $x_{i}$ são os elementos do cluster $k$.

$$
c_{k}(t+1)=\frac{1}{n_{k}} \sum_{i=1}^{n_{k}} x_{i}
$$

Com a atualização dos centros dos clusters, busca-se minimizar o índice da Equação 2.7:

$$
J_{k}=\sum_{x \in C_{k}}\left\|x_{i}-c_{k}(t+1)\right\|^{2}, k=1,2, \ldots, K
$$

4. Volte ao Passo 2 até a convergência.

$\mathrm{O}$ critério ideal de término do algoritmo seria quando a função objetivo não pudesse mais ser otimizada. Entretanto, não há garantias de que o resultado alcançado pelo $K$-Médias seja ótimo. Geralmente o critério de término utilizado é quando os centros dos $K$ clusters permanecem inalterados, ou seja, $c_{i}(t+1)=c_{i}(t)$, para $i=1,2, \ldots, K$.

\subsubsection{Redes Auto-Organizáveis - SOM}

A aplicação mais comum de redes neurais é feita na classificação de dados, onde dados são separados em grupos previamente conhecidos. Entretanto, um tipo particular de rede neural, a rede auto-organizável, ou SOM (Self Organizing Maps), desenvolvida por (Kohonen, 1982) pode separar dados em grupos desconhecidos inicialmente, através do aprendizado não-supervisionado (Everitt et al., 2001). 
Em linhas gerais, as redes auto-organizáveis são formadas por um conjunto de neurônios, onde cada dado tem seus atributos conectados a todos os neurônios da rede. A essa ligação entre neurônio e atributo é dado um peso inicialmente aleatório. $\mathrm{O}$ aprendizado ocorre à medida em que os dados são apresentados à rede, e o neurônio, ou grupo de neurônios, com conjunto de pesos mais próximo do dado é escolhido para representá-lo. O neurônio vencedor tem seus pesos alterados a fim de representar melhor o dado atribuído a ele. Assim cada neurônio, ou grupo de neurônios, torna-se especialista na identificação dos atributos.

Entre as vantagens do uso de redes auto-organizáveis na clusterização de dados é a possibilidade de representação de um conjunto de dados com muitos atributos em um mapa de baixa dimensão, além do fato de clusters similares estarem próximos um do outro no mapa (Jiang et al., 2004). Entre as desvantagens está o fato de poder representar apenas clusters de formas esféricas.

\subsubsection{Algoritmos de clusterização por densidade}

Conforme descrito no início do capítulo, um dado com $d$ atributos pode ser representado como um ponto em um espaço $d$-dimensional e os clusters correspondem a sub-conjuntos de dados que estejam próximos. Dessa forma, os clusters localizam-se em regiões de maior densidade no espaço de métricas e são separados por regiões de baixa densidade. Os métodos de clusterização por densidade utilizam critério de clusterização local, por considerarem a densidade de ligações entre os dados. A possibilidade de encontrar clusters de formas arbitrárias e o fato de não precisar da definição do número de clusters (Yip et al., 2006) como parâmetro inicial são as principais vantagens dos métodos baseados em densidade. Entretanto, alguns algoritmos podem exigir a definição de outros parâmetros, como o caso do algoritmo DBSCAN (Ester et al., 1996) descrito a seguir.

\section{DBSCAN - A Density Based Spatial Clustering of Applications with Noise}

Assim como existem diferentes medidas de similaridade, exitem também diferentes maneiras de identificar áreas de densidade. O algoritmo DBSCAN utiliza uma abordagem baseada em centro. A idéia é que cada dado de um cluster tenha uma vizinhança de um determinado raio que contenha um número mínimo de pontos. Sendo Eps o raio máximo da vizinhança formada por um número mínimo de pontos denotados por MinPts, a vizinhança de um dado $x_{i}$ é definida por $N_{E p s}\left(x_{i}\right)=\left\{x_{j} \in X \mid d\left(x_{i}, x_{j}\right) \leq E p s\right\}$. O formato da vizinhança varia de acordo com a medida de distância $d\left(x_{i}, x_{j}\right)$ escolhida (Ester et al., 1996).

Após a identificação das regiões densas, os pontos podem ser classificados de acordo com sua posição em relação à mesma:

- $x_{i}$ é um ponto central se $\left|N_{E p s}\left(x_{i}\right)\right| \geq$ MinPts

- $x_{i}$ é um ponto periférico se pertence à vizinhança de um ponto central $x_{j}$, ou seja, $x_{i} \in$ $N_{\text {Eps }}\left(x_{j}\right)$ 
- Se $x_{i}$ não se encaixar nos dois casos anteriores, é considerado ponto ruidoso

O algoritmo recebe como entrada o tamanho da vizinhança Eps, o número mínimo de pontos de uma vizinhança MinPts e um conjunto de dados $X$. Um cluster é formado por um conjunto de pontos densamente conectados. Se dois pontos centrais são próximos (a distância entre eles é menor que Eps), eles são colocados no mesmo cluster. Os pontos periféricos são colocados no mesmo cluster que os pontos centrais e pontos ruidosos são descartados da classificação, por não pertencerem a cluster nenhum. Maiores detalhes sobre o algoritmo e heurísticas para determinar os parâmetros Eps e MinPts podem ser obtidos em (Ester et al., 1996).

\subsubsection{Algoritmos de clusterização hierárquica}

Nessa abordagem são produzidas diversas partições do conjunto de dados com base na junção ou divisão dos clusters de acordo com a medida de similaridade. De acordo com o modo de produção das partições, os métodos de clusterização hierárquicos podem ser classificados como aglomerativos ou divisivos. Nos algoritmos aglomerativos a primeira partição é formada por $n$ clusters que são unidos até a formação de uma única partição com $n$ elementos. Já nos algoritmos divisivos, a primeira partição é formada por todos os $n$ elementos do conjunto de dados, que é dividida sucessivamente até a última partição formada por $n$ clusters com um elemento. Embora a clusterização hierárquica seja composta por uma série de passos, sua execução pode ser interrompida a qualquer momento. Um exemplo de critério de parada é quando a partição atual é considerada relevante de acordo com alguma medida de qualidade (Schaeffer, 2007).

$\mathrm{O}$ resultado da clusterização hierárquica pode ser visualizado através de um dendrograma. $\mathrm{O}$ dendrograma representa de maneira gráfica o processo de clusterização, ilustrando as sucessivas uniões ou divisões dos dados em clusters, como mostra a Figura 2.5. O dendrograma é uma árvore, onde as folhas representam os clusters formados por apenas um elemento. A medida que a altura da árvore cresce, os dados juntam-se para formar clusters maiores, até que todos façam parte de um mesmo cluster. Algumas técnicas para comparação entre dendrogramas são discutidas em (Everitt et al., 2001).

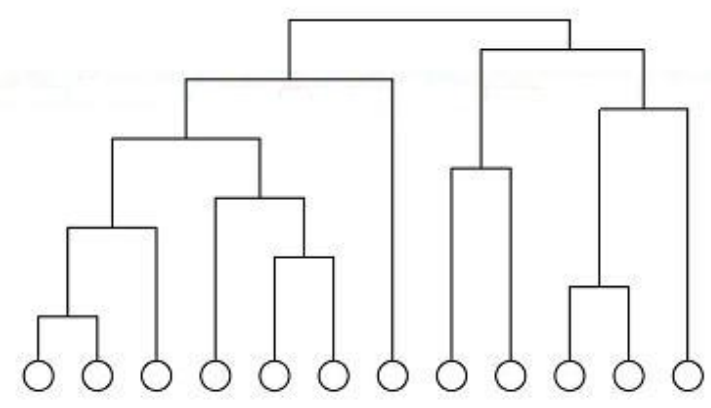

Figura 2.5: Saída gerada por algoritmo de clusterização hierárquica 
Como consequência da maneira como os clusters são formados, o dendrograma pode ser construído a partir da raiz em direção às folhas (estratégia top-down) se for utilizado um método divisivo, ou a partir das folhas em direção à raiz (estratégia bottom-up) se for utilizado o método aglomerativo. Essa diferença é exemplificada na Figura 2.6.

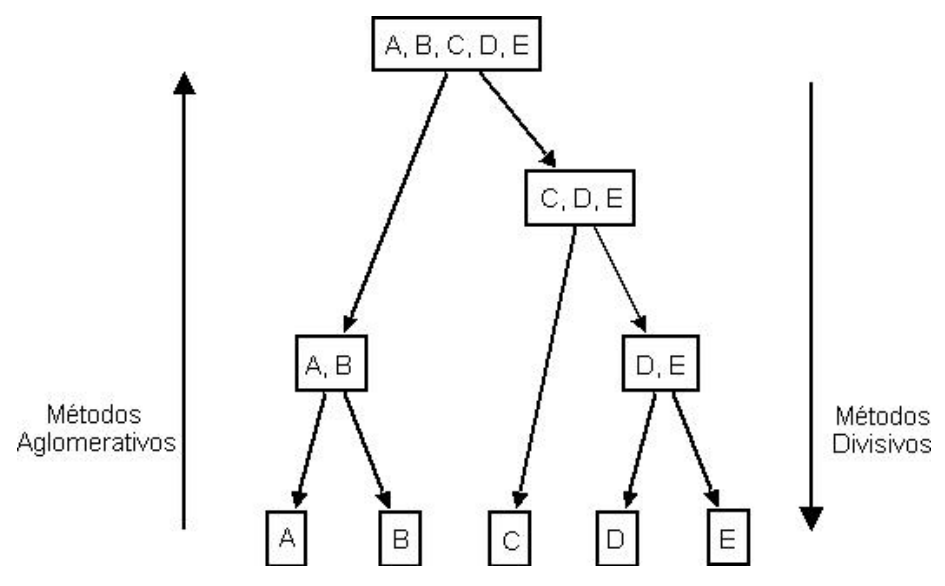

Figura 2.6: Construção do dendrograma nos algoritmos de clusterização hierárquica

As técnicas e características dos métodos de clusterização hierárquicos são apresentadas em função dos métodos aglomerativos, por serem estes mais utilizados (Everitt et al., 2001). As técnicas utilizadas pelos métodos divisivos na divisão dos clusters podem ser encontradas também em (Everitt et al., 2001).

Existem diferentes métodos aglomerativos, mas todos seguem a mesma idéia: a primeira partição é formada por $n$ clusters, cada um com um elemento do conjunto de dados, e a última partição possui um único cluster composto pelos $n$ dados. A diferença entre os métodos está na escolha da medida de similaridade utilizada, já que a cada passo são unidos os dois clusters mais similares.

As medidas de similaridade entre clusters podem basear-se na matriz de similaridade ou na matriz de dados. Os três primeiros algoritmos descritos a seguir utilizam a matriz de similaridade no cálculo da distância inter-cluster, enquanto o último utiliza o conjunto de dados.

- Single Linkage: também chamado de nearest neighbor, une clusters com a distância mínima entre pares de dados de clusters diferentes.

- Complete Linkage: também chamado de furthest neighbor, utiliza medida de distância oposta ao Single Linkage, utilizando a distância entre os pares de indivíduos mais distantes.

- Group Average Linkage: a distância entre os dois clusters é a média da distância entre todos os pares formados por elementos de clusters diferentes.

- Centroid Clustering: para cada cluster é calculado um centro de cluster $c_{k}$, e são unidos os dois clusters com a menor distância entre centros, dentre todos os pares de clusters. 
Apesar de encontrar clusters de diferentes formas e tamanhos (Karypis et al., 1999), os métodos aglomerativos possuem algumas desvantagens. Por exemplo, o método Single Linkage falha na detecção correta de clusters caso exista um dado que "conecte" dois clusters diferentes, levando à união dos clusters. Esse problema é chamado de chainning effect (Everitt et al., 2001). Além disso, como os métodos hierárquicos utilizam uma abordagem gulosa, a má escolha de unir ou dividir clusters não pode ser corrigida nos passos seguintes.

\subsubsection{Algoritmos de clusterização baseados em grafo}

Os algoritmos de clusterização baseados em grafos são fortemente relacionados com os algoritmos por particionamento e hierárquicos, descritos nas Seções 2.3.1 e 2.3.4 respectivamente. Isso significa que o resultado obtido pode ser uma partição ou uma hierarquia de partições. Os algoritmos de clusterização baseados em grafo representam os dados e sua proximidade através de um grafo $G(V, E)$, onde $V=\left\{v_{1}, \ldots, v_{n}\right\}$ é o conjunto de vértices e $E$ é o conjunto de arestas. Cada vértice representa um elemento do conjunto de dados e a existência de uma aresta conectando dois vértices é feita com base na proximidade entre os dois dados. A maneira mais simples de estabelecer as ligações entre os vértices é conectar cada vértice aos $(n-1)$ vértices restantes, onde o peso indica a similaridade entre os dois dados. Nessa classe de algoritmos de clusterização, um cluster é definido como um subgrafo do grafo inicial. O trabalho de (Schaeffer, 2007) oferece uma boa revisão sobre diferentes métodos de clusterização baseados em grafos.

O algoritmo hierárquico Single Linkage, apresentado na Seção 2.3.4, pode ser reformulado de acordo com o conceito de árvore geradora. A árvore geradora de $G$ corresponde ao subgrafo, conexo e acíclico, formado por todos os vértices de $G$. Se existem pesos nas arestas, a árvore geradora de menor peso total é chamada árvore geradora mínima e denotada por $A G M=\left(V, E^{\prime}\right)$. É importante notar que é possível obter diferentes árvores geradores mínimas a partir de um mesmo grafo $G$. A árvore geradora mínima pode ser usada na clusterização de dados usando a abordagem aglomerativa ou divisiva. Na versão hierárquica aglomerativa, cada vértice corresponde a um cluster. A cada iteração, dois subgrafos conectados pela aresta $e \in E^{\prime}$ de menor valor são unidos. Após essa união, a aresta $e$ tem seu peso redefinido como um peso superior à maior similaridade entre dois dados de $G$, evitando que a aresta seja novamente escolhida nas próximas iterações. Já na versão divisiva, as arestas de $A G M$ são descartadas em ordem decrescente de peso. A cada passo, os subgrafos conexos resultantes correspondem aos clusters, até que cada cluster seja formado por um único vértice.

Já o algoritmo de clusterização hierárquico Complete Linkage está relacionado ao conceito de coloração de vértices. O objetivo da coloração de vértices é atribuir uma cor a cada vértice do grafo, de modo que dois vértices conectados por uma aresta não possuam a mesma cor, e usando o menor número de cores possível. Entretanto a relação entre Complete Linkage e coloração de vértices não é tão direta quanto a relação entre o algoritmo Single Linkage e a árvore geradora mínima. Maiores detalhes podem ser obtidos em (Jain \& Dubes, 1988). 


\section{Cortes}

A teoria dos grafos oferece uma maneira de lidar com a divisão de vértices em grupos distintos. O particionamento de grafos consiste em dividir o conjunto de vértices $V$ em dois subconjuntos $S$ e $V \backslash S$. Essa divisão é chamada de corte. A busca pelo corte mínimo em um grafo depende da escolha da função a ser minimizada. A maneira mais simples de calcular o tamanho do corte é através do número de arestas que conectam vértices de subconjunos diferentes, no caso de grafos simples (arestas sem peso). Se as arestas apresentarem peso, o tamanho do corte é dado pela soma dos pesos das arestas que conectam vértices de subconjuntos diferentes. Entretanto, essa abordagem favorece cortes que apresentem vértices isolados. Uma alternativa é usar a versão normalizada do corte mínimo balanceando a cardinalidade dos conjuntos $S$ e $V \backslash S$, descrita em (Filippone et al., 2008).

O objetivo de um algoritmo de clusterização baseado em cortes é dividir os subconjuntos sucessivamente até que o número de clusters desejado seja atingido. A solução para esse problema não é facilmente encontrada, por tratar-se de um problema $N P$-completo (problemas em que soluções em tempo polinomial são desconhecidas), embora diversas heurísticas tenham sido desenvolvidas (Newman, 2004a). A teoria espectral de grafos oferece uma alternativa para o cálculo do corte de um grafo.

\section{Clusterização espectral}

A classe de métodos de clusterização espectral é baseada na teoria espectral de grafos (Chung, 1997). Um exemplo é o método de bisseção espectral (Newman, 2004a), onde o problema de corte mínimo em um grafo é abordado através da teoria espectral de grafos. O método é baseado nos autovetores da matriz Laplaciana de um grafo. A matriz Laplaciana de um grafo G é uma matriz $L$ simétrica $n \times n$, com os elementos definidos de acordo com a Equação 2.8, onde $k_{i}$ é o grau do vértice $v_{i}$.

$$
L_{i j}=\left\{\begin{array}{l}
-1, \text { se } i \neq j \text { e } v_{i} \text { é vizinho de } v_{j} \\
k_{i}, \text { se } i=j \\
0, \text { caso contrário }
\end{array}\right.
$$

Na matriz Laplaciana a soma de todas as linhas e colunas é igual a zero. O próximo passo é calcular os autovalores da matriz Laplaciana $L$. O segundo menor autovalor $\lambda_{2}$ indica uma medida de qualidade do corte e é chamado de conectividade algébrica do grafo. Menores valores para $\lambda_{2}$ correspondem a melhores cortes. $\mathrm{O}$ autovetor $u_{2}$ associado a $\lambda_{2}$ pode ser utilizado para dividir cada vértice $v_{i} \in V$ em dois subconjuntos, da seguinte maneira:

$$
\left\{\begin{array}{l}
v_{i} \in G_{1}, \text { se } u_{2}\left(v_{i}\right)<0 \\
v_{i} \in G_{2}, \text { caso contrário }
\end{array}\right.
$$


A principal desvantagem do algoritmo de bisseção espectral é que divide os vértices em apenas dois grupos. A divisão em mais grupos é feita através da aplicação recursiva da bisseção, embora não é garantido que essa abordagem resulte em boas partições.

\section{Chameleon: Clusterização hierárquica dinâmica}

O algoritmo Chameleon foi desenvolvido por (Karypis et al., 1999) e a similaridade entre clusters é medida com base em um modelo dinâmico. Chameleon une duas medidas de similaridade entre clusters: interconectividade e proximidade. Essas medidas já foram discutidas na Seção 2.2.2, bem como suas desvantagens quando usadas como única medida de similaridade. Além disso, Chameleon inova no cálculo da interconectividade e proximidade incorporando características próprias de cada cluster, fator que torna o modelo dinâmico.

Chameleon modela os dados em um grafo esparso, onde os nós representam os dados e as arestas a similaridade entre eles. O algoritmo é formado por duas fases: na primeira, é utilizado um algoritmo de particionamento de grafos para dividir o grafo inicial em pequenos sub-clusters; na segunda fase, os sub-clusters são combinados de forma a encontrar os clusters reais. Uma visão geral do algoritmo é fornecida pela Figura 2.7

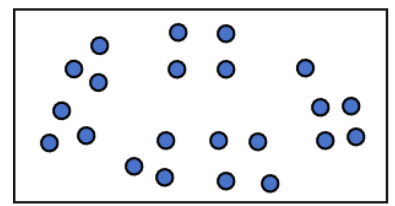

Dados iniciais

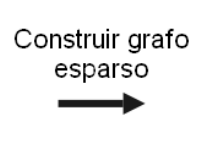

Grafo do tipo k-nearest neighbor
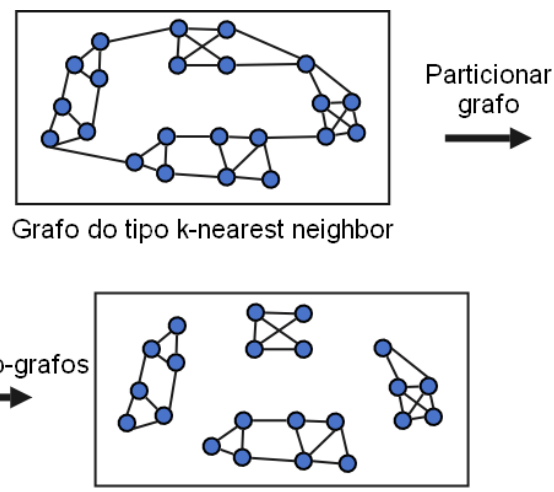

Figura 2.7: Etapas do algoritmo Chameleon

A seguir é descrito o funcionamento do algoritmo: a modelagem dos dados, as medidas de similaridade usadas, o particionamento do grafo em sub-clusters e a combinação desses sub-clusters.

\section{- Modelagem dos dados}

A partir da matriz de similaridade, os dados do conjunto são modelados em um grafo esparso, estratégia adotada por muitos algoritmos de clusterização hierárquica (Jain \& Dubes, 1988). O grafo é formado pela abordagem $k$-vizinhos mais próximos: cada vértice corresponde a um dado e é ligado aos seus $k$ vizinhos mais similares. Em outras palavras, seja $G=(V, E)$ um grafo tal que $V=X$ e $E=\left\{e_{i j} \mid j \in N N_{k}(i)\right\}$, onde $N N_{k}(i)$ é o conjunto dos $k$ vizinhos mais próximos de $i$. A Figura 2.8 ilustra alguns grafos formados a partir da utilização dessa técnica. 


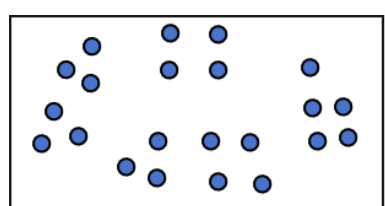

(a) Dados iniciais

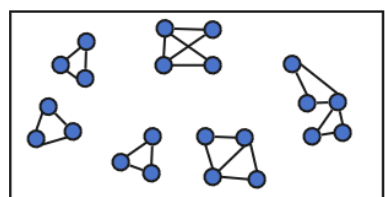

(c) Grafo 2-NN

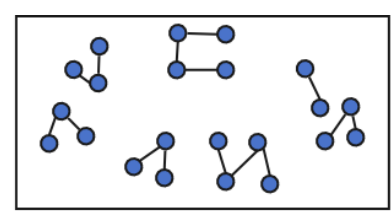

(b) Grafo 1-NN

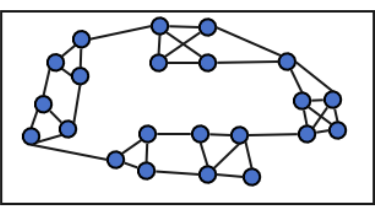

(d) Grafo 3-NN

Figura 2.8: Construção de grafos a partir dos k-vizinhos mais próximos: (a) dados originais, (b)1-, (c)2-, (d)3-vizinhos mais próximos

Essa maneira de representação dos dados oferece duas vantagens principais: dados pouco similares não são conectados e o grafo gerado é esparso, resultando em eficiência computacional.

\section{- Medida de similaridade}

A similaridade entre clusters é determinada de maneira dinâmica pelo Chameleon, calculando as medidas de interconectividade relativa (RI) e proximidade relativa (RC). Dois clusters são unidos caso apresentem alta interconectividade e seus elementos estejam próximos, o que é traduzido em altos valores de RI e RC.

Alguns algoritmos utilizam a interconectividade absoluta como medida de similaridade entre clusters. A interconectividade absoluta entre dois clusters $C_{i}$ e $C_{j}$ é calculada a partir do conceito de aresta de corte ${ }^{1}$ e definida como a soma do peso das arestas que ligam os dois clusters $E C\left(C_{i}, C_{j}\right)$. A interconectividade absoluta é então normalizada em relação à interconectividade interna dos clusters $C_{i}$ e $C_{j}$, obtida através da soma das arestas que cruzam o corte-mínimo que divide o cluster em duas partes iguais (bisseção mínima). $\mathrm{O}$ valor resultante dessa normalização é chamado de interconectividade relativa e é dada pela Equação 2.9

$$
R I\left(C_{i}, C_{j}\right)=\frac{\left|E C\left(C_{i}, C_{j}\right)\right|}{\frac{\left|E C\left(C_{i}\right)\right|+\left|E C\left(C_{j}\right)\right|}{2}}
$$

O uso da interconectividade relativa permite que Chameleon possa adaptar-se a variadas formas de clusters bem como variações no grau de interconectividade dos clusters (Karypis et al., 1999).

Alguns algoritmos de clusterização hierárquica, como group-average linkage descrito na Seção 2.3.4 utilizam a proximidade absoluta para calcular a similaridade entre clusters. Existem diferentes maneiras de calcular a proximidade absoluta, como já foi dito na Seção 2.2.2.

\footnotetext{
${ }^{1}$ conjunto de arestas cuja remoção torna o grafo desconexo (Cormen et al., 2001)
} 
Uma possibilidade é calcular a distância mínima dentre todos os pares de pontos formados por elementos de clusters diferentes. Como essa abordagem é pouco tolerante a ruídos e outliers (Karypis et al., 1999), o Chameleon utiliza a média do peso das arestas que conectam vértices de um cluster $C_{i}$ a um cluster $C_{j}$. Nesse caso, essa é uma boa maneira de calcular a similaridade entre os clusters, já que o grafo é obtido através dos k-vizinhos mais próximos e vértices pouco similares não estão conectados.

Da mesma forma que foi feito com a interconectividade relativa, a proximidade absoluta é normalizada em relação a proximidade interna de cada cluster. A proximidade interna é obtida pela média do peso das arestas que cruzam a bisseção mínima dos elementos do cluster. Assim a proximidade relativa entre um par de clusters é dada pela Equação 2.10.

$$
R C\left(C_{i}, C_{j}\right)=\frac{\bar{S} E C\left(C_{i}, C_{j}\right)}{\frac{\left|C_{i}\right|}{\left|C_{i}\right|+\left|C_{j}\right|} \bar{S} E C\left(C_{i}\right)+\frac{\left|C_{j}\right|}{\left|C_{i}\right|+\left|C_{j}\right|} \bar{S} E C\left(C_{j}\right)}
$$

onde $\bar{S} E C\left(C_{i}\right)$ e $\bar{S} E C\left(C_{j}\right)$ correspondem à proximidade interna de $C_{i}$ e $C_{j}, \bar{S} E C\left(C_{i}, C_{j}\right)$ é a proximidade absoluta dos clusters, $\left|C_{i}\right|$ e $\left|C_{j}\right|$ são o número de dados em cada cluster. Além disso, a proximidade absoluta é normalizada pela média ponderada da proximidade relativa dos clusters. Assim, clusters com mais elementos são favorecidos, e a união entre clusters esparsos com clusters densos é evitada (Karypis et al., 1999).

\section{- Primeira fase: Particionando o grafo}

As medidas de similaridade citadas acima apresentam um bom resultado apenas quando aplicada a clusters com um número razoável de elementos (Karypis et al., 1999). Isso porque o cálculo da interconectividade relativa e proximidade relativa podem não apresentar valores reais para clusters com poucos dados. Por isso, o grafo inicial deve ser dividido em sub-clusters com um número razoável de elementos que permita a modelagem dinâmica do algoritmo.

Chameleon encontra os sub-clusters aplicando um algoritmo de particionamento de grafos, que divide o grafo inicial em muitas partições de modo que a soma do peso das arestas que ligam as partições (arestas de corte) seja minimizada. Encontrar um particionamento de corte mínimo significa minimizar a similaridade entre os clusters, já que cada aresta do grafo representa o grau de similaridade entre os dados. Idealmente, um dado deve ter maior similaridade com dados de seu próprio cluster do que de outros clusters, o que é atendido pelo algoritmo de particionamento adotado.

Chameleon utiliza um particionamento de grafos multi-nível para encontrar os sub-clusters iniciais, cujo algoritmo faz parte do pacote hMetis (Karypis, 1998) e é capaz de produzir partições de alta qualidade para os mais diversos tipos de grafos (Karypis et al., 1999). A Figura 2.9 ilustra a aplicação do algoritmo no particionamento do conjunto de dados em duas partições. 


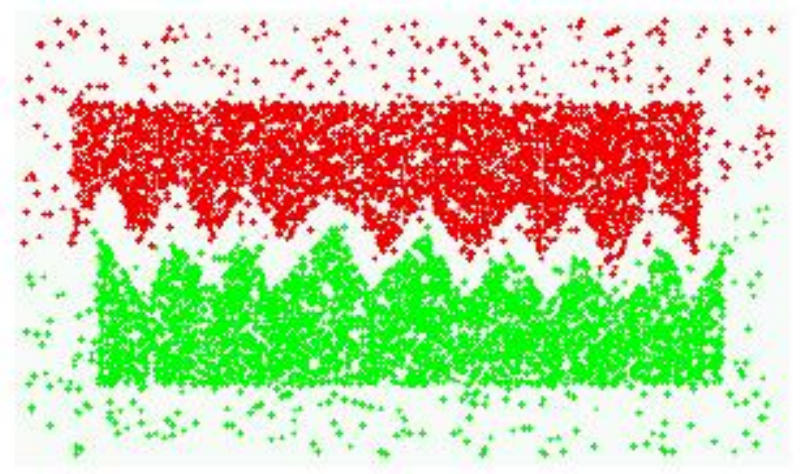

(a)

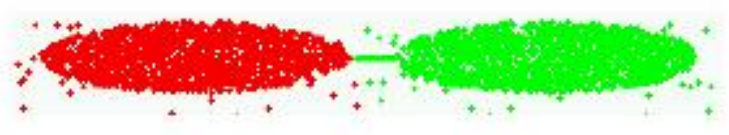

(b)

Figura 2.9: Divisão em duas partições pelo algoritmo de particionamento de grafos multi-nível. Em (a) o algoritmo identifica regiões esparsas; em (b) o algoritmo identifica a conexão entre os clusters. (Karypis et al., 1999)

Os sub-clusters iniciais são obtidos a partir de um único cluster formado por todos os dados. Repetidamente o maior sub-cluster é selecionado e hMetis é usado na bisseção desse subcluster. Esse processo chega ao fim quando o maior sub-cluster possui tamanho menor que MinSize, parâmetro definido inicialmente que regula a granularidade dos sub-clusters. $\mathrm{O}$ valor de MinSize deve ser suficientemente grande para permitir o cálculo da interconectividade relativa e proximidade relativa, como já foi dito anteriormente.

\section{- Segunda fase: União dos sub-clusters}

Após a geração dos sub-clusters pelo particionamento do grafo inicial, o próximo passo é a união desses sub-clusters pelo algoritmo aglomerativo de clusterização hierárquica. Chameleon seleciona dois clusters para união com base nas medidas de similaridade descritas anteriormente: interconectividade relativa (RI) e proximidade relativa (RC). Para isso, duas abordagens podem ser utilizadas: parâmetros escolhidos pelo usuário ou otimização de uma função pré-definida.

Quando a abordagem adotada envolve parâmetros definidos pelo usuário, dois clusters são unidos apenas quando RI e RC excedem algum valor específico, $T_{R I}$ e $T_{R C}$ respectivamente. Assim, para cada cluster $C_{i}$, o algoritmo verifica se algum cluster $C_{j}$ adjacente obedece à restrição dada pela Equação 2.11. Se mais de um cluster obedecer a essa restrição, $C_{i}$ é unido ao cluster com o qual possui maior interconectividade absoluta, ou seja, o cluster com o qual $C_{i}$ é mais conectado.

$$
R I\left(C_{i}, C_{j}\right) \geq T_{R I} \text { e } R C\left(C_{i}, C_{j}\right) \geq T_{R C}
$$

Dependendo da escolha de $T_{R I}$ e $T_{R C}$, pode acontecer que em determinado momento nenhum cluster satisfaça a condição imposta pela Equação 2.11. Quando isso acontecer, o 
algoritmo pode ser finalizado e gerar a solução ou os parâmetros $T_{R I}$ e $T_{R C}$ podem ser variados a diferentes taxas, até que algum par de clusters atenda as condições.

A segunda abordagem envolve a escolha de uma função que combine a interconectividade relativa e a proximidade relativa. O algoritmo seleciona para união o par de clusters que maximize essa função. Como o objetivo é unir clusters com altos valores de RI e RC, a função escolhida pode calcular o produto entre interconectividade relativa e proximidade relativa. A Equação 2.12 mostra essa função, onde pode-se dar maior importância a uma das duas medidas através do parâmetro $\alpha$.

$$
R I\left(C_{i}, C_{j}\right) *\left[R C\left(C_{i}, C_{j}\right)\right]^{\alpha}
$$

Quando $\alpha>1$ a proximidade relativa entre os elementos tem maior importância; quando $\alpha<1$ a interconectividade relativa tem maior importância.

\subsection{Validação}

A aplicação de um algoritmo de clusterização resulta em uma ou mais divisões dos dados em diferentes grupos. Entretanto, fatores como a escolha da medida de similaridade e parâmetros utilizados pelo algoritmo podem influenciar na qualidade da partição obtida. Por isso é importante determinar a relevância dos resultados obtidos pelo algoritmo. Isso é geralmente feito com base em índices estatítiscos que medem quantitativamente a qualidade de uma partição. A maneira como tal índice é utilizado é dada pelo critério de validação. A seguir serão apresentados três tipos de critérios de validação descritos na literatura(Jain \& Dubes, 1988). Maiores detalhes sobre os critérios de avaliação e os diferentes índices usados na avaliação podem ser obtidos em (Facelli et al., 2005).

- Critérios externos: a qualidade do agrupamento é medida de acordo com uma divisão previamente estabelecida do conjunto de dados. Essa divisão pode indicar uma partição já conhecida do conjunto de dados ou uma divisão realizada por um especialista da área. Para que a divisão de um conjunto de dados seja considerada válida ela deve ser "especial" em algum sentido. Para isso é necessário a realização de testes de hipótese, a fim de comprovar uma hipótese pré-definida. Na realização de tais testes, deve-se conhecer a distribuição dos índices sob a hipótese que corresponde à divisão aleatória dos dados (hipótese nula) (Jain \& Dubes, 1988). A análise de Monte Carlo oferece uma maneira de calcular uma estimativa de tal distribuição, embora sua aplicação seja difícil e custosa (Facelli et al., 2005).

- Critérios internos: nesse critério, os dados originais ou a matriz de similaridade são usados para medir a qualidade do agrupamento. Em outras palavras, um índice que utilize critério interno mediria o quanto uma partição justifica-se pela matriz de similaridade. Índices internos devem lidar com diversos problemas, como por exemplo a estimativa do número "real" 
de clusters presentes no conjunto de dados ou avaliar quão grande ou quão pequeno é o valor de um índice (Jain \& Dubes, 1988).

- Critérios relativos: duas divisões do mesmo conjunto de dados são comparadas para identificar qual representa melhor o conjunto de dados. Esse tipo de critério é usado principalmente para estabelecer o melhor valor para um parâmetro usado pelo algoritmo ou para comparar resultados de dois algoritmos diferentes. O número de clusters $K$ é um exemplo de parâmetro que um critério relativo pode auxiliar na escolha. Para isso o algoritmo de clusterização é executado para todos os possíveis valores de $K$ em um intervalo $K_{\min }$ e $K_{\max }$. Ao apresentar em um gráfico os valores dos índices em função de $K$, o número ideal de clusters é dado pelo valor mínimo, máximo ou inflexão na curva apresentada (Facelli et al., 2005).

A seguir são apresentados alguns exemplos de índices externos e relativos. Índices usados com o critério relativo podem ser usados também como índices de critério interno (Facelli et al., 2005).

\subsection{1 Índice Davies-Bouldin}

O índice Davies-Bouldin (DB) é um índice de validação relativa e foi proposto originalmente como um método de parada de algoritmos de clusterização (Jain \& Dubes, 1988). O valor do índice é comparado com o número de clusters, e o algoritmo é encerrado quando o valor do índice é mínimo. Dada uma partição de $n$ dados em $K$ clusters, a medida descrita na Equação 2.13 mede a similaridade entre pares de cluster $\left(C_{i}, C_{j}\right)$.

$$
R_{C_{i}, C_{j}}=\frac{e_{C_{i}}+e_{C_{j}}}{d\left(C_{i}, C_{j}\right)}
$$

onde $e_{C_{i}}$ é o erro médio para o cluster $C_{i}, e_{C_{j}}$ é o erro médio para o cluster $C_{j}$ e $d\left(C_{i}, C_{j}\right)$ é a distância euclidiana entre os centros dos clusters de $C_{i}$ e $C_{j}$. O valor do índice para o cluster $C_{i}$ é dado pela maior dissimilaridade entre dois pares de clusters, ou seja, o maior valor de $R_{C_{i}, C_{j}}$, conforme mostra a Equação 2.14.

$$
R_{C_{i}}=\max _{i \neq j}\left(R_{C_{i}, C_{j}}\right)
$$

O índice compara a similaridade entre os dados dentro de um cluster e a dissimilaridade entre dados de clusters diferentes. Isso pode ser observado na definição do índice DB dada pela Equação 2.15, que define o valor do índice DB para uma partição de $K$ clusters.

$$
D B(K)=\frac{1}{K} \sum_{i=1}^{K} R_{C_{i}}
$$

Quanto menor o valor de $\mathrm{DB}(K)$, melhor é a partição. Entretanto, quando a partição é formada por $K=n$ clusters, com um elemento em cada cluster, o índice atinge valor 0 , apesar de não ser 
uma partição interessante. Por isso, o índice DB deve ser calculado apenas enquanto cada cluster ainda tiver um número considerável de objetos. Outra desvantagem é que o índice DB é aplicado com sucesso apenas para clusters hiperesféricos (Jain \& Dubes, 1988).

\subsection{2 Índice Rand Corrigido}

O índice de validação externo Rand Corrigido ( $\mathrm{CR}$, do inglês Correted Rand) é muito utilizado na comparação de algoritmos de clusterização, e oferece como vantagem a independência do número de clusters da partição (Jain \& Dubes, 1988). O índice CR determina a semelhança entre duas partições $P 1$ e $P 2$ examinando a qual cluster pares de dados foram assinalados nas duas partições. Isso quer dizer que se dois dados foram assinalados ao mesmo cluster em $P 1$ e $P 2$ o valor do índice aumenta; por outro lado, se dois elementos foram assinalados ao mesmo cluster em $P 1$ mas pertencem a clusters diferentes em $P 2$ o valor do índice diminui. O índice CR é a versão normalizada do índice Rand (Jain \& Dubes, 1988) e é definido pela Equação 2.16, onde: $k_{P_{1}}$ e $k_{P_{2}}$ são o número de clusters das partições $P_{1}$ e $P_{2} ; n$ é a quantidade de dados do conjunto inicial; $n_{i}$ é o número de elementos do cluster $C_{i} \in P_{1}$ e $n_{j}$ é o número de elementos do cluster $C_{j} \in P_{2} ; n_{i j}$ é o número de elementos que pertencem aos clusters $C_{i} \in P_{1}$ and $C_{j} \in P_{2}$, ou seja, o número de elementos comuns a $P 1$ e $P 2$.

$$
\begin{aligned}
C R & =(A-B) /(C-D), \text { onde } \\
A & =\sum_{i=1}^{k_{P_{1}}} \sum_{j=1}^{k_{P_{2}}}\left(\begin{array}{c}
n_{i j} \\
2
\end{array}\right) \\
B & =\left[\sum_{i=1}^{k_{P_{1}}}\left(\begin{array}{c}
n_{i} \\
2
\end{array}\right) \sum_{j=1}^{k_{P_{2}}}\left(\begin{array}{c}
n_{j} \\
2
\end{array}\right)\right] /\left(\begin{array}{c}
n \\
2
\end{array}\right) \\
C & =\left[\sum_{i=1}^{k_{P_{1}}}\left(\begin{array}{c}
n_{i} \\
2
\end{array}\right) \sum_{j=1}^{k_{P_{2}}}\left(\begin{array}{c}
n_{j} \\
2
\end{array}\right)\right] / 2 \\
D & =\left[\sum_{i=1}^{k_{P_{1}}}\left(\begin{array}{c}
n_{i} \\
2
\end{array}\right) \sum_{j=1}^{k_{P_{2}}}\left(\begin{array}{c}
n_{j} \\
2
\end{array}\right)\right] /\left(\begin{array}{c}
n \\
2
\end{array}\right)
\end{aligned}
$$

Valores próximos a 0 para o índice CR indicam partições aleatórias, que pouco revelam sobre a relação entre os dados, enquanto valores próximos a 1 são obtidos por partições mais relevantes.

\subsection{Considerações Finais}

Neste capítulo foi apresentada uma breve revisão bibliográfica sobre clusterização de dados relevantes a este trabalho. Diversas etapas do processo de clusterização foram descritas com alguns detalhes, como por exemplo diferentes medidas de similaridade entre dados e entre clusters. 
Foram descritos também algoritmos focados na etapa de algoritmos de clusterização de dados que utilizam abordagens diferentes na identificação dos clusters: particionamento, redes autoorganizáveis, baseado em densidade, hierárquico e baseado em grafo. O algoritmo de clusterização Chameleon (Karypis et al., 1999), um algoritmo hierárquico que baseia-se no particionamento de grafos para identificar os clusters, foi descrito com maiores detalhes neste capítulo. $O$ foco desse trabalho encontra-se nessa etapa do processo de clusterização de dados.

Outra etapa apresentada foi o processo de validação e análise dos resultados obtidos pelo algoritmo, onde foram descritos diferentes critérios e índices utilizados na avaliação dos resultados. Nesse trabalho será adotado o índice de validação externo CR, por ser o índice mais usado na literatura para comparação entre algoritmos de clusterização (Jain \& Dubes, 1988). No Capítulo 3 serão apresentados os conceitos de redes complexas pertinentes a este trabalho, com o objetivo de auxiliar o processo de identificação de clusters. 


\section{3}

\section{Detecção de comunidades em redes \\ complexas}

Uma rede composta por vértices e arestas é uma modelagem útil para representar interações entre elementos de um conjunto de itens. Recentemente, tem-se observado um interesse crescente no estudo de redes complexas formadas por milhões ou até bilhões de vértices, principalmente pela disponibilidade de computadores e redes de comunicação que permitem analisar dados em uma escala muito maior do que era possível anteriormente. Existem muitos exemplos de redes de larga escala, como a Internet, redes de interação social, redes de interação entre proteínas, redes de citações em artigos, entre outros.

A classificação de redes complexas pode ser feita a partir da existência de uma hierarquia de estruturas organizadas. A mais antiga e estudada iniciativa para modelagem de redes de larga escala foi feita por (Erdös \& Rényi, 1959) e chamada de Redes Randômicas (Random Networks), pois as redes possuiam estruturas aparentemente aleatórias. Nesse tipo de rede não existe qualquer hierarquia de organização das arestas. Uma forma de geração de redes randômicas é atribuir uma probabilidade $p$ de criar uma aresta entre dois vértices. O número total de arestas do grafo é uma variável aleatória com valor esperado $E(m)=p[n(n-1) / 2]$, onde $m$ é o número de arestas e $n$ o número de vértices (Albert \& Barabasi, 2002). A Figura 3.1 mostra a geração de uma rede randômica de $n$ vértices com diferentes valores de $p$.

Em 1998, (Watts \& Strogatz, 1998) formalizaram o conceito de Redes de Pequeno-Mundo (Small World Networks), em que embora existam poucas ligações entre os vértices da rede, a maioria desses vértices pode ser alcançada em um pequeno número de passos a partir de qualquer outro. (Watts \& Strogatz, 1998) definiram tais redes como possuindo vértices com um alto coe- 


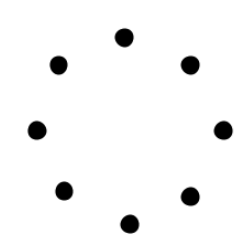

(a)

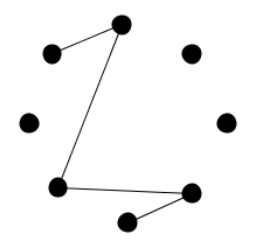

(b)

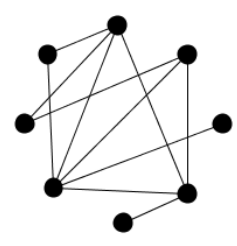

(c)

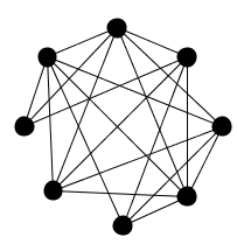

(d)

Figura 3.1: Exemplo de rede randômica com 8 vértices. (a) Quando $p=0$ o grafo gerado não possui arestas; (b) Quando $p=0.1$ poucas arestas são adicionadas contribuindo para a formação de árvores; (c) A adição de mais arestas, $\operatorname{com} p=0.3$, possibilita a formação de ciclos no grafo;

(d) Para $p=0.8$, o grafo gerado aproxima-se de um grafo completo.

ficiente de clustering ${ }^{1}$ e baixa média de comprimento dos caminhos mais curtos da rede. Redes desse tipo podem ser construídas através da mudança aleatória de poucas arestas de uma rede regular $^{2}$. Cada aresta da rede regular possui probabilidade $p$ de ter o vértice destino alterado. $\mathrm{O}$ novo vértice destino é escolhido aleatoriamente dentre os demais vértices, desde que a modificação não crie arestas duplas ou laços. Quando $p=0$ nenhuma aresta é modificada resultando em uma rede regular. A escolha aleatória de uma fração $p>0$ de arestas, e a consequente modificação dos vértices destinos dessas arestas, resulta na criação de uma rede de pequeno-mundo. Entretanto, se $p \approx 1$, a rede gerada será equivalente a uma rede randômica. O processo de criação de redes de pequeno-mundo é ilustrado na Figura 3.2. Redes sociais e linguísticas são exemplos de redes de pequeno-mundo.

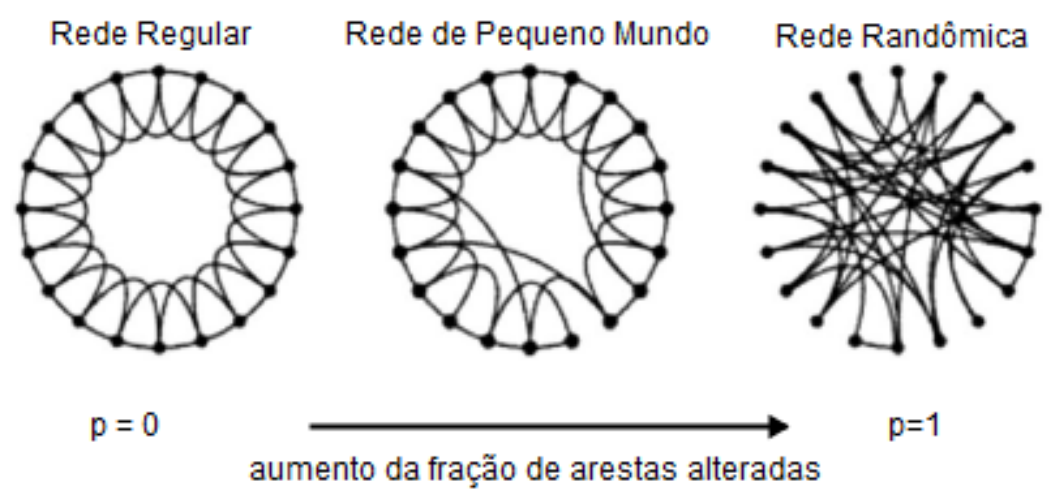

Figura 3.2: Processo de alteração de uma fração $p$ de arestas de uma rede regular formada por 20 vértices. Para determinados valores de $p$, a rede criada é uma rede de pequeno-mundo. Conforme o valor de $p$ aproxima-se de 1, grande parte das arestas é modificada, resultando em uma rede randômica (Albert \& Barabasi, 2002).

Muitas redes do mundo real apresentam vértices com mais conexões do que outros. Em 1999, (Barabasi \& Albert, 1999) descobriram que a distribuição do grau para os vértices de muitas redes

\footnotetext{
${ }^{1}$ proporção de arestas que conectam os vizinhos de um vértice

${ }^{2}$ rede em que os vértices são conectados a um número constante de vizinhos
} 
complexas obedece a lei da potência (power-law): $P(k) \sim k^{-\gamma}$, onde $k$ é o número de ligações de um vértice aleatório e $\gamma>0$ é o expoente de escala. Em outras palavras, $P(k)$ corresponde à fração de vértices com $k$ ligações. Esse tipo de rede é chamada de Redes Livre de Escala (ScaleFree Networks). Essa distribuição heterogênea significa que a probabilidade de que um conjunto de nós tenha um grande número de ligações não é pequena, ao contrário das Redes Randômicas que possuem distribuição homogênea de graus de vértices. Esse tipo de rede é formado acrescentando arestas à rede com probabilidade $p$, proporcional ao grau dos vértices. Assim, a criação de "hubs" (vértices com grande número de arestas incidentes) é favorecida, como mostra a Figura 3.3.

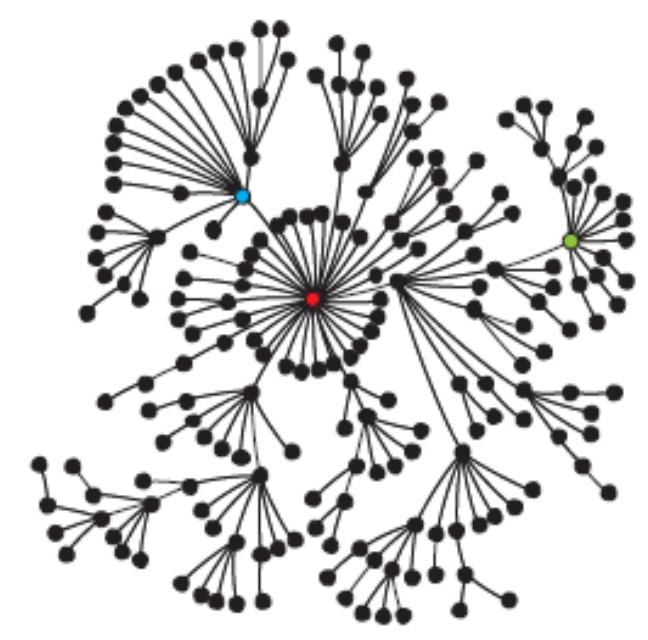

Figura 3.3: Rede Livre de Escala, formada por 200 vértices e 199 arestas, com a presença de "hubs" (vértices com grande número de arestas incidentes). Vértices em diferentes cores possuem maior grau k: vermelho $\rightarrow k=33$; azul $\rightarrow k=12$ e verde $\rightarrow k=11$ (Strogatz, 2001).

Depois de tais descobertas, muitas pesquisas têm sido realizadas, tornando o estudo sobre redes complexas uma sólida área de pesquisa. Dentre os campos de pesquisa que merecem destaque encontra-se a identificação de comunidades em redes complexas. Uma propriedade que pode ser observada em diversas redes é a estrutura de comunidades, ou seja, a possibilidade de dividir a rede em grupos de nós, de modo que a quantidade de conexões entre nós de uma mesma comunidade seja alto, enquanto o número de conexões entre nós de comunidades diferentes seja pequeno. A decomposição de uma rede em comunidades, é importante para a compreensão das relações entre diferentes componentes, além de permitir identificar funções de um componente com base nas funções de seus membros. A Figura 3.4 ilustra uma rede com estrutura de comunidades.

Os métodos de detecção de comunidades em redes complexas podem focalizar a adição ou remoção de arestas da rede, sendo classificados como métodos "aglomerativos" ou "divisivos", respectivamente. Essa classificação dos métodos de detecção de comunidades segue o mesmo conceito da classificação dos métodos de clusterização hierárquica descritos na Seção 2.3.4. No método aglomerativo, a rede inicialmente não possui arestas. Estas são adicionadas de acordo com alguma medida de similaridade calculada entre os diversos pares de nós, a partir do par de maior similaridade. Já no método divisivo, os pares de nós menos similares são identificados e a 


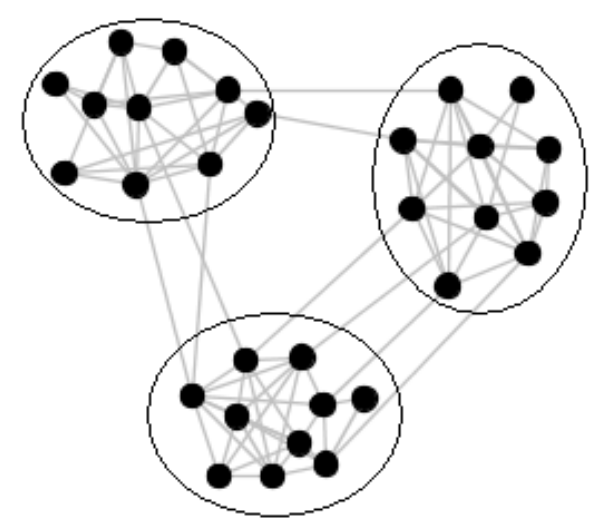

Figura 3.4: Rede com estrutura de comunidade, formada por três comunidades.

aresta que os une é removida. Ao executar esse procedimento repetidamente, a rede é dividida em comunidades cada vez menores.

Assim como os algoritmos de clusterização hierárquica, a divisão da rede em comunidades pode ser ilustrada por um dendrograma como o da Figura 3.5. Cortes horizontais no dendrograma revelam diferentes divisões da rede em comunidades, onde cortes mais próximos à base do dendrograma resultam em maior número de comunidades formadas por poucos nós.

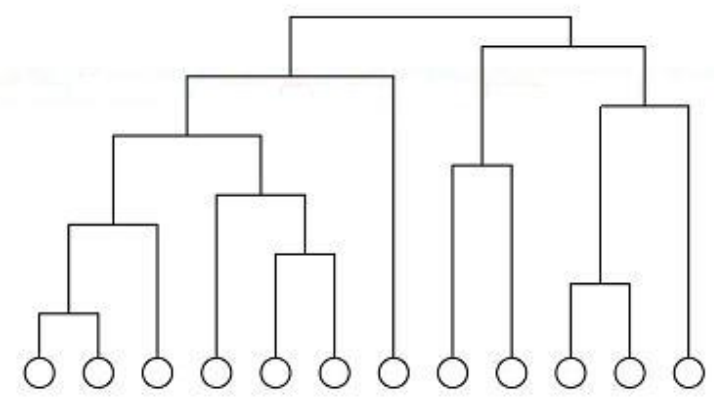

Figura 3.5: Saída gerada por algoritmo de detecção de comunidades

Nesse capítulo são apresentadas três técnicas de detecção de comunidades em redes complexas, descritas a seguir.

\subsection{Edge Betweenness}

O método descrito nessa seção segue a classe de métodos divisivos com uma abordagem diferente: a aresta removida não é aquela que conecta o par de nós menos similar, e sim a aresta de maior "betweenness", ou seja, a aresta responsável por conectar muitos pares de nós. O cálculo do betweenness da aresta (edge betweenness) surgiu a partir do conceito de vertex betweenness extendido por (Newman \& Girvan, 2004), onde o betweenness de um vértice $u$ é dado pelo número de caminhos mais curtos entre pares de vértices que passam por $u$. No caso de uma aresta 
$(u, w)$, seu edge betweenness é dado pelo número de caminhos mais curtos entre pares de vértices que passam pela aresta $(u, w)$. Essa medida de betweenness visa favorecer arestas que ligam nós de comunidades diferentes e penalizar aquelas que ligam nós de uma mesma comunidade. Desse ponto em diante, a definição betweenness corresponde ao conceito de edge betweenness.

Existem diversas maneiras de calcular medidas de betweenness, mas todas seguem um princípio comum: como o número de arestas conectando duas comunidades é pequeno, todos os caminhos que ligam nós em comunidades diferentes devem passar por essas arestas. Assim sua participação na composição dos caminhos que ligam as duas comunidades é alta e pode ser quantificada, fornecendo uma forma de identificá-las (Newman \& Girvan, 2004). Três medidas de betweenness são sugeridas por (Newman \& Girvan, 2004): shortest-path betweenness, random-walk betweenness e current-flow betweenness. A descrição de cada medida de betweenness, bem como formas de calculá-las, serão feitas posteriormente.

Outra característica do método de edge betweenness é o cálculo do betweenness toda vez que uma aresta é removida da rede. Nos algoritmos divisivos tradicionais baseados em edge betweenness, o cálculo do betweenness é feito apenas uma vez no início do algoritmo, e a remoção das arestas segue em ordem decrescente de betweenness. Um problema dessa abordagem é revelado quando duas arestas conectam duas comunidades, e por algum motivo a maior parte dos caminhos gerados entre os pares de nós passaram por apenas uma dessas arestas. O algoritmo irá remover a aresta de maior betweenness e outra aresta continuará conectando as comunidades, podendo nunca ser removida pelo algoritmo. Por esse motivo o valor de betweenness é recalculado toda vez que uma aresta é removida.

Os passos do algoritmo de detecção de comunidades são mostrados a seguir:

1. Calcule os valores de betweenness de todas as arestas da rede;

2. Remova da rede a aresta de maior betweenness;

3. Recalcule os valores de betweenness para as demais arestas;

4. Volte ao Passo 2.

A seguir serão descritas diferentes formas para o cálculo do betweenness.

\section{Shortest-path betweenness}

A idéia mais intuitiva de obter os caminhos entre dois nós de uma rede é a busca pelos caminhos mais curtos entre eles. Assim o valor de betweenness de cada aresta será dado pelo número de caminhos que essa aresta participa. À primeira vista, calcular o betweenness com base em caminhos mais curtos tem complexidade $O\left(m n^{2}\right)$ em um grafo com $m$ arestas e $n$ vértices (Cormen et al., 2001). Essa complexidade é explicada pelo fato de que os caminhos mais curtos entre dois vértices podem ser calculados usando busca em largura com tempo $O(m)$, o que deve ser feito para 
todos os $O\left(n^{2}\right)$ pares de vértices. (Newman \& Girvan, 2004) propuseram uma adaptação do método acima para calcular o betweenness de todas as arestas em tempo $O(m n)$. Como o cálculo do betweenness deve ser feito a cada remoção de aresta, o algoritmo de identificação de comunidades tem complexidade $O\left(m^{2} n\right)$. Entretanto, (Newman \& Girvan, 2004) notaram que apenas as arestas de um mesmo componente da aresta removida têm seus betweenness afetados; portanto apenas os betweenness dessas arestas precisam ser recalculados. A medida que a remoção das arestas divide a rede em comunidades, o custo computacional com cálculo do betweenness é reduzido (Newman \& Girvan, 2004).

\section{Random-walk betweenness}

De maneira geral, random-walk betweenness de uma aresta $(u, w)$ é igual ao número de vezes que uma caminhada aleatória, partindo de um vértice $s$ até um vértice $t$, passa pela aresta $(u, w)$, tomando-se a média de todos os pares de vértices $s$ e $t$.

Primeiramente é calculado o betweenness pelo número esperado de vezes que uma caminhada aleatória entre pares de nós irá passar por uma aresta em particular. Considerando todos os pares de nós da rede, a soma desses valores dá origem à segunda medida de betweenness da aresta.

\section{Current-flow betweenness}

Essa medida de betweenness é motivada pelas idéias da teoria de circuitos. Um circuito é criado, onde cada aresta da rede corresponde a uma resitência e um par de nós corresponde a uma unidade de corrente fonte e destino. A corrente irá percorrer a rede por um determinado número de caminhos e os caminhos com menor resistência teriam a maior fração da corrente. O total de corrente na aresta será a soma da corrente considerando todos os pares de nós fonte/destino, resultando no valor de betweenness da aresta. Esses caminhos podem ser identificados através da resolução de equações de Kirchhoff (Newman \& Girvan, 2004).

\subsection{Partícula Browniana}

Essa técnica de identificação de comunidades em redes complexas foi descrita inicialmente por (Zhou, 2003b) e estendida pelo mesmo autor em (Zhou, 2003a). É baseada no conceito de Movimento Browniano: uma partícula Browniana começa sua trajetória em um vértice da rede, escolhendo o próximo vértice de maneira aleatória. As informações obtidas pela partícula são utilizadas para medir a distância entre os vértices, definindo as comunidades que compõem a rede e a estrutura de cada uma.

Considere uma rede formada por um conjunto de $n$ vértices $V=\left\{v_{1}, \ldots, v_{n}\right\}$ e $m$ arestas. A matriz de adjacência $A$ indica a força da interação entre os vértices. Se $A_{i j}$ igual a zero, não 
há conexão entre os vértices $v_{i}$ e $v_{j}$; se $A_{i j} \equiv A_{j i}>0$ existe uma aresta que liga os vértices $v_{i}$ e $v_{j}$ e o valor numérico indica a força da interação entre eles. O conjunto de vizinhos do vértice $v_{i}$ são denotados por $E_{i}$. Considerando que existe uma partícula Browniana na rede, a cada passo essa partícula move-se do vértice $v_{i}$ para um vértice $v_{j}$ com probabilidade $P_{i j}$, dada pela matriz de transferência $P$. O valor de $P_{i j}$ pode ser calculado de maneira intuitiva por: $P_{i j}=A_{i j} / \sum_{l=1}^{n} A_{i l}$.

A distância entre os vértices $v_{i}$ e $v_{j}$ pode ser calculada como a média de passos necessários para a partícula Browniana mover-se de $v_{i}$ a $v_{j}$. A distância $d_{i j}$ é dada pela Equação 3.1:

$$
d_{i j}=\sum_{l=1}^{N}\left(\frac{1}{I-B(j)}\right)_{i l}
$$

onde $I$ é a matriz identidade $n \times n$ e a matriz $B(j)$ é igual à matriz de transferência $P$, onde $B_{l j} \equiv 0$ para qualquer $v_{l} \in V$, ou seja, a coluna $v_{j}$ da matriz de transferência $\mathrm{P}$ é preenchida por zeros. As distâncias de $v_{j}$ a todos os outros vértices em $V$ pode ser obtida através da solução do sistema de equações lineares descrito pela Equação 3.2:

$$
[I-B(j)]\left\{d_{1 j}, \ldots, d_{N j}\right\}^{T}=\{1, \ldots, 1\}^{T}
$$

A partir da matriz de distâncias, algumas propriedades podem ser obtidas:

- se $d_{i j} \leq d_{i k}$ para todo $v_{k} \in V$, então $v_{j}$ é classificado como atrator global do vértice $v_{i}$, ou seja, $v_{i}$ está mais próximo de $v_{j}$ levando em consideração a distância média;

- se $v_{j} \in E_{i}$ e $d_{i j} \leq d_{i l}$ para todo $v_{l} \in E_{i}$, então $v_{j}$ é classificado como atrator local do nó $v_{i}$, ou seja, dentre todos os vizinhos de $v_{i}, v_{j}$ é o mais próximo.

De maneira intuitiva, pode-se dizer que um vértice $v_{i}$ deve pertencer a mesma comunidade que seu atrator local $v_{j}$, pois $v_{j}$ possui a menor distância até $v_{i}$ dentre todos os vizinhos deste. Assim, é possível decompor os vértices da rede em comunidades baseadas nos atratores locais, chamadas comunidades- $L$. Essa comunidade é formada pelo conjunto de vértice $L$ tal que:

1. se $v_{i} \in L$ e $v_{j}$ é o atrator local de $v_{i}$, então $v_{j} \in L$;

2. se $v_{i} \in L$ e existe um vértice $v_{k}$ que possui $v_{i}$ como atrator local, então $v_{k} \in L$

3. um subconjunto de $L$ não caracteriza uma comunidade- $L$.

O conceito de comunidades- $L$ pode ser expandido para a rede toda: um vértice $v_{i}$ deve pertencer à mesma comunidade que seu atrator global. Dessa forma pode-se construir comunidades baseadas nos atratores globais de cada vértice, chamadas comunidades-G.

$\mathrm{O}$ artigo de (Zhou, 2003b) esclarece também que para redes pequenas as comunidades obtidas através de atratores locais ou globais têm grandes chances de compartilharem a mesma estrutura, enquanto que para redes maiores, pode acontecer que uma comunidade- $G$ englobe diversas comunidades- $L$. 
Um aspecto que pode ser analisado em relação a uma comunidade $C$ é o índice instabilidade $I_{c}$. Um vértice $v_{i}$ que pertence à comunidade $C$ é considerado instável caso $\sum_{v_{k} \in C^{\prime}} A_{i k}>\sum_{v_{k} \in C} A_{i k}$, ou seja, se a interação total de $v_{i}$ com os vértices de outra comunidade $C^{\prime}$ é maior que a interação total de $v_{i}$ com os vértices de sua comunidade $C$. O índice $I_{c}$ indica o número de nós instáveis da comunidade $C$.

\subsubsection{Exemplos de comunidades locais e globais}

Para exemplificar a divisão da rede em comunidades, o método acima foi testado em algumas redes em que a estrutura de comunidades já é conhecida. Um exemplo disso é a rede do clube de caratê, onde durante dois anos foram documentadas as interações sociais entre membros de um clube de caratê de uma universidade americana (Zachary, 1977). Durante os dois anos de observações, o clube foi dividido em dois, após uma disputa entre o administrador e o instrutor do clube. Essa rede possui 34 vértices e 78 arestas, com a divisão em duas comunidades de 16 e 18 vértices respectivamente, marcadas de cores diferentes na Figura 3.6. O algoritmo detectou 3 comunidades locais, agrupadas espacialmente na Figura 3.6. A comunidade $L 1$ possui 11 elementos, sendo que o vértice 13 é instável e possui forte ligação com a comunidade $L 2$; a comunidade $L 2$ tem 6 elementos, sendo que o vértice 9 possui forte ligação com a comunidade $L 3$; enquanto a comunidade L3 possui 17 elementos. Para essa rede, as comunidades locais e globais são iguais.

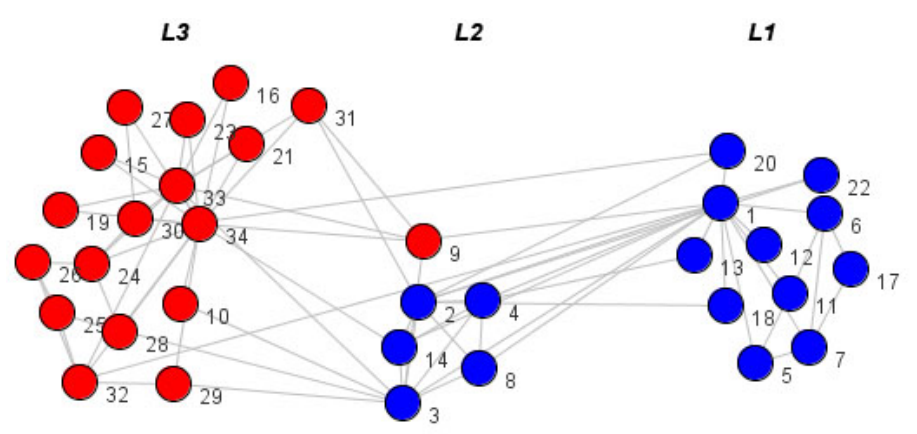

Figura 3.6: Divisão de comunidades da rede de interações do clube de caratê de (Zachary, 1977). Originalmente os dados são divididos em duas comunidades representadas pelas diferentes cores, enquanto a divisão dada pelo algoritmo de (Zhou, 2003b) é dada pela localização espacial dos nós.

Outra base de dados utilizada para testes descreve a temporada de um campeonato de futebol americano entre universidades (Girvan \& Newman, 2002). Os 115 vértices do grafo representam os times e as 613 arestas indicam a ocorrência de um jogo entre os times. Esses 115 times são divididos em 12 grupos pelos organizadores. Esses grupos são divididos de modo que seja mais comum um jogo entre times de universidades geograficamente próximas do que universidades distantes. Para essa rede, o método encontrou 15 comunidades, onde 11 eram localmente estáveis: L2 (9 elementos), L3 (13 elementos), L4 (14 elementos), L5 (10 elementos), L6 (8 elementos), L7 (6 elementos), L8 (7 elementos), $L 9$ (6 elementos), L10 (4 elementos), L11 (6 elementos) e $L 13$ (9 elementos). A comunidade $L 1$ (9 elementos) possui um elemento com interação maior com a 
comunidade $L 10$ e a comunidade $L 12$ (10 elementos) um elemento com interação maior com a comunidade $L 3$. Já todos os elementos das comunidades $L 14$ (2 elementos) e $L 15$ (2 elementos) possuem maior interação com várias outras comunidades. A Figura 3.7 mostra as comunidades locais separadas por cores.

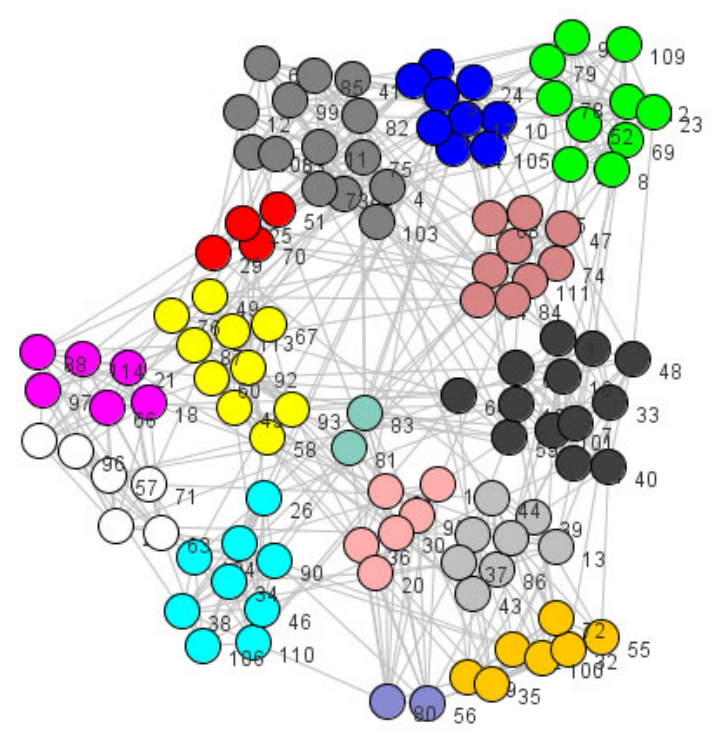

Figura 3.7: Divisão de comunidades da rede de interações do campeonato de futebol americano de (Girvan \& Newman, 2002) dada pelo algoritmo de (Zhou, 2003b)

\subsection{2 Índice de dissimilaridade}

O método exemplificado na seção anterior é uma maneira simples de agrupar vértices e arestas em sub-grafos com base na distância medida pela partícula Browniana. Uma extensão realizada pelo mesmo autor em (Zhou, 2003a) define um índice de dissimilaridade entre vértices vizinhos através da matriz de distâncias, fornecendo um parâmetro que quantifica as diferenças entre as comunidades. O índice de dissimilaridade indica até que ponto dois vértices vizinhos devem pertencer à mesma comunidade, e pode ser usado na decomposição hierárquica da rede em clusters. Cada comunidade é limitada por valores inferiores e superiores de dissimilaridade, respectivamente denotados por $\theta_{\text {low }}$ e $\theta_{\text {upp }}$.

O conjunto de distâncias $\left\{d_{i 1}, \ldots, d_{i, i-1}, d_{i, i+1}, \ldots, d_{i n}\right\}$ mede a distância de todos os outros vértices em relação ao vértice $v_{i}$ e pode ser visto como a perspectiva da rede pelo ponto de vista do vértice $v_{i}$. Suponha então dois vértices vizinhos $v_{i}$ e $v_{j}$, a diferença entre suas perspectivas da rede pode ser medida de forma quantitativa pelo índice de dissimilaridade $\Lambda\left(v_{i}, v_{j}\right)$ definido pela Equação 3.3:

$$
\Lambda\left(v_{i} v, j\right)=\frac{\sqrt{\sum_{k \neq i, j}^{n}\left[d_{i k}-d_{j k}\right]^{2}}}{n-2}
$$


Caso $v_{i}$ e $v_{j}$ pertençam à mesma comunidade, então a distância média $d_{i k}$ de $v_{i}$ para um vértice qualquer $v_{k}$ será semelhante à distância média $d_{j k}$ do vértice $v_{j}$ a $v_{k}$. Assim a perspectiva da rede dos dois vértices será semelhante, resultando em valores menores de $\Lambda\left(v_{i}, v_{j}\right)$ para vértices de uma mesma comunidade. Consequentemente, o valor de $\Lambda\left(v_{i}, v_{j}\right)$ será maior caso os vértices pertençam a comunidades diferentes.

Após o cálculo da matriz de distâncias $\left\{d_{i, j}\right\}$ e da matriz dos índices de dissimilaridade de todos os pares de nós vizinhos $\left\{\Lambda\left(v_{i}, v_{j}\right)\right\}$, é possível formalizar um algoritmo para decompor a rede em comunidades:

1. Inicialmente a rede forma uma única comunidade. O limiar superior de dissimilaridade $\theta_{\text {upp }}$ da comunidade equivale ao valor máximo de todos os índices de dissimilaridade calculados.

2. Para cada comunidade, um parâmetro limiar de resolução $\theta$ é definido e possui o valor inicial de $\theta_{\text {upp }}$ da comunidade. Além disso, se dois vizinhos $v_{i}$ e $v_{j}$ possuem $\Lambda\left(v_{i}, v_{j}\right) \leq \theta$ eles são classificados como "amigos".

3. O valor de $\theta$ é decrementado diferencialmente. Os pares de vizinhos classificados como "amigos" são examinados e diferentes conjuntos formados. Cada conjunto é composto por todos amigos dos vértices do conjunto. Caso algum vértice da comunidade não tenha amigos, são incluídos em um conjunto de amigos com o qual tenha maior interação de acordo com a matriz de adjacência $A$. Após isso, todos os vértices da comunidade estão distribuídos em sub-clusters de vértices disjuntos.

4. Cada vértice deve ter maior interação com os vértices do seu próprio sub-cluster do que com os vértices de outro sub-cluster. Caso algum vértice não cumpra esse requisito, é movido para o conjunto de vértices com o qual possui maior interação.

5. Se nenhum sub-cluster foi formado, ou seja, todos os vértices são amigos, volte ao Passo 3, onde $\theta$ é decrementado. Se forem formados dois ou mais conjuntos, então o limiar inferior de dissimilaridade da comunidade em processamento $\theta_{\text {low }}$ recebe o valor de $\theta$. Cada subconjunto formado é considerado uma nova comunidade, onde $\theta_{u p p}=\theta$. Com isso um novo nível é criado na hierarquia das comunidades. O algoritmo retorna ao Passo 2 para subdividir as comunidades restantes.

6. Após todas as (sub)comunidades terem sido processadas, a relação entre as diferentes comunidades e os limiares inferiores e superiores de cada comunidade podem ser visualizados em um dendrograma.

\subsection{Modularidade e estrutura de comunidades}

(Newman \& Girvan, 2004) definiram uma métrica chamada modularidade, para qualificar as estruturas das comunidades. Considere uma divisão da rede em $K$ comunidades. Seja a matriz e 
$K \times K$ cujo elemento $e_{i j}$ corresponde a metade do número de arestas que conectam as comunidades $i$ e $j$ em relação ao total de arestas da rede. Dessa forma $e_{i j}+e_{j i}$ corresponde ao total de arestas que conectam os vértices de ambas comunidades. Já $e_{i i}$ corresponde ao número de arestas dentro da comunidade $i$ em relação ao total de arestas.

Um objetivo que deve ser alcançado por um algoritmo de detecção de comunidades é a maximização da fração de arestas que conectam vértices de uma mesma comunidade, ou seja, $\sum_{i} e_{i i}$. Entretanto essa medida não oferece uma boa métrica para avaliar a qualidade das comunidades, já que seu valor máximo é facilmente atingido quando todos os nós da rede pertencem à mesma comunidade. Para isso, mais um componente é definido: $a_{i}=\sum_{j} e_{i j}$, que representa a soma das arestas que conectam a comunidade $i$ com as demais comunidades. Em uma rede com as mesmas $K$ comunidades em que as arestas são adicionadas de maneira aleatória (respeitando o grau de cada vértice), $e_{i j}=a_{i} a_{j}$. Então pode-se definir o índice de modularidade como mostra a Equação 3.4:

$$
Q=\sum_{i}\left(e_{i i}-a_{i}^{2}\right)
$$

Se a estrutura da comunidade oferecer um número de arestas entre nós da mesma comunidade igual do que se as arestas fossem adicionadas aleatoriamente, tem-se que $Q=0$, o que indica que a estruturas das comunidades encontrada pelo algoritmo não é melhor do que se as arestas fossem simplesmente colocadas de maneira aleatória. Conforme o valor de $Q$ aproxima-se de 1, a estrutura das comunidades são melhores do que se as arestas fossem adicionadas aleatoriamente e na prática valores de $Q$ acima de 0.3 indicam que a estrutura de comunidades encontrada compensa ser considerada (Newman \& Girvan, 2004).

Após a definição de um índice para quantificar a qualidade das comunidades, é possível construir um algoritmo que otimize o valor de $Q$ sobre todas as possíveis divisões da rede em comunidades. Como a otimização da Equação 3.4 considerando-se todas as possíveis divisões em comunidades é exponencial, a solução adotada por (Newman, 2004b) baseia-se na técnica de otimização gulosa. Trata-se de um algoritmo aglomerativo de clusterização hierárquica, onde inicialmente cada vértice da rede é considerado uma comunidade, e repetidamente as comunidades são agrupadas em pares, de forma que o valor de $Q$ tenha o maior aumento (ou menor decréscimo) possível.

É importante ressaltar que apenas comunidades que possuem arestas ligando seus vértices podem ser possivelmente unidas pelo algorimto. Isso limita a um máximo de $m$ pares de comunidades, onde $m$ é o número de arestas do grafo. A variação em $Q$ quando duas comunidades são unidas é dada pela Equação 3.5:

$$
\Delta Q=e_{i j}+e_{j i}-2 a_{i} a_{j}
$$


que pode ser calculado em tempo constante. $\mathrm{O}$ valor inicial de $e_{i j}$ é igual à metade do grau de cada vértice, já que inicialmente cada comunidade é formada por apenas um vértice. Após a junção de duas comunidades os valores de $e_{i j}$ devem ser atualizados, somando-se o conteúdo de cada linha e coluna da matriz correspondentes às comunidades unidas. Além disso, o valor de $Q$ é calculado a cada iteração, tornando simples a tarefa de escolher a melhor maneira de dividir a rede em comunidades.

\subsection{Considerações Finais}

Neste capítulo foram descritos os principais conceitos a respeito da área de redes complexas, bem como suas áreas de aplicação. Por tratar-se de uma abordagem capaz de lidar com grandes conjuntos de dados, é interessante estudar a aplicação dos conceitos de redes complexas em algoritmos de clusterização de dados. Redes complexas podem auxiliar na superação das dificuldades encontradas por algoritmos de clusterização clássicos quando têm um grande conjunto de dados como entrada (Jain \& Dubes, 1988), ou na capacidade de identificação de clusters com formas e tamanhos variados.

Uma propriedade encontrada em redes complexas reais muito relacionada à área de clusterização de dados é a presença de grupos de nós densamente conectados entre si, e pouco conectados com nós de outros grupos. A existência de tais grupos indica a presença de estrutura de comunidades em uma rede complexa, e sua identificação é feita através de métodos de detecção de comunidades. Neste capítulo foram descritas três técnicas de detecção de comunidades em redes complexas: Edge Betweenness, baseada na remoção de arestas que conectam um grande número de nós; Partícula Browniana, onde a distância entre dois nós é medida por uma partícula Browniana; e Modularidade, onde a união de duas comunidades é feita com base na maximização do índice de modularidade.

No Capítulo 4 serão apresentadas técnicas inspiradas em modelos biológicos, com o objetivo de utilizar os conceitos da computação bioinspirada na detecção de comunidades. 


$\frac{7}{4}$

\section{Técnicas de Computação Bioinspirada}

Existem diversas técnicas para elaboração de heurísticas e algoritmos de aproximação com a intenção de resolver problemas de otimização, como simulated anneling (Kirkpatrick et al., 1983) e tabu search (Glover \& Laguna, 1993). Recentemente técnicas inspiradas em princípios e modelos de sistemas biológicos têm ganhado força, como algoritmos genéticos (Goldberg, 1989) e colônia de formigas (Dorigo et al., 1996). Entre as vantagens de resolver problemas com técnicas bioinspiradas estão a necessidade de pouca informação para encontrar a solução, além de terem sido aplicadas com sucesso em diversos problemas de biologia molecular, computação e mecânica. Para esse trabalho foram escolhidos três modelos computacionais inspirados biologicamente: colônia de formigas, nuvem de partículas e aprendizado por reforço.

\subsection{Sistema de Colônia de Formigas}

Uma técnica recente utilizada para construção de heurísticas é baseada no comportamento real de colônias de formigas. O objetivo é verificar como animais simples como as formigas podem coletivamente realizar tarefas complexas, através do cumprimento de regras simples.

Através da observação de colônias de formigas reais foi proposto por (Dorigo et al., 1996) um novo algoritmo de aproximação para a solução de problemas de otimização combinatória, que recebeu o nome de Ant System (AS). A característica mais importante obtida da observação de colônias de formigas foi a maneira como elas encontram os menores caminhos entre a fonte de alimentos e seu ninho. Inicialmente, as formigas procuram por alimento de maneira aleatória em locais próximos ao ninho. Durante o percurso, as formigas deixam uma trilha de uma substância chamada feromônio marcando o caminho. Quando outras formigas precisam escolher qual caminho seguir, 
elas tendem a escolher aqueles marcados por grandes quantidades de feromônio. Assim que a fonte de alimento é encontrada, a formiga avalia a qualidade e a quantidade do alimento. Essas informações são transmitidas às demais formigas através da quantidade de feromônio depositada no caminho de volta. Quanto maior é a quantidade de feromônio mais atrativo o caminho será para as demais formigas. O resultado é que a maioria das formigas irá escolher o menor caminho, ainda que a possibilidade de explorar novos caminhos exista (Blum, 2005). Apesar da inspiração em colônia de formigas real, os algoritmos de otimização desenvolvidos possuem algumas diferenças em relação às colônias reais, como atuação em ambiente com tempo discreto e formigas artificiais com memória.

Como exemplo, considere a Figura 4.1. As formigas percorrem um caminho do ninho à fonte de alimento e vice-versa (Figura 4.1 (a)). Quando um obstáculo é colocado no caminho, as formigas devem decidir por qual lado seguir, direita ou esquerda (Figura 4.1 (b)). Essa escolha é influenciada pela quantidade de feromônio depositada no caminho. Quando a primeira formiga chega ao obstáculo, tem probabilidade igual de escolher ir ao ponto $\mathrm{A}$ ou $\mathrm{B}$, já que ainda não há feromônio depositado no caminho. Como o caminho até ao alimento pelo ponto A é mais curto, a formiga alcançará o destino mais rápido e voltará pelo mesmo caminho, reforçando a trilha de feromônio. Como as formigas que escolherem o caminho através do ponto B levarão mais tempo para chegar ao alimento, a trilha de feromônio será mais fraca. Isso faz com que a quantidade de feromônio depositada no caminho que passa pelo ponto A seja maior do que pelo ponto B. Logo, a maioria das formigas passarão a escolher o menor caminho até o alimento (Figura 4.1 (c)).

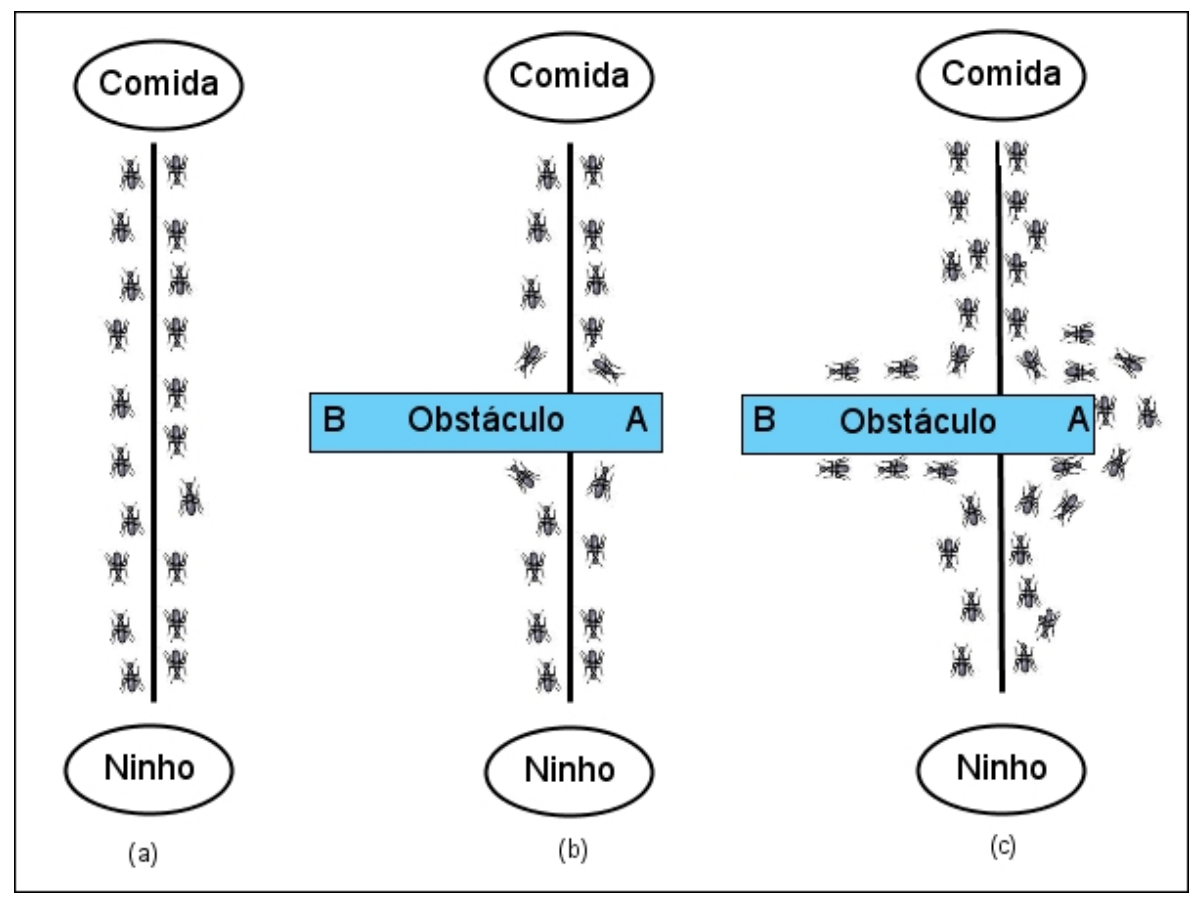

Figura 4.1: Formigas reais em busca por alimento: (a) formigas seguem um caminho de seu ninho à fonte de alimento (b)um obstáculo é colocado no caminho e as formigas devem decidir qual caminho seguir (c)a quantidade de feromônio no menor caminho é maior e mais formigas seguem por ele. 


\subsubsection{Colônia de Formigas e o Caixeiro Viajante}

O primeiro problema resolvido através da heurística baseada em colônia de formigas foi o problema do caixeiro viajante, definido a seguir: Seja um conjunto de cidades e as distâncias entre elas. O objetivo é visitar todas as cidades apenas uma vez percorrendo a menor distância possível.

Para resolver o problema do caixeiro viajante usando o AS, toda aresta $(i, j)$ armazena, além da distância $d_{i j}$ entre as cidades, a quantidade de feromônio $\tau_{i j}$ depositada no caminho. Cada formiga é colocada em uma cidade aleatória. A formiga então passa da cidade $i$ para uma cidade não visitada $j$. Quando todas as cidades foram visitadas, a formiga volta para a cidade de origem. Além disso, a formiga possui uma tabela, chamada tabu-list, que contém as cidades que já visitou. A cada passo, a formiga escolhe a próxima cidade $j$ a ser visitada, levando em conta dois aspectos: cidades próximas devem ser escolhidas com maior probabilidade, o que caracteriza uma heurística gulosa; arestas usadas por muitas formigas em iterações anteriores têm maior probabilidade de serem escolhidas novamente.

Quando as formigas passam por todas as cidades encerra-se um ciclo. Nesse momento, as arestas que fazem parte do caminho escolhido pelas formigas têm a quantidade de feromônio atualizada. No próximo ciclo as arestas que têm a quantidade de feromônio atualizada têm maior probabilidade de serem escolhidas. Especificamente, após um ciclo ( $n$ iterações), a quantidade de feromônio de cada aresta $(i, j)$ é atualizada pela Equação 4.1:

$$
\tau_{i j}(t+n)=\rho \tau_{i j}(t)+\Delta \tau_{i j}
$$

onde $\tau_{i j}(t)$ representa a quantidade de feromônio da aresta $(i, j)$ no tempo $t$ e $\rho$ é o parâmetro que determina a "evaporação" do feromônio. A variação da quantidade de feromônio na aresta $(i, j)$ é dada por:

$$
\Delta \tau_{i j}=\sum_{k=1}^{m} \Delta \tau_{i j}^{k}
$$

onde $m$ é igual ao número de formigas na rede e $\Delta \tau_{i j}^{k}$ corresponde a quantidade de feromônio depositado na aresta $(i, j)$ pela formiga $k$, e é obtido através da Equação 4.3. Assim a quantidade de feromônio na aresta $(i, j)$ é maior caso a aresta $(i, j)$ faça parte do caminho percorrido pela formiga $k$ (dado pela tabu - list).

$$
\Delta \tau_{i j}^{k}=\left\{\begin{array}{l}
\frac{Q}{L_{k}}, \text { se }(i, j) \in \text { caminho descrito por tabu }-l_{i s t_{k}} \\
0, \text { caso contrário }
\end{array}\right.
$$

onde $Q$ é uma constante e $L_{k}$ é o comprimento do caminho percorrido pela formiga $k$.

Dessa forma, a formiga $k$ deve escolher qual a próxima cidade que deve visitar, onde a probabilidade de transição da cidade $i$ para a cidade $j$ é dada pela Equação 4.4: 


$$
p_{i j}^{k}(t)=\left\{\begin{array}{l}
\frac{\left[\tau_{i j}(t)\right]^{\alpha} *\left[\eta_{i j}\right]^{\beta}}{\sum_{k \in \text { permitido }}\left[\tau_{i k}(t)\right]^{\alpha} *\left[\eta_{i k}\right]^{\beta}}, \text { se } j \in \text { permitido }_{k} \\
0, \text { caso contrário }
\end{array}\right.
$$

onde $\eta_{i j}=\frac{1}{d_{i j}}$, chamada de visibilidade, permitido $o_{k}=N-$ tabu list $_{k}$ e $\alpha$ e $\beta$ são parâmetros usados para balancear a importância do feromônio em relação a visibilidade, ou seja, a importância da escolha prioritária das cidades mais próximas (dada pela visibilidade) em relação à intensidade de feromônio no caminho.

O algoritmo termina quando o número de ciclos chega ao valor máximo (definido previamente) ou quando todas as formigas percorrem o mesmo caminho. O que pode ser notado na descrição do algoritmo é que as estruturas utilizadas são específicas ao problema do caixeiro viajante, como por exemplo a estrutura usada para guardar a distância entre as cidades e a quantidade de feromônio de cada aresta. Caso a heurística fosse utilizada para solucionar outro problema de otimização, seria necessário modificar o algoritmo, substituindo as estruturas de dados.

\section{Influência da quantidade de formigas}

Considerando o problema do caixeiro viajante em um grafo completo formado por 10 (dez) cidades, o impacto da quantidade de formigas na busca pela melhor solução é ilustrado na Figura 4.2. Para esse problema, pode-se perceber que à medida que o número de formigas aumenta, a quantidade de formigas que encontram a melhor solução também aumenta.

Quando são utilizadas apenas $10(\mathrm{dez})$ formigas, poucas encontram o melhor caminho devido à pouca quantidade de feromônio depositada nas arestas. A medida que cresce o número de formigas, a quantidade de feromônio nas arestas aumenta e mais formigas percorrem o melhor caminho.

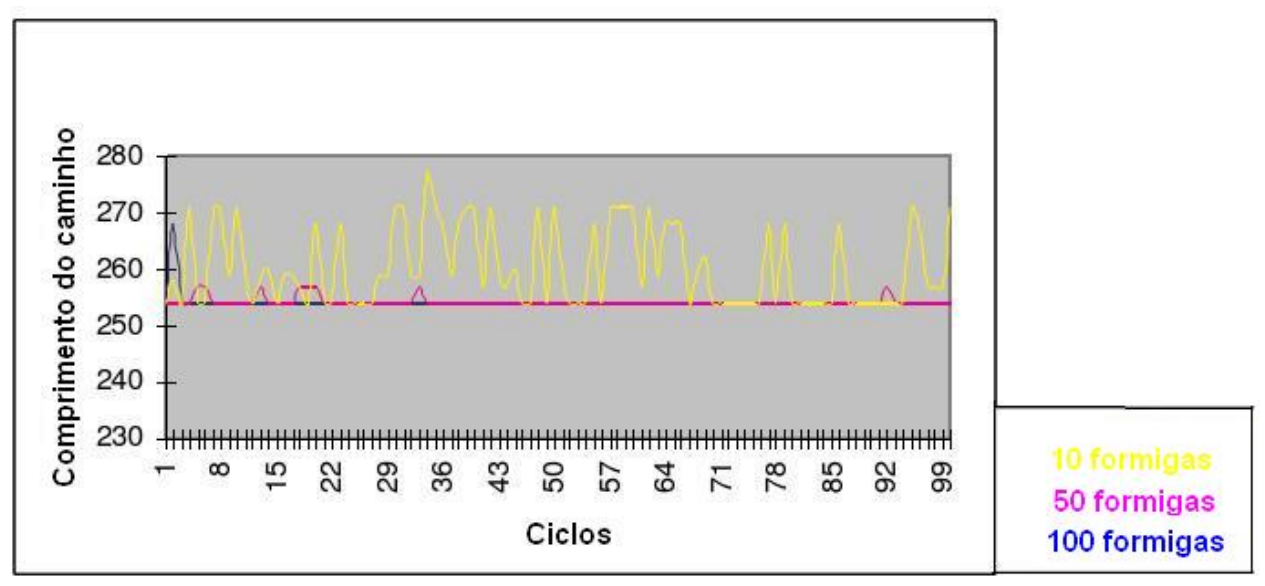

Figura 4.2: Influência da quantidade de formigas na busca pelo menor caminho 


\subsection{Otimização por Nuvem de Partículas - PSO}

A técnica de otimização por nuvem de partículas (Particle Swarm Optimization - PSO) foi proposta inicialmente por (Kennedy \& Eberhart, 1995). É uma técnica de otimização estocástica baseada em população e inspirada no comportamento social ou de um bando de pássaros. O PSO possui diversos pontos em comum com outros algoritmos evolutivos, e destaca-se pela facilidade de implementação e poucos parâmetros a serem ajustados.

Otimização por nuvem de partículas possui algumas similaridades com algoritmos genéticos (AG) e pode ser utilizada para resolver os mesmos tipos de problemas. Da mesma forma que AG's, o PSO é formado inicialmente por uma população aleatória de possíveis soluções, chamada swarm. A diferença é que a cada solução é adicionada uma velocidade, possibilitando a busca direcionada de melhores soluções, sem a utilização de operações como crossover e/ou mutação, e todos os elementos da população participam da busca pela melhor solução. Além disso, um sistema baseado em partículas possui uma memória, ao contrário dos AG’s.

O PSO foi inicialmente aplicado com sucesso na otimização de várias funções contínuas nãolineares (Kennedy \& Eberhart, 1995). Embora a utilização do PSO em problemas de otimização combinatória é ainda limitada, ele como vantagens a simplicidade conceitual e baixo custo computacional. Além da aplicação na otimização de funções, o PSO tem sido utilizado em aplicações como controle de energia (Abido, 2002), atribuição de tarefas (Salman et al., 2002), entre outros.

\subsubsection{Descrição do PSO clássico}

O PSO pode ser descrito da seguinte forma: cada partícula representa uma possível solução do problema de otimização. As partículas percorrem o espaço de busca e guardam a melhor solução que já encontraram, chamada pbest. Além disso, as partículas comunicam a melhor posição que cada uma encontrou até então, e a melhor posição de todas as partículas é chamada gbest. Assim cada partícula possui além de sua melhor solução, a melhor solução encontrada pela swarm. Durante uma iteração cada partícula atualiza sua velocidade, de acordo com os valores de pbest e gbest. Isso significa que se uma partícula descobre uma nova solução promissora, todas as outras partículas moverão-se em direção à nova solução, explorando a região mais detalhadamente durante o processo.

Seja $n$ o tamanho da população (swarm). Cada partícula do swarm possui os seguintes atributos:

- $x_{i}$ : posição atual no espaço de busca. Essa posição representa uma possível solução ao problema;

- $v_{i}$ : velocidade atual da partícula $i$;

- pbest: melhor solução já encontrada pela partícula $i$. 
A cada iteração, a partícula $i$ deve atualizar sua posição e velocidade de acordo com duas variáveis: sua melhor solução encontrada (pbest) e a melhor solução encontrada pela swarm (gbest). A Equação 4.5 mostra como é atualizada a velocidade da partícula $i$. Considere que o objetivo buscado é a minimização da função $f$ e a existência de uma swarm com $n$ partículas.

$$
v_{i j}(t+1)=w \times v_{i, j}(t)+c_{1} r_{1, i}(t)\left[\text { pbest }_{j}(t)-x_{i, j}(t)\right]+c_{2} r_{2, i}(t)\left[\text { gbest }_{j}(t)-x_{i, j}(t)\right]
$$

onde: $v_{i, j}$ é a velocidade da $i$-ésima partícula na $j$-ésima dimensão; $j=1, \ldots, d$, e $d$ é o número de dimensões do problema; $c_{1}$ e $c_{2}$ são coeficientes de aceleração; $r_{1}$ e $r_{2}$ números aleatórios de duas sequências uniformes no intervalo $(0,1)$ e $w$ é o peso de inércia.

Após o cálculo da velocidade é necessário atualizar a posição da partícula na iteração $t+1$ através da Equação 4.6, além de atualizar a melhor posição da partícula (pbest) e a melhor posição global (gbest) através das Equações 4.7 e 4.8.

$$
\begin{gathered}
x_{i}(t+1)=x_{i}(t)+v_{i}(t+1) \\
\operatorname{pbest}(t+1)=\left\{\begin{array}{c}
\text { pbest }(t), \text { se } f\left(x_{i}(t+1)\right) \geq f(\text { pbest }(t)) \\
x_{i}(t+1), \text { caso contrário }
\end{array}\right. \\
\text { gbest }(t+1)=\underset{\text { pbest }_{i}}{\operatorname{argmin}}\left(f\left(\text { pbest }_{i}(t+1)\right)\right), 1 \leq i \leq n,
\end{gathered}
$$

$\mathrm{O}$ valor de cada componente $v_{i}$ pode ser restringido ao intervalo $\left[-v_{\max }, v_{\max }\right]$ para reduzir a probabilidade de que as partículas deixem o espaço de busca.

Seguindo esses passos o PSO é descrito pelo Algoritmo 1.

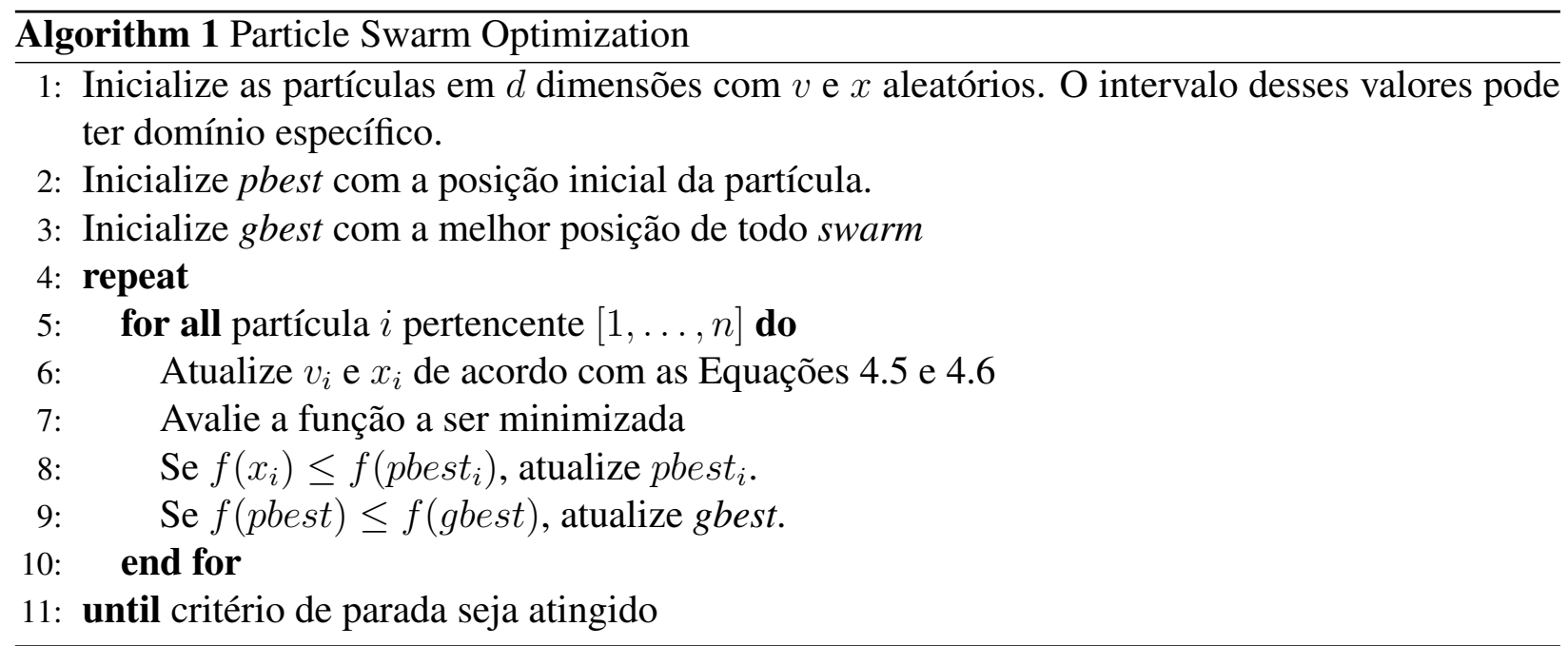


O algoritmo anterior foi o primeiro modelo proposto e é conhecido como modelo gbest, por levar em consideração a melhor solução encontrada em todo swarm. Algumas otimizações podem ser feitas no algoritmo original e são descritas na próxima seção.

\section{Modelo Ibest}

Desde a introdução do algoritmo PSO, várias melhorias foram sugeridas, como por exemplo o uso da inércia $w$, resultando em uma convergência mais rápida (vandenBergh \& Engelbrecht, 2004). Outra melhoria do PSO original foi a inclusão do conceito de vizinhança. As partículas são divididas em grupos chamados de vizinhança, onde cada vizinhança mantém sua melhor solução, chamada lbest. Por exemplo, se a vizinhança adotada for igual a 2, a partícula $i$ atualiza sua velocidade considerando apenas os valores de pbest das partículas $i-1 \mathrm{e} i+1$. Dessa maneira, ao invés da partícula levar em consideração a melhor solução de todo swarm, utiliza apenas a melhor solução de sua vizinhança. Essa técnica evita que as partículas fiquem "presas" a um mínimo local, mas possui uma convergência mais lenta (Eberhart \& Kennedy, 1995).

\section{Modelo gbest x Modelo lbest}

Essa seção tem a finalidade de observar a performance das duas versões do PSO, gbest e lbest, na otimização da busca pelo mínimo global de funções.

Como primeiro exemplo, seja a função

$$
f(x)=\sin (x)
$$

que possui um mínimo global $f_{\min }(x)=-1$, com $x=3 \pi / 2$. As partículas convergem com facilidade para esse ponto quando é utilizado o modelo gbest, já que essa função não possui mínimos locais. Agora, quando o modelo gbest é usado para minimizar a função de Rastrigin (The MathWorks, 2006)

$$
f\left(x_{1}, x_{2}\right)=20+x_{1}^{2}+x_{2}^{2}-10\left(\cos 2 \pi x_{1}+\cos 2 \pi x_{2}\right)
$$

que possui diversos mínimos locais e apenas um mínimo global, esse mesmo modelo falha em alguns momentos na busca pelo mínimo global. Na função de Rastrigin o mínimo global está localizado no ponto $(0,0)$. Na maioria das vezes as partículas se prendem aos mínimos locais, sem conseguir explorar toda a função e encontrar o mínimo global.

Quado o modelo lbest é aplicado na resolução da função de Rastrigin, as partículas convergem para o mínimo global e não para o mínimo local. Na Figura 4.3 pode-se observar que para essa função todas as partículas tendem a convergir para o mínimo global com o passar do tempo. Entretanto, como a posição inicial das partículas é escolhida aleatoriamente, pode acontecer que em algumas execuções o modelo gbest tenha melhor desempenho do que o modelo lbest. 


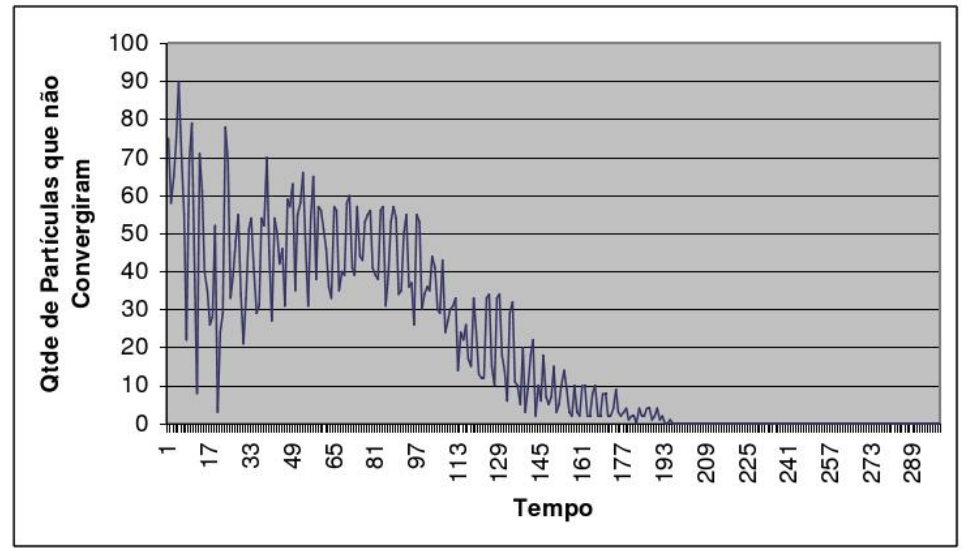

Figura 4.3: Convergência das partículas para o mínimo global da função de Raistrigin

\subsubsection{PSO com velocidade adaptativa}

A definição clássica de PSO descrita na seção anterior, chamada modelo gbest, utiliza informações obtidas por todo swarm para atualizar a velocidade das partículas. Enquanto isso o modelo lbest estabelece a noção de vizinhança, atualizando a velocidade da partícula $i$ a partir das melhores soluções das partículas $i-1$ e $i+1$ (considerando uma vizinhança de tamanho 2). O conceito de vizinhança está presente em swarms naturais, onde a atualização da localização e velocidade é feita de acordo com o comportamento de seus vizinhos. Quando uma partícula está rodeada por vizinhos movimentando-se em diferentes direções, é natural que essa partícula movimente-se aleatoriamente e com baixa velocidade. Por outro lado, quando existe uma direção dominante entre seus vizinhos, a partícula pode seguir tal direção com maior velocidade.

O trabalho de (Li \& Wang, 2007) propõe um modelo de PSO com velocidade adaptativa, onde cada partícula ajusta sua direção e velocidade de acordo com o comportamento de seus vizinhos. A posição do agente é atualizada de acordo com o modelo de Vicsek (Vicsek et al., 1995) e a velocidade é ajustada de acordo com um parâmetro de ordem local usado para medir o consenso de direção entre os vizinhos do agente, conforme descrito a seguir.

\section{Modelo com velocidade constante de Vicsek}

O modelo de Vicsek busca o alinhamento de direções em sistemas formados por partículas, e baseia-se em uma única regra: a cada iteração, uma partícula com velocidade absoluta constante assume a média de direção de movimento das partículas na sua vizinhança de raio $r$, mais a adição de alguma pertubação aleatória.

Considere uma swarm formada por $n$ partículas movimentando-se de maneira sincronizada no espaço complexo. Cada partícula $i$ movimenta-se com a mesma velocidade $v_{0}$ mas com diferentes direções. As posições iniciais das partículas são escolhidas aleatoriamente. A direção inicial de cada partícula é escolhida aleatoriamente no intervalo $[0,2 \pi)$. A cada iteração $t$, a partícula $i$ atualiza sua direção de acordo com a Equação 4.9. $\left[\theta_{i}(t)\right]_{r}$ é a média de direção de movimento 
dos vizinhos da partícula $i$. Os vizinhos da partícula $i$ são as partículas que encontram-se dentro de um círculo de raio $r$ com centro na posição atual de $i$. A direção da partícula $i, \theta_{i}(t)$, também é levada em consideração no cálculo de $\theta_{i}(t+1)$. $\Delta \theta$ é uma pertubação aleatória escolhida com probabilidade uniforme no intervalo $[-\eta / 2, \eta / 2]$ e $\eta$ é um parâmetro livre (definido pelo usuário).

$$
\theta_{i}(t+1)=\left\langle\theta_{i}(t)\right\rangle_{r}+\Delta \theta
$$

O sistema apresenta dois estados distintos: na ausência de pertubação, todas as partículas alinham-se rapidamente na mesma direção; com pertubação máxima, as partículas movimentamse aleatoriamente. A transição entre esses dois estados pode ser caracterizada pelo parâmetro de ordem definido na Equação 4.10.

$$
\Phi_{\theta}(t)=\frac{1}{n}\left|\sum_{j=1}^{n} e^{i \theta_{j}(t)}\right|, 0 \leq \Phi_{\theta}(t) \leq 1
$$

Através do parâmetro de ordem possível identificar o momento em que a movimentação das particulas do sistema deixa de ser aleatória passando a ser ordenada.

\section{Modelo com velocidade adaptativa}

No modelo com velocidade adaptativa proposto por (Li \& Wang, 2007), cada partícula ajusta sua direção e velocidade de acordo com o comportamento de seus vizinhos. Para isso um parâmetro de ordem local do agente $i$, no espaço complexo, é definido pela Equação 4.11.

$$
\phi_{i}(t+1) e^{i \theta_{i}(t+1)}=\frac{1}{n_{i}(t+1)} \sum_{j \in \Gamma_{i}(t+1)}^{n} e^{i \theta_{j}(t)}, i=1,2, \ldots, n \text { e } t=1,2, \ldots
$$

onde $e^{i \theta_{j}(t)}$ é o vetor unitário direcional e $\Gamma_{i}(t+1)$ é o conjunto de $n_{i}(t+1)$ vizinhos da partícula $i$ no instante $(t+1)$. O parâmetro de ordem local $\phi_{i}(t+1)$ mede o consenso local de direção entre os vizinhos de $i$ no instante $(t+1):$ quando $\phi_{i} \approx 0$ as partículas movimentam-se desordenamente, sem uma direção dominante; quando $\phi_{i} \neq 0$ as partículas possuem direção relativamente dominante e $\phi_{i}=1$ apenas quando todos as partículas de $\Gamma_{i}$ movem-se na mesma direção. Assim, maiores valores para $\phi_{i}$ indicam maior concordância de direção entre os vizinhos. A direção de movimento da partícula $i$ é dada pelo ângulo $\theta_{i}(t+1) \in[0,2 \pi)$, resultante da média da direção de movimento das partículas que formam o conjunto $\Gamma_{i}(t+1)$.

A posição da partícula $i$ no instante $t$ é definida no plano complexo por $\overrightarrow{x_{i}}(t)$. Duas partículas $i$ e $j$ são consideradas vizinhas no instante $t$ se $\left\|\overrightarrow{x_{i}}(t)-\overrightarrow{x_{j}}(t)\right\| \leq r$. A cada instante $t$, toda partícula atualiza sua direção de movimento, velocidade e posição, conforme as Equações 4.9, 4.11 e 4.12, respectivamente.

$$
\overrightarrow{x_{i}}(t+1)=\overrightarrow{x_{i}}(t)+v_{0} \times \phi_{i}^{\alpha} e^{i \theta_{j}(t)}
$$


Na Equação $4.12 \overrightarrow{v_{i}}(t) \equiv v_{0} \times \phi_{i}^{\alpha} e^{i \theta_{j}(t)}$ representa a movimentação da partícula $i$ no instante $t$ com velocidade $\left|\overrightarrow{v_{i}}(t)\right|=v_{0} \times \phi_{i}^{\alpha}$ e direção $e^{i \theta_{j}(t)}$.

$\mathrm{O}$ parâmetro $\alpha \geq 0$ indica grau de consenso entre as direções dos vizinhos de $i$ que deve ser atingido para que a partícula movimente-se com maior ou menor velocidade. A influência da escolha de $\alpha$ na velocidade das partículas é ilustrada na Figura 4.4. Se $\alpha=0$, então $\phi_{i}^{\alpha} \equiv$ 1 e o modelo adaptativo reduz-se ao modelo de Vicsek com velocidade constante. Se $\alpha>0$, será necessário que todos os seus vizinhos tenham atingido um consenso em relação a direção de movimento para que a partícula mova-se com velocidade máxima. Quanto maior o valor de $\alpha$, maior deve ser o consenso entre a direção de movimento dos vizinhos para que a partícula mova-se com maior velocidade.

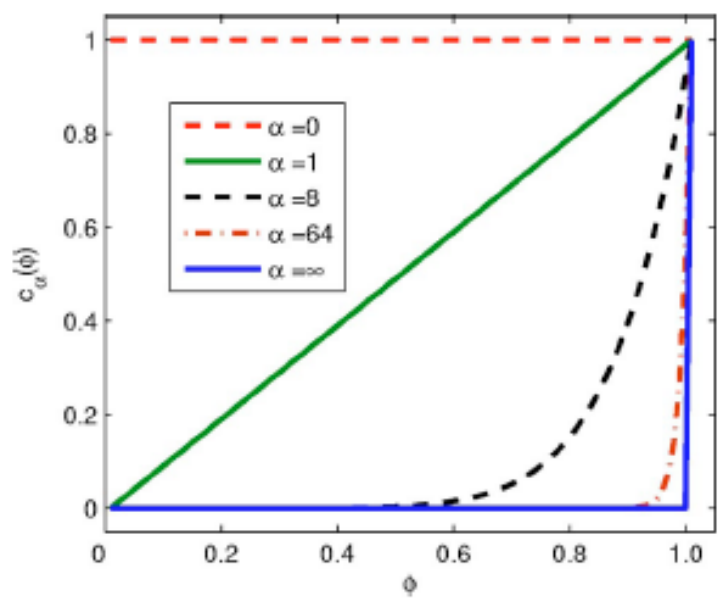

Figura 4.4: Influência de $\alpha$ na definição do coeficiente de velocidade $c_{\alpha}(\phi)$. Para qualquer valor de $\alpha, c_{\alpha}(\phi)=1$ se $\phi=1$. Para $\alpha=0, c_{\alpha}(\phi) \equiv 1$. Para $0<\alpha<\infty, 0<c_{\alpha}(\phi)<1$ se $0<\phi<1$. Para $\alpha=\infty, c_{\alpha}(\phi)=0$ se $0<\phi<1$.

Inicialmente, $\theta_{i}$ e $\overrightarrow{x_{i}}(0)$ já encontram-se disponíveis para a partícula $i$. Para cada partícula $i$, são calculados a direção de movimento $\theta_{i}(0)$ (através da média de direção de movimento dos vizinhos de $i$ ) e $\phi_{i}(0)$ (de acordo com o parâmetro de ordem local descrito na Equação 4.11). Isso significa que desde o início, com $t=0$, a partícula movimenta-se com velocidade adaptativa.

Segundo (Li \& Wang, 2007), para valores suficientemente grandes de $\alpha$ a probabilidade de convergência do sistema é alta. Particularmente, a possibilidade de convergência é perto de 1 quando $\alpha=\infty$ mesmo sem a presença de uma partícula líder ou qualquer outra informação global.

\subsection{Aprendizado por Reforço}

A interação com o ambiente é uma das principais e mais naturais formas de aprendizado usada pelo ser humano. Nesse tipo de aprendizado não há professores, e sim o ambiente que responde 
à execução de uma ação e sofre consequências relacionadas a essas ações a fim de atingir algum objetivo. Como exemplo, considere a construção de um robô, ou agente, que tem como objetivo recarregar sua bateria sempre que estiver baixa. Para isso, o robô precisa aprender quais ações tomar interagindo com o ambiente para atingir o objetivo. O robô é capaz de observar o estado em que o ambiente está e escolher como alterar esse estado a partir de um conjunto de ações. As possíveis ações podem ser "andar em frente" ou "virar". Sua tarefa é aprender uma estratégia de controle, ou política, para escolher as ações que o levem a atingir seu objetivo. Para que o agente possa distinguir entre as ações é necessário a definição de uma função de recompensa que atribui um valor numérico à ação escolhida. Por exemplo, ações que levam o robô diretamente a recarregar a bateria quando estiver baixa, seu objetivo, podem levar a recompensas altas; para as demais ações podem ser atribuídas recompensas de valor zero, por exemplo. Assim, a tarefa do robô é executar várias ações, analisar as consequências e definir uma política. A política desejada é aquela que, independente do estado inicial, escolhe ações que maximizam a recompensa acumulada pelo agente (Mitchell, 1997).

Inúmeros problemas reais podem ser abordados como o exemplo acima, onde o objetivo é maximizar a recompensa ou minimizar os custos acumulados (Mitchell, 1997). Por exemplo, problemas de otimização de uma fábrica, onde uma sequência de ações de produção deve ser escolhida, com o objetivo de maximizar o valor das mercadorias menos os custos envolvidos em sua produção. Assim, os problemas tratados pelo aprendizado por reforço são aqueles onde o agente deve aprender a escolher ações que alterem o estado do ambiente e uma função de recompensa acumulativa é usada para definir a qualidade de uma sequência de ações. Nesse contexto, os problemas podem ter algumas limitações, como permitir que ações tenham saídas determinísticas ou não-determinísticas, ou onde não existe conhecimento sobre o efeito das ações no ambiente.

A interação do sistema de aprendizagem, ou agente, com o ambiente pode ser modelada como um processo de decisão Markoviano ou MDP (Markovian Decision Process) (Sutton \& Barto, 1998), como mostra a Figura 4.5. Essa interação do agente com o ambiente é composta por um conjunto de estados, um conjunto de ações relacionadas a cada estado e atribuição de custos pela ação tomada. Em outras palavras, estados são observados, ações são tomadas e custos são atribuídos em unidades de tempo discretas (Haykin, 1999). A seguir cada um dos componentes que compõem o processo de aprendizagem são descritos em detalhes:

- o agente: deve aprender através da experiência adquirida a tomar decisões a partir da interação com o ambiente.

- um conjunto finito de estados $X$ que descreve o ambiente: o ambiente muda de estado à medida em que há interação entre o agente e o ambiente, sendo $X_{n}$ o estado ocupado pelo ambiente no tempo discreto $n$.

- um conjunto finito de possíveis ações $A_{i}$ : as ações podem ser tomadas pelo agente para cada estado $i$, denotado por $A_{i}=\left\{a_{i k}\right\}$, onde $k$ indica a possibilidade de escolha de mais de uma 
ação a ser executada pelo agente no estado $i$. Após a execução de uma ação pelo agente, o estado ocupado pelo ambiente é modificado. O transição do estado $i$ para um novo estado $j$ pode ser probabilística ou não.

- uma função de custo (ou função de reforço) $g\left(i, a_{i k}, j\right.$ ): para cada transição feita pelo ambiente do estado $i$ a um novo estado $j$, devido à ação $a_{i k}$, um custo imediato é atribuído. Nesse momento acontece o reforço: se a ação tomada pelo agente é boa, o custo é baixo (o agente recebe uma recompensa); se não é uma boa ação, o custo atribuído é alto (o agente sofre uma penalidade).

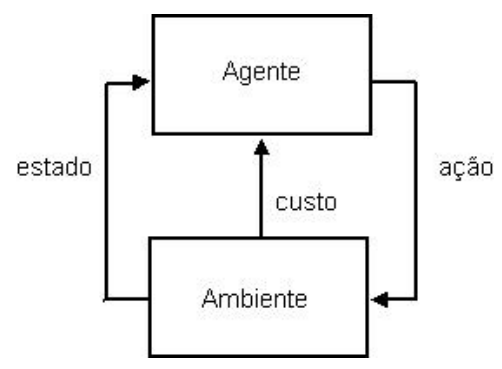

Figura 4.5: Diagrama da interação entre o sistema de aprendizado e seu ambiente.

A tarefa do agente é encontrar um mapeamento de estados em ações que minimizem ou maximizem o valor de uma função objetivo. Nesse trabalho será considerado que o agente deve minimizar uma função de custo, que pode ser facilmente estendido para casos em que o objetivo é a maximização da recompensa.

Esse mapeamento de estados em ações é chamado política e denotada por $\pi$. A política $\pi$ é uma função $\pi: X \rightarrow A$, que mapeia um estado $X_{n}=i$ em uma ação $A_{n}=a$ no tempo $n=0,1,2, \ldots$ Esse mapeamento é tal que $\pi(i) \in A_{i}$ para todos estados $i \in X$, onde $A_{i}$ corresponde ao conjunto das possíveis ações que o agente pode tomar no estado $i$.

O objetivo do agente é aprender a função $\pi$ que minimiza a função de custo, ou seja, $\pi(i)=a$ tal que $a$ seja a ação ótima a ser tomada no estado $i$. Em outros métodos de aprendizado de funções, através de redes neurais por exemplo, estão disponíveis exemplos de treinamento na forma $\{i, \pi(i)\}$. No aprendizado por reforço o que está disponível ao agente é o valor do custo (ou recompensa) imediato da ação executada, o que implica que as ações não podem ser escolhidas isoladamente: a escolha de uma ação de baixo custo pode levar a ações de alto custo no futuro, o que não é desejado. Esse é o problema de atribuição de crédito (Haykin, 1999), onde é necessário balancear o custo das ações imediatas em relação ao custo de ações futuras.

Um dos principais desafios enfrentados no aprendizado por reforço é a necessidade de balancear exploração do ambiente e conhecimento adquirido ${ }^{1}$. A cada passo o agente deve fazer uma escolha: escolher uma ação já conhecida com maior recompensa ou escolher uma ação desconhecida e explorar o ambiente, descobrindo talvez uma ação mais vantajosa.

\footnotetext{
${ }^{1}$ em inglês, exploration $\mathrm{x}$ exploitation
} 


\subsubsection{O Aprendizado}

A questão principal do aprendizado por reforço é como medir quão bom é para o agente estar no estado $i$ em função do custo. Isso pode ser medido pela estimativa de uma função valor. Como o custo total depende das ações tomadas pelo agente, a função valor é definida em relação a uma política $\pi$ específica. Para isso, vamos considerar inicialmente que cada par estado-ação leva a apenas um estado. Essa definição será estendida posteriormente.

O agente busca aprender uma política selecionando a próxima ação $a$ para o estado atual $i$ tal que $a=\pi(i)$. Uma maneira intuitiva de aprendizado é escolher uma política $\pi$ que produz o menor custo acumulado a partir de um estado inicial $X_{0}=i$ arbitrário (Mitchell, 1997), como mostra a Equação 4.13:

$$
\begin{aligned}
V^{\pi}(i) & =g\left(X_{0}, \pi\left(X_{0}\right), X_{1}\right)+\gamma g\left(X_{1}, \pi\left(X_{1}\right), X_{2}\right)+\gamma^{2} g\left(X_{2}, \pi\left(X_{2}\right), X_{3}\right)+\ldots \\
& =\sum_{n=0}^{\infty} \gamma^{n} g\left(X_{n}, \pi\left(X_{n}\right), X_{n+1}\right) \mid X_{0}=i
\end{aligned}
$$

A função $V^{\pi}(i)$ é chamada função valor para a política $\pi$ a partir do estado $i$, ou seja, uma soma dos custos atribuídos a cada ação tomada a partir do estado $i$ seguindo a política $\pi$. De maneira intuitiva, a função valor $V(i)$ estima o quanto é "lucrativo" estar no estado $i$ (Sutton \& Barto, 1998). Por lucrativo, entende-se o ganho esperado no futuro a partir do estado $i$. A diferença entre a função de custo e a função valor é que a primeira determina o custo imediato da ação, enquanto a segunda diz qual o custo esperado caso determinada ação seja tomada no estado atual.

O parâmetro $\gamma$ usado na Equação 4.13 é chamado fator de desconto, onde $0 \leq \gamma<1$. Caso $\gamma=$ 0 apenas custos imediatos são considerados; a medida que $\gamma$ aproxima-se de 1, os custos futuros são mais relevantes em relação aos custos imediatos. Assim, através do valor de $\gamma$ é possível balancear as consequências das decisões a longo-prazo em relação as decisões a curto-prazo. É razoável que $V^{\pi}$ considere custos futuros menos relevantes, descontando exponencialmente seu valor $\gamma^{n}$, já que em muitos casos é preferivel diminuir os custos no presente do que no futuro (Mitchell, 1997).

É possível redefinir $V^{\pi}(i)$, através da relação entre o valor do estado $i$ e seus estados posteriores (Haykin, 1999), como mostra a Equação 4.14.

$$
V^{\pi}(i)=g\left(i, \pi(i), X_{1}\right)+\gamma V^{\pi}\left(X_{1}\right)
$$

Como o objetivo do agente é aprender uma política que minimize o custo total dado por $V^{\pi}$, seu valor ótimo, denotado por $V^{*}(i)$, pode ser definido de acordo com a Equação 4.15:

$$
V^{*}(i)=\min _{\pi} V^{\pi}(i)
$$

Em outras palavras, a política ótima $\pi^{*}$ pode ser escrita como: $\pi^{*}=\operatorname{argmin}_{\pi} V^{\pi}(i), \forall i \in X$ 


\section{Função de transição de estados: não-determinismo}

Em alguns problemas de decisão markoviano é possível que uma mesma ação leve a mais de um estado, oferecendo consequentemente custos diferentes. Em um problema onde o agente deve aprender a jogar gamão por exemplo, cada ação é naturalmente probabilística, já que depende do resultado de um lance de dados (Mitchell, 1997).

Seja $p_{i j}(a)$ o termo que indica a probabilidade de estando no estado $i$ ir ao estado $j$ devido à ação $a$, ou seja, $p_{i j}(a)=P\left(X_{n+1}=j \mid X_{n}=i, A_{n}=a\right)$. Além disso, a probabilidade de transição $p_{i j}(a)$ deve obedecer duas restrições:

(1) $p_{i j}(a) \geq 0$, para todo $i$ e $j$;

(2) $\sum_{j} p_{i j}(a)=1$, para todo $i$.

Uma maneira de considerar o não-determinismo na função valor descrita pela Equação 4.14 é utilizar o valor esperado do custo total acumulado quando a política $\pi$ é seguida, como mostra a Equação 4.16

$$
V^{\pi}(i)=E\left[g\left(i, \pi(i), X_{1}\right)+\gamma V^{\pi}\left(X_{1}\right)\right]
$$

Agora, para calcular o valor esperado de $V^{\pi}(i)$ é necessário calcular $E\left[g\left(i, \pi(i), X_{1}\right)\right]$ e $E\left[V^{\pi}\left(X_{1}\right)\right]$ :

1. $E\left[g\left(i, \pi(i), X_{1}\right)\right]$ : é o custo imediato esperado de $g\left(i, \pi(i), X_{1}\right)$ em relação a um estado $X_{1}$ seguindo a ação determinada pela política $\pi$. Assim:

$$
E\left[g\left(i, \pi(i), X_{1}\right)\right]=\sum_{j=1}^{N} p_{i j}(\pi(i)) * g(i, \pi(i), j)
$$

onde $N$ é o número de estados do ambiente e $p_{i j}$ é a probabilidade de transição do estado inicial $i$ para o novo estado $j$. Para simplificar, o custo imediato esperado será denotado por $c(i, \pi(i))$ :

$$
c(i, \pi(i))=\sum_{j=1}^{N} p_{i j}(\pi(i)) * g(i, \pi(i), j)
$$

2. $E\left[V^{\pi}\left(X_{1}\right)\right]$ : todos os possíveis estados que a ação sugerida pela política $\pi$ pode levar devem ser considerados no cálculo dos custos futuros:

$$
E\left[V^{\pi}\left(X_{1}\right)\right]=\sum_{j=1}^{N} p_{i j}(\pi(i)) V^{\pi}(j)
$$

Assim, a função valor considerando o não-determinismo na transição de estados é descrita pela Equação 4.18. 


$$
V^{\pi}(i)=c(i, \pi(i))+\gamma \sum_{j=1}^{N} p_{i j}(\pi(i)) * V^{\pi}(j), i=1,2, \ldots, N
$$

A definição da função valor ótima não sofre alterações, e continua a ser definida pela Equação 4.15.

\section{Q-valor}

Para que o agente possa aprender quais ações tomar é necessário que consiga diferenciar, ou classificar, as diferentes ações possíveis para cada estado. Suponha que o agente encontra-se no estado $i$ e deve escolher uma ação. O impacto da escolha da ação atual pode ser quantificado através de uma adaptação da função valor, como mostra a Equação 4.19:

$$
Q^{\pi}(i, a)=c(i, a)+\gamma \sum_{j=1}^{N} p_{i j}(a) * V^{\pi}(j)
$$

O Q-valor para um estado $i \in X$ e ação $a \in A_{i}$ é definido como o custo imediato atribuído à ação $a$ mais o custo dos estados sucessores seguindo a política $\pi$ (Haykin, 1999). A diferença entre a função valor e o Q-valor é que a primeira tem como argumento um estado $i$ e mostra o custo total seguindo a política $\pi$ desde o primeiro instante, enquanto o segundo tem como argumento uma ação $a \in A_{i}$ que não necessariamente é a mesma definida pela política. Assim todas as ações possíveis para o estado $i$ podem ser classificadas de acordo com o custo total que sua escolha acarreta.

A Figura 4.6 ilustra o funcionamento do Q-valor. Dados um estado $i$ e uma ação $a \in A_{i}$ :

- O sistema está no estado $i$ e uma ação $a \in A_{i}$ é tomada. O próximo estado é $(i, a)$ deterministicamente.

- O sistema está no estado $(i, a)$, o que significa que no estado $i$ a decisão $a$ foi tomada e realizada uma transição com probabilidade $p_{i} j(a)$ ao estado $j$ com custo $g(i, a, j)$ (Haykin, 1999).

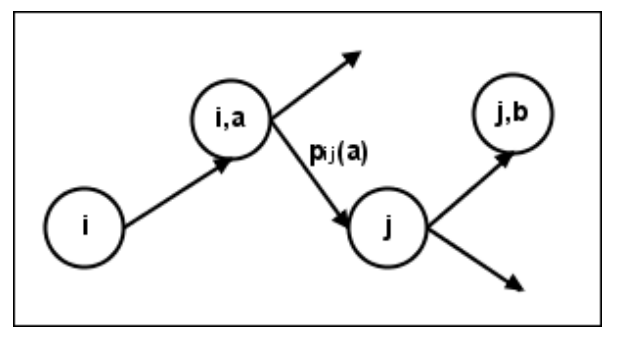

Figura 4.6: Interpretação do Q-valor (Haykin, 1999) 
Então a ação que minimiza o custo da função valor e deve ser escolhida pela política $\pi(i)$ é dada pela Equação 4.20.

$$
Q^{\pi}(i, \pi(i))=\underset{a \in A_{i}}{\operatorname{argmin}} Q^{\pi}(i, a)
$$

O Q-valor ótimo $Q^{\pi^{*}}\left(i, \pi^{*}(i)\right)$ é então obtido substituindo, na Equação 4.20, a política arbitrária $\pi$ pela política ótima $\pi^{*}$.

\subsubsection{Q-learning}

Q-learning é um procedimento incremental que determina a política ótima de uma maneira passo a passo. Esse método foi apresentado inicialmente por (Watkins, 1989) e é usado para resolver problemas de decisão Markovianos, onde não há conhecimento das probabilidades de transição. Com o aprendizado dos Q-valores o agente é capaz de aprender também a política ótima. O aprendizado da política ótima dá-se através da experiência obtida com base em exemplos da forma:

$$
s_{n}=\left(i_{n}, a_{n}, j_{n}, g_{n}\right)
$$

onde $n$ denota o tempo discreto, e cada exemplo $s_{n}$ consiste em: uma ação $a_{n}$ tomada no estado $i_{n}$ que resulta em uma transição para o estado $j_{n}=i_{n+1}$ com um custo $g_{n}=g\left(i_{n}, a_{n}, j_{n}\right)$.

A base do algoritmo de (Watkins, 1989) está na estreita ligação entre o Q-valor e a função valor $V^{*}$ :

$$
V^{*}(j)=\min _{b \in A_{j}} Q(j, b)
$$

Através dessa relação, é possível reescrever a Equação 4.19:

$$
Q(i, a)=c(i, a)+\gamma \sum_{j=1}^{N}\left(p_{i j}(a) * \min _{b \in A_{j}} Q(j, b)\right)
$$

Pela definição de $c(i, a)$ dada pela Equação 4.17 é possível formular a Equação 4.22:

$$
Q(i, a)=\sum_{i=1}^{N} p_{i j}(a)\left(g(i, a, j)+\gamma \min _{b \in A_{j}} Q(j, b)\right)
$$

Apesar da Equação 4.22 fornecer uma forma de atualização dos Q-valores, ainda leva em consideração a probabilidade de transição $p_{i j}$. Essa dependência pode ser eliminada considerando um único exemplo da forma $s_{n}=\left(i_{n}, a_{n}, j_{n}, g_{n}\right)$ como descrito em 4.21, e não todas as possibilidades de transição (Haykin, 1999). Assim os Q-valores são obtidos através da interação do agente com o ambiente, como mostra a Equação 4.23 . 


$$
Q\left(i_{n}, a_{n}\right)=g\left(i_{n}, a_{n}, j_{n}\right)+\gamma \min _{b \in A_{j_{n}}} Q\left(j_{n}, b\right)
$$

Até o momento já é possível obter o Q-valor sem o conhecimento das probabilidades de transição. Agora é necessário definir uma regra de aprendizado para os Q-valores. Para isso, o agente possui uma tabela relacionando todos os pares estado-ação $(i, a)$. Cada item dessa tabela, $Q_{n}(i, a)$, representa a estimativa do Q-valor feita pelo agente até a iteração $n$. Se o ambiente fosse determinístico, ou seja, se a partir do estado $i$ toda execução da ação $a$ levasse ao mesmo estado $j$, a Equação 4.23 poderia ser utilizada como regra de aprendizado dos Q-valores. Agora, em um ambiente não-determinístico, essa regra de aprendizado poderia não convergir. Considere a atualização do Q-valor $Q_{n}(i, a)$. Sendo $i$ o estado atual, uma ação $a$ pode levar a estados diferentes, e o custo associado a cada transição também seria diferente. Dessa maneira, mesmo que os Q-valores da tabela $Q_{n}(i, a)$ fossem ótimos inicialmente, seriam modificados repetidamente pela Equação 4.23 e consequentemente não haveria convergência. Essa dificuldade pode ser superada adicionando-se uma taxa de aprendizagem que diminua gradualmente o impacto de novos exemplos na atualização dos Q-valores. A atualização do Q-valor a partir da nova regra de aprendizado é dada pela Equação 4.24

$Q_{n+1}(i, a)=\left(1-\eta_{n}(i, a)\right) Q_{n}(i, a)+\eta_{n}(i, a)\left[g(i, a, j)+\gamma * \min _{b \in A_{j}} Q_{n}(j, b)\right] \operatorname{para}(i, a)=\left(i_{n}, a_{n}\right)$

onde $j$ é o estado sucessor, resultante da tomada da ação $a_{n}$ no estado $i_{n}$, e $\eta_{n}\left(i_{n}, a_{n}\right)$ é a taxa de aprendizado no tempo $n$ para o par estado-ação $(i, a)$.

$\mathrm{O}$ valor da taxa de aprendizado $\eta_{n}\left(i_{n}, a_{n}\right)$ controla o peso que será dado para a experiência recém adquirida em relação ao Q-valor já existente. Ela é diferente para cada exemplo $\left(i_{n}, a_{n}\right)$ para assegurar que a taxa de aprendizado seja alta quando tratar-se de um par estado-ação que foi visitado poucas vezes e baixa caso contrário.

Um valor de $\eta_{n}(i, a)$ que garante a convergência para valores ótimos de $Q^{*}(i, a)$ (Haykin, 1999) é dada por:

$$
\eta_{n}=\frac{\alpha}{\beta+n}
$$

onde $\alpha$ e $\beta$ são inteiros positivos. Essa definição de taxa de aprendizado garante que as mudanças de $Q(i, a)$ sejam feitas gradualmente.

No $Q$-learning, a cada iteração o agente repetidamente observa seu estado atual $i_{n}$, escolhe uma ação $a_{n}$, executa essa ação e observa o novo estado $j_{n}$ e o custo $g_{n}$ atribuído a ação. A Equação 4.24 atualiza o valor da tabela apenas para o par estado-ação atual $\left(i_{n}, a_{n}\right)$. Os Q-valores dos demais pares estado-ação não são modificados.

Após o cálculo dos Q-valores ótimos, é possível obter de forma direta a política ótima, escolhendo a ação $a$ que minimize o Q-valor para o estado $i$. 


\subsubsection{Programação Neurodinâmica}

A definição de uma política ótima para problemas de decisão Markovianos pode ser modelada matematicamente através da programação dinâmica. O objetivo é escolher a melhor ação a ser tomada pelo sistema para cada possível estado do ambiente. A programação dinâmica baseia-se no princípio de "divisão e conquista", que diz que uma política ótima pode ser obtida construindo uma política ótima para um sub-problema e estendê-la até que o problema tenha sido resolvido por completo (Haykin, 1999).

Entretanto o uso de programação dinâmica para resolução de problemas muito grandes é limitado devido à maldição da dimensionalidade (Bellman, 1957), pois a medida que cresce o número de estados e o número de ações possíveis, crescem também os requisitos computacionais da programação dinâmica. Apesar disso, os métodos de programação dinâmica são eficientes na resolução de problemas de decisão Markovianos se comparados com outros métodos, como programação linear por exemplo (Sutton \& Barto, 1998).

Apesar do grande número de estados serem características intrínsecas de problemas complexos, outro fator deve ser levado em consideração na escolha de um método para encontrar uma política ótima: insuficiência de informações a respeito do ambiente. Os algoritmos de programação dinâmica usados na determinação de uma política ótima têm como requisitos o conhecimento prévio do ambiente, ou seja, conhecimento das probabilidades de transição $p_{i j}$ e dos custos $g(i, a, j)$ (Sutton $\&$ Barto, 1998).

Em problemas dessa natureza, com grande número de estados e/ou insuficiência de informações, a aplicação de métodos de programação dinâmica torna-se inviável ou impossível. Por isso pode ser necessário optar por uma política sub-ótima, o que pode ser feito pela Programação Neurodinâmica. Nesse contexto, o interesse recai sobre procedimentos que utilizem redes neurais e/ou simulação para aproximar a função valor $V^{*}(i)$ para todo $i \in X$.

A função valor $V^{*}(i)$ ótima é substituída por uma aproximação $V(i, w)$, onde $w$ é o vetor de pesos de uma rede neural. Logo, a função $V(i, w)$ é a saída da rede neural em resposta ao estado $i$ oferecido como entrada, como mostra a Figura 4.7.

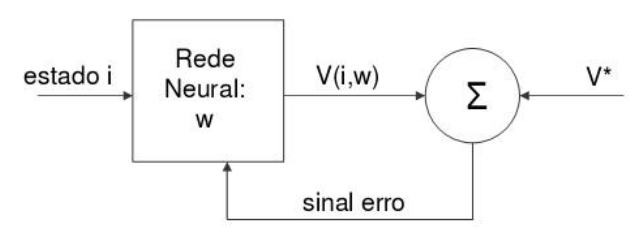

Figura 4.7: Utilização de rede neural para aproximação da função valor $V^{*}$ (Haykin, 1999)

O objetivo é então solucionar problemas de programação dinâmica com grande número de estados em que a função valor $V(i, w)$ pode ser descrita por um vetor de pesos de pequena dimensão (Haykin, 1999). Na abordagem tradicional do problema, os valores da função valor de todos os estados são armazenados em uma tabela, chamada lookup table. Já na representação compacta 
(utilizando a rede neural) apenas o vetor de pesos $w$ e a estrutura da rede são armazenados. Além disso, o cálculo de $V(i, w)$ é gerado somente quando necessário. Naturalmente, é desejado que a escolha de $w$ seja feita de modo que $V(., w)$ possa aproximar de maneira razoável $V^{*}($.

A aplicação de redes neurais é feita geralmente em problemas onde a rede neural é usada como um aproximador universal: o mapeamento entrada-saída da rede neural é combinado a uma função não-linear com a intenção de minimizar algum erro (Haykin, 1999). Entretanto não há dados de treinamento, ou seja pares $\left\{\left(i, V^{*}(i)\right)\right\}$ disponíveis. Uma alternativa é a utilização da simulação de Monte Carlo (Bertsekas \& Tsitsiklis, 1996) na geração de exemplos $\left(i_{n}, a_{n}\right)$ que fornecem a experiência necessária com o ambiente. Assim é possível aplicar as técnicas de programação neurodinâmica a problemas em que não há um modelo explícito disponível.

O método de Iteração de Política Aproximada utiliza redes neurais para aproximação da função valor e é similar ao algoritmo de Iteração de Política definido pela programação dinâmica. A Iteração de Política, consiste na melhora de uma política arbitrária através de diversas iterações, alternando entre etapas de avaliação de política (onde são calculados os valores da função valor e dos Q-valores usando a política atual) e atualização de política (onde a política é melhorada, refletindo os novos valores calculados no passo anterior). Esses dois passos são alternados até que não haja mais mudanças na função valor. No método de Iteração de Política Aproximada, o passo de avaliação de política é substituído por uma avaliação aproximada. O cálculo da função valor é feito por uma rede neural (por exemplo, Multilayer Perceptron treinado com o algoritmo backpropagation (Haykin, 1999). Dada a política atual $\pi, V^{\pi}(i, w)$ aproxima a função valor real $V^{\pi}(i)$. O vetor de pesos $w$ da rede neural é determinado através do método dos mínimos quadrados (Haykin, 1999), em que a saída desejada é dada pela simulação de Monte Carlo (Bertsekas \& Tsitsiklis, 1996). É importante ressaltar que para que o algoritmo de iteração de política aproximada tenha resultados satisfatórios, é necessário escolher adequadamente a política inicial, o que pode ser feito através de heurísticas (Haykin, 1999).

Outro método utilizando na programação neurodinâmica é chamado Q-learning Aproximado. O algoritmo é baseado no Q-learning e utiliza redes neurais na definição da regra de aprendizado dos Q-valores. Maiores detalhes podem ser obtidos em (Haykin, 1999).

\subsection{Considerações Finais}

Neste capítulo foram apresentados alguns modelos computacionais inspirados biologicamente. Técnicas bioinspiradas destacam-se por possuírem poucos parâmetros a serem ajustados e poderem ser facilmente aplicadas a diferentes problemas. Foram descritas neste capítulo três técnicas biologicamente inspiradas: Colônia de Formigas, baseado na capacidade de formigas reais em realizarem tarefas complexas coletivamente; Otimização por Nuvem de Partículas, inspirada no comportamento social; e Aprendizado por Reforço, onde o aprendizado dá-se pela interação com o ambiente, que oferece recompensas e penalizações a cada ação executada. 
No Capítulo 5, o algoritmo de clusterização proposto, envolvendo as áreas de redes complexas e computação bioinspirada, será descrito em detalhes. Além disso será apresentado um exemplo simples, ilustrando passo a passo a execução do algoritmo. 


\section{Clusterização de dados e detecção de comunidades}

É comum que conjuntos de dados apresentem grupos de dados de diferentes formas, tamanhos e densidades. Muitos algoritmos de clusterização têm dificuldades em lidar com essas variações (Karypis et al., 1999). Por exemplo, algoritmos baseados em particionamento, como o K-Médias, conseguem identificar apenas clusters de formas esféricas com tamanhos similares. Já algoritmos baseados em grafos, como Single Linkage e Chameleon, são capazes de reconhecer clusters de diferentes formas, tamanhos e densidades. Isso acontece principalmente pela representação dos dados em forma de grafos. Essa modelagem revela a relação topológica entre os dados de entrada e não sua estrutura geométrica.

Embora a representação dos dados em forma de um grafo ofereça a vantagem de detectar clusters de formas e tamanhos arbitrários, algumas restrições são encontradas, já mencionadas na Seção 2.3.5. Abordagens baseadas em grafos geralmente buscam por soluções exatas, tornando restrita suas aplicações em problemas reais, que normalmente envolvem milhares ou até milhões de dados. Para contornar tal restrição, existem heurísticas que oferece soluções próximas à ótima em muitos casos, tal como adotado em técnicas de detecção de comunidades em redes complexas.

Redes complexas oferecem uma maneira eficiente para lidar com grafos formados por muitos de vértices, pois buscam por uma solução próxima à ótima usando abordagens probabilísticas e estatísticas (Newman, 2003). Como já foi discutido no Capítulo 3, muitas redes complexas compartilham uma propriedade interessante: a existência de grupos de nós densamente conectados entre si e pouco conectados com nós de outros grupos. Esses agrupamentos de nós são denotados 
comunidades. Quando a rede modela a similaridade entre os dados, a identificação de comunidades na rede corresponde à identificação de clusters no conjunto de dados.

O algoritmo proposto nesse trabalho é baseado em grafos e na detecção de comunidades em redes complexas. A detecção de comunidades é realizada com base na otimização por nuvem de partículas (PSO) com velocidade adaptativa, de acordo com o modelo descrito na Seção 4.2.2. Nas próximas seções o algoritmo é descrito em detalhes. É apresentada também uma execução passo a passo do algoritmo com uma rede simples como entrada, exemplificando seu funcionamento.

\subsection{Visão geral}

O algoritmo proposto procura aliar as vantagens da representação dos dados em forma de um grafo com a capacidade das redes complexas em lidar com grande volume de dados. $\mathrm{O}$ algoritmo é formado por dois passos:

1. Modelagem dos dados como uma rede. Nessa rede cada nó representa um dado do conjunto de entrada, e a interação entre dois dados é indicada pela presença ou ausência de uma aresta entre eles. Essa rede pode ou não possuir um peso, quantificando a interação entre dois dados. A formação da rede é descrita na Seção 5.2.

2. Com a rede gerada como entrada, o segundo passo é dividí-la hierarquicamente em clusters. Nessa etapa, cada nó possui um ângulo inicial, que é atualizado gradualmente de acordo com os ângulos de seus vizinhos. Assim, cada cluster é identificado com base na concordância entre os ângulos dos nós da rede. A regra de atualização dos ângulos e o algoritmo baseado nessa regra são descritos respectivamente nas Seções 5.3 e 5.4.

\subsection{Formação da rede}

A modelagem do conjunto de dados em um grafo é adotada por inúmeros algoritmos de clusterização (Schaeffer, 2007). Nessa abordagem, o conjunto de dados, formado por $n$ items, é representado por um conjunto de vértices $V=\left\{v_{0}, \ldots, v_{n-1}\right\}$. Cada vértice $v_{i} \in V$ corresponde a um dado no espaço de atributos. A existência da aresta $\left(v_{i}, v_{j}\right)$ é definida de acordo com uma medida de similaridade pré-definida. Nesse trabalho a distância euclidiana foi adotada como medida de similaridade entre dois dados.

Uma maneira comum de modelar um conjunto de dados como rede é técnica de $K$-vizinhos mais próximos $(\mathrm{KNN})$, utilizada pelo algoritmo Chameleon, descrito na Seção 2.3.5. Nessa abordagem, cada vértice é conectado aos seus $K$ vizinhos mais próximos. Assim, $v_{i}$ será conectado ao vértice $v_{j}$ se $v_{j} \in N N_{K}(i)$ ou $v_{i} \in N N_{K}(j)$, onde $N N_{K}(i)$ é o conjunto dos $K$ vizinhos mais próximos de $v_{i}$. 
Dentre as vantagens de gerar uma rede através da técnica KNN estão a esparsidade da rede resultante e o fato de que dois dados pouco similares não se encontram conectados na rede. Entretanto, a rede gerada pode não representar corretamente o conjunto de dados. Se for escolhido um valor muito alto para $K$ dois clusters diferentes podem ser fortemente conectados. Já a escolha de um valor baixo para $K$ pode fazer com que um cluster grande seja erradamente dividido em clusters menores.

Na modelagem proposta, a rede é gerada inicialmente através da técnica KNN. Para minimizar o problema acarretado pela escolha de um valor alto para $K$, as arestas da rede gerada possuem um peso. O peso entre dois nós é dado pela distância eles, como mostra a Equação 5.1.

$$
d_{i j}=\left\|v_{j}-v_{i}\right\|
$$

onde || || é a distância euclidiana entre dois dados.

Assim, a similaridade entre dois dados é preservada através do peso na aresta que os liga. $\mathrm{O}$ problema de que dois clusters sejam fortemente conectados por um alto valor de $K$ é compensado pela regra de atualização dos ângulos de cada nó, dando uma maior importância a vizinhos mais próximos, como será descrito na seção a seguir.

\subsection{Regra de atualização do ângulo}

A regra de atualização de ângulo proposta é baseada na técnica de otimização por nuvem de partículas descrita na Seção 4.2.2. O objetivo principal da regra de atualização é aproximar nós de um mesmo cluster e separar nós de diferentes clusters. Para isso, cada nó $v_{i} \in V$ possui um ângulo inicial $\theta_{i}(t=0)$, escolhido aleatoriamente no intervalo $[0,2 \pi)$. A cada iteração $t, \theta_{i}$ é atualizado de acordo com os ângulos de seus vizinhos. Cada nó pode então ser considerado como uma partícula em um sistema adaptativo: através da interação com os demais elementos, nós de um mesmo cluster tendem a ter ângulos similares. A Figura 5.1 ilustra essa idéia de agrupamento de um nó da rede artificial da Figura 5.2, onde a cor de cada nó indica o cluster ao qual pertence.

A dinâmica de atualização dos ângulos é definida pela Equação 5.2.

$$
\theta_{i}(t+1)=\theta_{i}(t)+\eta_{i}(t)\left[\frac{\sum_{j=1}^{M_{i}} w_{i j} \theta_{j}(t)}{\sum_{j=1}^{M_{i}} w_{i j}}-\theta_{i}(t)\right]
$$

onde $M_{i}$ é o número de vizinhos do nó $v_{i}, \eta_{i}(t)$ é a taxa de atualização do ângulo de $v_{i}$ na iteração $t$ e $w_{i j}$ é o peso dado a cada vizinho $v_{j}$, representando a influência de $v_{j}$ em $v_{i}$.

A definição de $w_{i j}$ tem como objetivo aproximar nós que pertencem ao mesmo cluster. É formado por duas partes: $C N\left(v_{i}, v_{j}\right)$ e $S N\left(v_{i}, v_{j}\right)$, conforme a Equação 5.3.

$$
w_{i j}=C N\left(v_{i}, v_{j}\right) \times S N\left(v_{i}, v_{j}\right)
$$




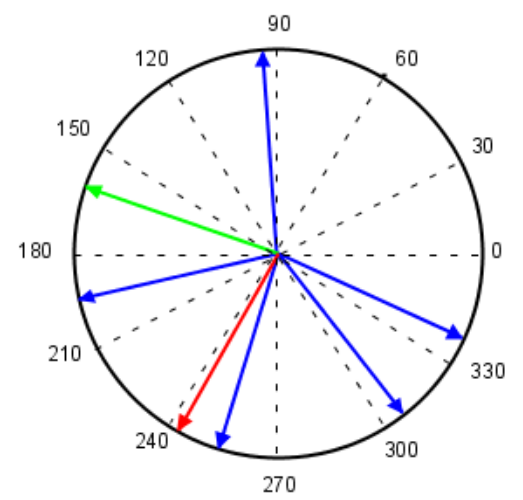

(a)

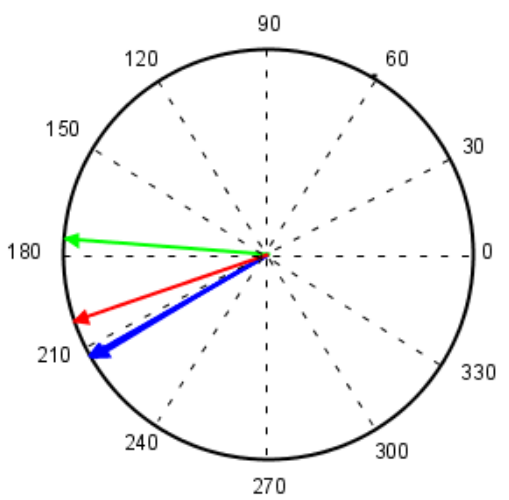

(b)

Figura 5.1: As setas indicam o valor do ângulo de um nó $v_{i}$, da rede artificial da Figura 5.2, e seus vizinhos. As cores indicam o cluster ao qual o nó pertence. (a) Inicialmente os ângulos dos nós movimentam-se aleatoriamente. (b) Após algumas iterações, nós de um mesmo cluster entram em "acordo" e tendem a ter ângulos similares.

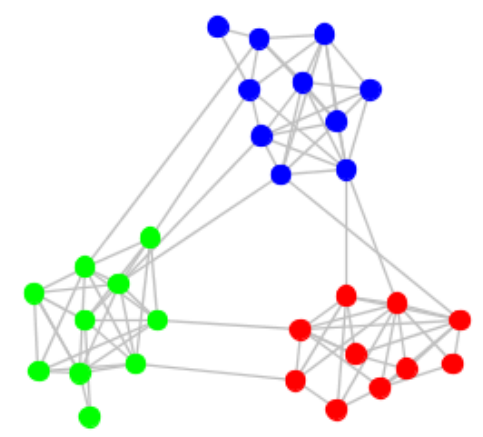

Figura 5.2: Rede artificial original. Nós de diferentes cores pertencem à diferentes clusters.

$C N\left(v_{i}, v_{j}\right)$ pode ser considerado como uma regra de "atração" entre nós de um mesmo cluster, aproximando vizinhos que estejam mais próximos de $v_{i}$. Isso é definido pela Equação 5.4, onde o parâmetro $\alpha$ controla o grau de influência da vizinhança de $v_{i}$. Alterando o valor de $\alpha$, é possível ajustar a importância de $v_{j}$.

$$
C N\left(v_{i}, v_{j}\right)=e^{-\alpha d_{i j}}
$$

A regra de atualização de ângulos pode ser aplicada a redes sem peso. Nesse caso não existe o conceito de distância entre dois nós (a aresta sem peso indica apenas a presença ou não de interação entre os nós) e $C N\left(v_{i}, v_{j}\right)=1$ para todos os pares de vizinhos $\left(v_{i}, v_{j}\right)$.

$S N\left(v_{i}, v_{j}\right)$ é definido pela Equação 5.5 , onde $c\left(v_{i}, v_{j}\right)$ é o número de vizinhos em comum entre os nós $v_{i}$ e $v_{j}$. A idéia é que se dois nós pertencem ao mesmo cluster, eles provavelmente compartilham um alto número de vizinhos. Assim $S N\left(v_{i}, v_{j}\right)$ "acelera" a aproximação desses nós. Por outro lado, se dois nós compartilham poucos vizinhos, $S N\left(v_{i}, v_{j}\right)$ dá pouca importância à aproximação entre $v_{i}$ e $v_{j}$. 


$$
S N\left(v_{i}, v_{j}\right)=\frac{c\left(v_{i}, v_{j}\right)}{M_{i}}
$$

Assim, $C N\left(v_{i}, v_{j}\right)$ busca aproximar ângulos de todos os vizinhos de $v_{i}$ e $S N\left(v_{i}, v_{j}\right)$ dificulta tal aproximação para vizinhos que pertençam a clusters diferentes, já que tais vizinhos possuem provavelmente poucos vértices em comum com $v_{i}$. Entretanto $S N\left(v_{i}, v_{j}\right)$ não anula totalmente a aproximação entre nós de clusters diferentes, apenas a diminui. Essa interferência de nós de outros clusters pode causar que os ângulos de todos os nós se aproximem, impedindo a identificação de clusters. Para evitar esse efeito indesejado, uma taxa de atualização do ângulo $\eta_{i}(t)$ é acrescentada à regra de atualização de ângulo e é definida pela Equação 5.6:

$$
\eta_{i}(t)=e^{\frac{-\beta}{\sigma_{i}}}
$$

onde $\beta$ é um parâmetro definido pelo usuário e $\sigma_{i}$ é o desvio padrão entre os ângulos de $v_{i}$ e seus vizinhos.

A taxa de atualização do ângulo diminui conforme o desvio padrão $\sigma_{i}$ entre os ângulos de $v_{i}$ e seus vizinhos diminui. Como cada ângulo possui um valor inicialmente aleatório, $\sigma_{i}$ possui um valor alto. Assim $\eta_{i}(t) \approx 1$ inicialmente, e os ângulos de cada nó podem aproximar-se livremente formando "bandas" (agrupamentos). Após algumas iterações de atualização dos ângulos, $\sigma_{i}$ tem seu valor reduzido, e consequentemente $\eta_{i}(t)$ também é reduzido. Quando $\eta_{i}(t) \approx 0$, os ângulos não são mais alterados, e o sistema é considerado estável.

Considerando a rede artificial da Figura 5.2, é possível ver a evolução do processo de atualização de ângulos na Figura 5.3. Nesse exemplo é usado $\beta=5$. Nesse caso, três clusters podem ser identificados pelos três agrupamentos presentes na série temporal.

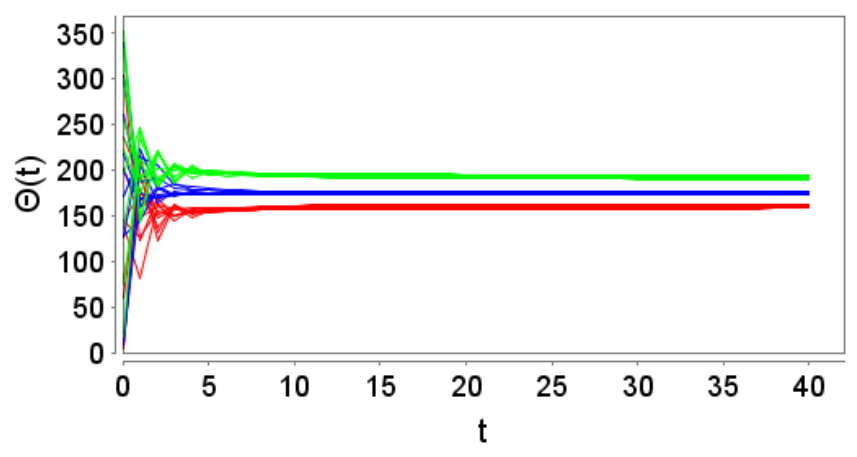

Figura 5.3: Evolução do processo de atualização de ângulos. Nas primeira iterações, os ângulos encontram-se desordenados. Após algumas iterações, os ângulos dos vértices dividem-se em grupos estáveis.

Entretanto, nem sempre todos os clusters são identificados em uma única execução do processo de atualização de ângulos. A Figura 5.4 mostra outra execução do processo de atualização ângulos para a rede artificial da Figura 5.2, considerando $\beta=5$. É possível notar que o agrupamento 
de ângulos dos vértices que pertencem originalmente aos clusters em azul e verde não são mais facilmente identificados. Isso se deve a dois fatores: inicialização aleatória dos ângulos e número de arestas ligando vértices de clusters diferentes. Caso dois clusters sejam densamente conectados, a diferenciação entre os agrupamentos pode tornar-se difícil. Além disso, a inicialização aleatória pode contribuir para que vértices de dois clusters aproximem-se mais rapidamente. Para lidar com essa situação, a rede é particionada gradativamente pelo algoritmo de clusterização, descrito na Seção 5.4 .

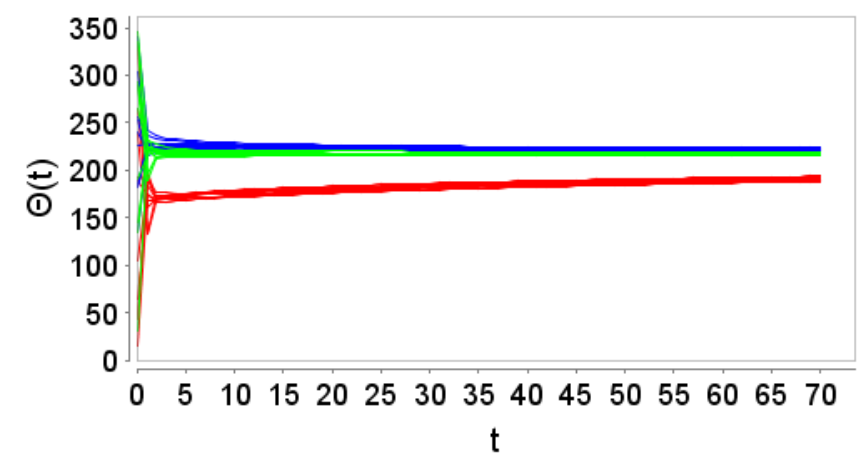

Figura 5.4: Evolução do processo de atualização de ângulos dos nós da rede artificial da Figura 5.2. A divisão de ângulos dos vértices que pertencem originalmente aos clusters em azul e verde não é tão clara, diferente do que acontece na execução mostrada na Figura 5.3.

As subseções a seguir mostram a influência dos parâmetros da regra de atualização de ângulos na formação dos agrupamentos.

\subsubsection{Cálculo do peso $w_{i j}$}

Essa subseção possui dois objetivos principais: mostrar como a variação de $\alpha$ auxilia na identificação de clusters com diferentes níveis de refinamento; e mostrar os efeitos de $S N\left(v_{i}, v_{j}\right)$ (definido pela Equação 5.5) no cálculo de $w_{i j}$.

Um conjunto de dados pode apresentar clusters com diferentes níveis de refinamento, ou seja, mais de uma estrutura (divisão) válida para um mesmo conjunto de dados. Uma estrutura corresponde a um refinamento de uma estrutura superior, com menor número de clusters. O algoritmo proposto é capaz de identificar diferentes estruturas através da variação do parâmetro $\alpha$.

Um exemplo simples de conjunto de dados com mais de uma estrutura válida é o da Figura 5.5(a). Adotando um baixo grau de refinamento, o conjunto de dados pode ser dividido em 2 clusters, como mostra a Figura 5.5(b). Aumentando o nível de detalhes, o conjunto de dados pode ser dividido em 4 clusters, como mostra a Figura 5.5(c).

Considere a construção de uma rede tomando como entrada o conjunto de dados da Figura 5.5(a). A rede é construída conforme a modelagem proposta na Seção 5.2. Para esse exemplo, cada vértice é ligado aos seus $K=8$ vizinhos mais próximos. 


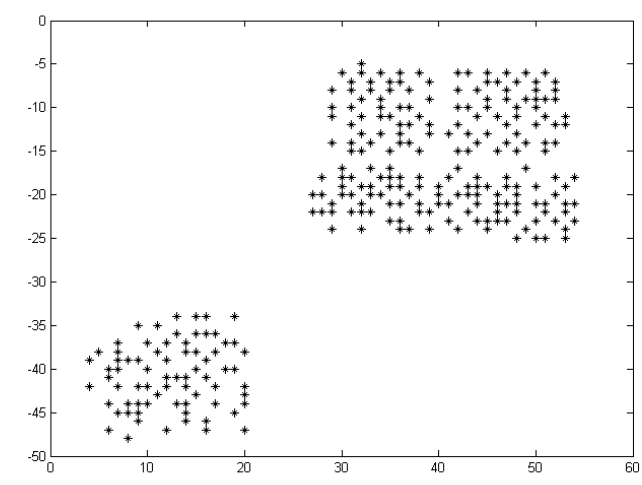

(a)

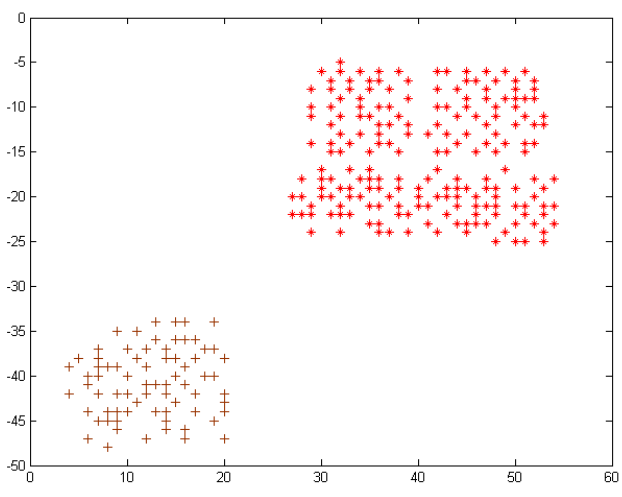

(b)

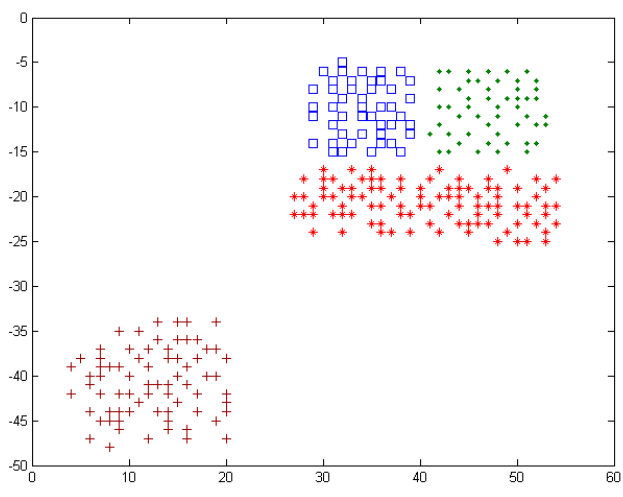

(c)

Figura 5.5: (a) Conjunto de dados original (b) Estrutura E1, baixo nível de refinamento, dividindo os dados em 2 clusters; (c) Estrutura E2, maior nível de refinamento, dividindo os dados em 4 clusters.

A Figura 5.6 mostra as interações de um vértice dessa rede, $v_{0}$, com seus vizinhos. Para mostrar a influência de $\alpha$ na diferenciação de vértices de diferentes clusters, a cor do vértice indica a qual cluster ele pertence originalmente, de acordo com a estrutura E2 apresentada na Figura 5.5(c). O peso nas arestas indica a distância euclidiana entre os vértices.

Inicialmente, considere a definição do peso de um vizinho como sendo a regra de atração entre dois vértices, ou seja, $w_{i j}=C N\left(v_{i}, v_{j}\right)$. A Figura 5.7 ilustra a variação de $\alpha$ no cálculo dessa definição inicial de $w_{i j}$ para o vértice $v_{0}$. Conforme o valor de $\alpha$ aumenta, o peso dado a vizinhos mais distantes diminui, fazendo com que essas ligações quase desapareçam. Como esses vizinhos são praticamente desconsiderados na atualização do ângulo, é como se eles pertencessem a um outro cluster. Assim, se é escolhido um valor alto para $\alpha$, as conexões entre vértices distantes são "enfraquecidas", permitindo revelar a divisão de clusters com maior níveis de detalhes. Por outro lado, se é escolhido um valor pequeno para $\alpha$, mesmo as conexões entre vizinhos distantes têm 


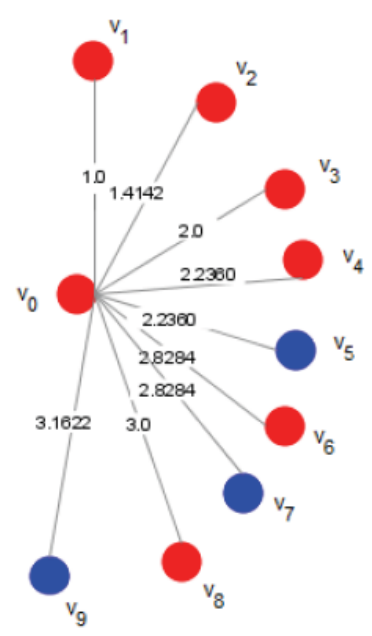

Figura 5.6: Interações entre o vértice $v_{0}$ e seus vizinhos, após a modelagem do conjunto de dados em uma rede, onde o peso nas arestas indica a distância euclidiana entre os vértices. A cor de cada vértice indica a qual cluster ele pertence originalmente, de acordo com a estrutura $E 2$ apresentada na Figura 5.5(c).

grande participação na atualização do ângulo de um vértice, e a divisão dos dados em um número menor de clusters pode ser encontrada.

Como pode ser observado na Figura 5.7, os vizinhos $v_{4}$ e $v_{5}$ têm a mesma participação na atualização do ângulo de $v_{0}$. Entretanto, apenas $v_{4}$ pertence originalmente ao mesmo cluster de $v_{0}$. Para garantir que $v_{4}$ tenha maior peso do que $v_{5}$, é usada a proporção de vértices em comum $S N\left(v_{0}, v_{j}\right)$. Vértices que pertencem ao mesmo cluster tendem a possuir maior proporção de vizinhos em comum do que vértices que pertencem a clusters diferentes. A Tabela 5.1 mostra a proporção de vértices em comum entre $v_{0}$ e seus vizinhos. Como pode ser visto, a proporção de vizinhos em comum entre $v_{0}$ e $v_{4}$ é maior do que entre $v_{0}$ e $v_{5}$.

Tabela 5.1: Proporção de vértices em comum entre $v_{0}$ e seus vizinhos $\left(S N\left(v_{0}, v_{j}\right)\right)$

\begin{tabular}{|c||c|}
\hline$v_{j}$ & $S N\left(v_{0}, v_{j}\right)$ \\
\hline$v_{1}$ & 0.6666 \\
\hline$v_{2}$ & 0.6666 \\
\hline$v_{3}$ & 0.6666 \\
\hline$v_{4}$ & 0.5555 \\
\hline$v_{5}$ & 0.3333 \\
\hline$v_{6}$ & 0.5555 \\
\hline$v_{7}$ & 0.3333 \\
\hline$v_{8}$ & 0.6666 \\
\hline$v_{9}$ & 0.3333 \\
\hline
\end{tabular}

O peso que cada vizinho tem na atualização do ângulo de um vértice pode ser redefinido como $w_{i j}=C N\left(v_{i}, v_{j}\right) \times S N\left(v_{i}, v_{j}\right)$. Na Figura 5.8 é possível notar a influência de $S N\left(v_{0}, v_{j}\right)$ no 


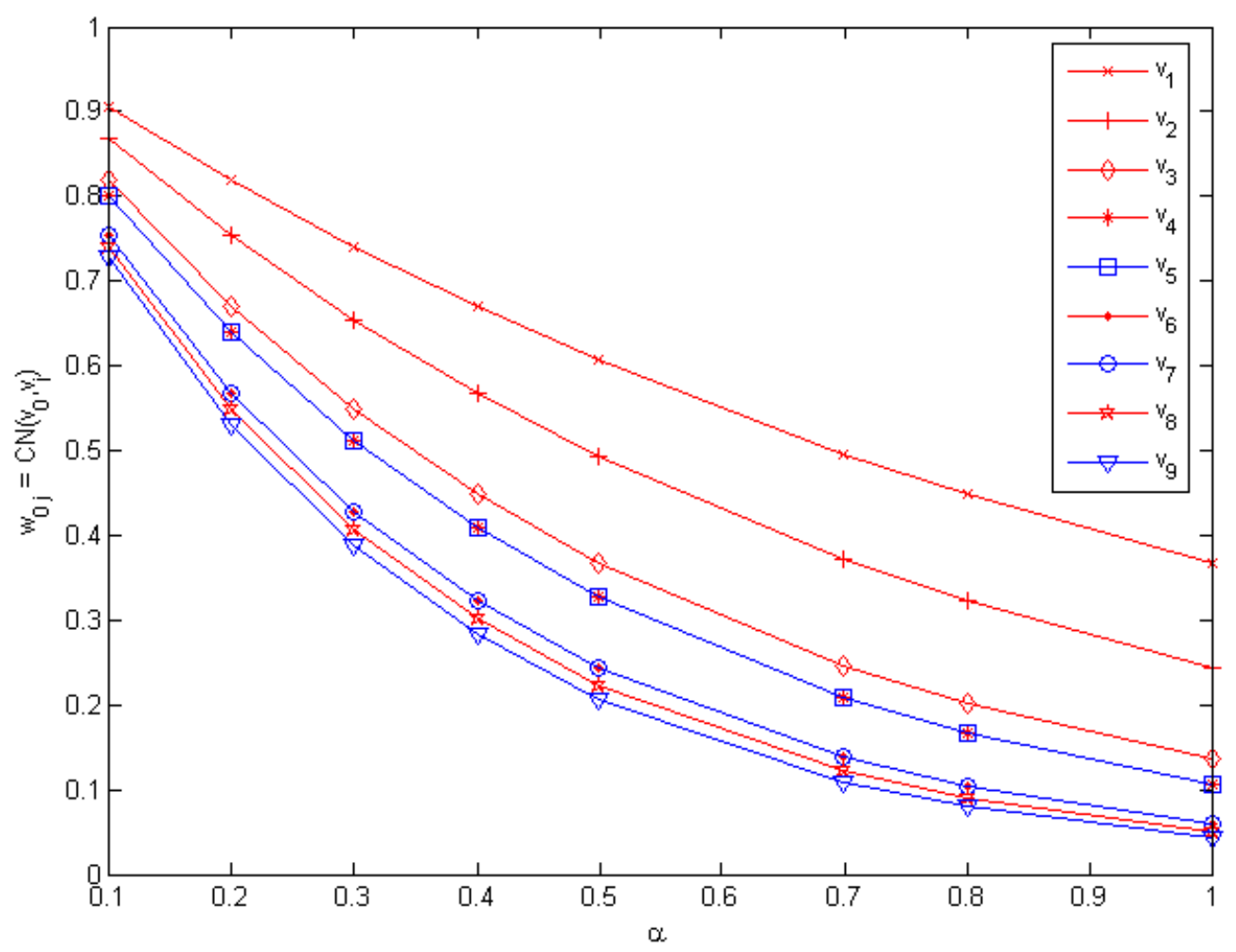

Figura 5.7: Relação entre o peso do vértice $v_{j}$ na atualização do ângulo de $v_{0}$ e a variação de $\alpha$. A cor da série indica o cluster ao qual o vértice pertence originalmente na estrutura $E 2$.

Conforme o valor de $\alpha$ aumenta, a influência de vizinhos mais distantes na atualização do ângulo de $v_{0}$ diminui mais acentuadamente do que a influência de vizinhos mais próximos.

cálculo final do peso $w_{i j}$. Como pode ser visto na figura, agora o vértice $v_{4}$ tem maior influência do que $v_{5}$ na atualização do ângulo de $v_{0}$. Isso acontece porque a proporção de vértices em comum entre $v_{0}$ e $v_{4}$ é maior do que a proporção entre $v_{0}$ e $v_{5}$. Além disso, a Figura 5.8 mostra que os vizinhos que pertencem ao outro cluster são os que têm menos influência na atualização do ângulo de $v_{0}$.

\subsubsection{Taxa de atualização de ângulo e estabilidade do sistema}

Conforme a Equação 5.6, a taxa de atualização dos ângulos tem seu comportamento controlado por dois parâmetros: $\sigma_{i}$ e $\beta$, onde o primeiro é dependente da atualização dos ângulos e o segundo é definido pelo usuário.

Para ilustrar a influência de $\sigma_{i}$ na definição de $\eta_{i}(t)$, considere um nó $v_{i}$ da rede artificial da Figura 5.2. Na simulação, é tomado o valor constante de $\beta=5$. A Figura 5.9(a) mostra a evolução de $\sigma_{i}$ no decorrer das iterações, enquanto a Figura 5.9(b) mostra a evolução da taxa de aprendizado $\eta_{i}(t)$. Como pode ser observado, à medida em que $v_{i}$ e seus vizinhos aproximam-se, o valor de $\eta_{i}(t)$ diminui, até que $\eta_{i}(t) \approx 0$. A diminuição de $\eta_{i}(t)$ na Figura 5.9(b) está fortemente ligada à 


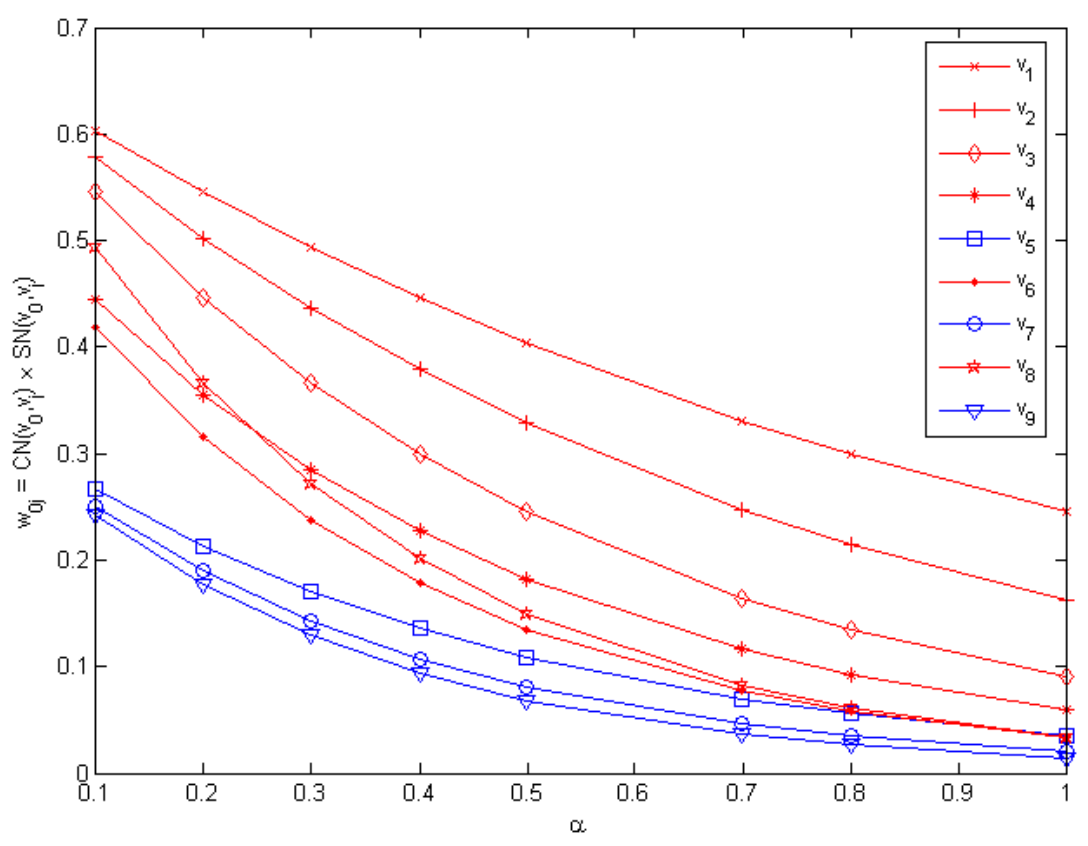

Figura 5.8: Influência de $S N\left(v_{0}, v_{j}\right)$ no cálculo do peso final $w_{0, j}$ de cada vizinho de $v_{0}$. A cor da série indica o cluster ao qual o vértice pertence originalmente na estrutura $E 2$. É possível notar que os vizinhos que não pertencem ao mesmo cluster de $v_{0}$ são os que possuem o menor peso.

diminuição de $\sigma_{i}$ na Figura 5.9(a), contribuindo para que o sistema estabilize quando os ângulos de vértices de um mesmo cluster estejam agrupados.

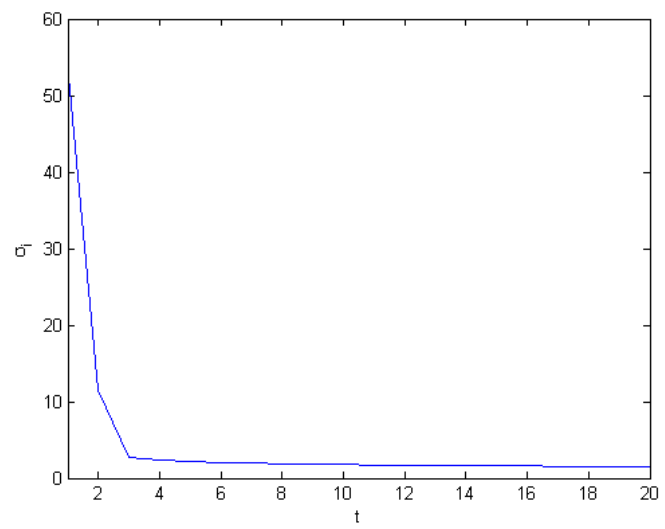

(a)

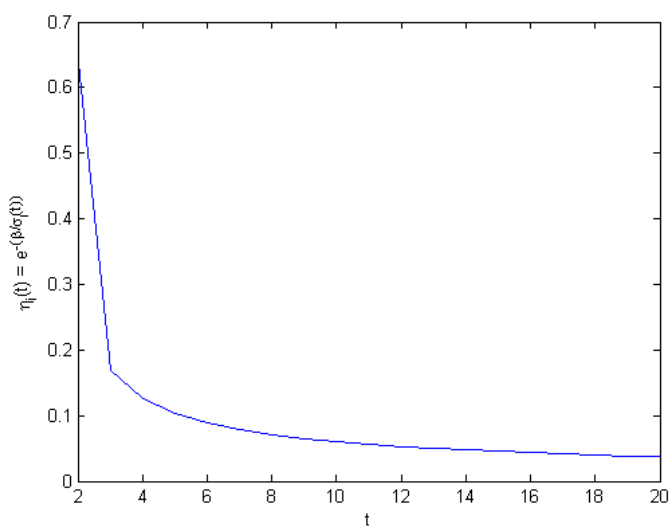

(b)

Figura 5.9: (a) O agrupamento de nós de um mesmo cluster é indicado pelo desvio padrão dos ângulos de $v_{i}$ e seus vizinhos; (b) Decrescimento da taxa de atualização dos ângulos à medida em que estes começam a agrupar-se. 
O segundo fator que influencia na performance do algoritmo é a escolha do parâmetro $\beta$. Para exemplificar essa influência, é utilizada a rede artificial da Figura 5.2 como entrada para o algoritmo.

Quando o valor de $\beta$ é pequeno, $\eta_{i}(t) \approx 1$ e os ângulos aproximam-se livremente durante quase toda a execução. A estabilidade é atingida quando todos os ângulos estão agrupados, dificultando a identificação da separação entre os clusters. Essa situação é ilustrada na Figura 5.10(a), onde $\beta=0.5$.

Considerando $\beta=50, \eta_{i}(t) \approx 0$ e os ângulos aproximam-se muito lentamente. Nesse caso, o valor de $\sigma_{i}$ tem pouca importância, de acordo com a definição de $\eta_{i}(t)$. Quando a estabilidade é atingida, nenhum agrupamento é formado, como mostra a Figura 5.10(b).

A Figura 5.10(c) mostra a escolha do valor ideal de $\beta$, permitindo que inicialmente os ângulos aproximem-se livremente. $\operatorname{Com} \beta=5, \sigma_{i}$ influencia na medida correta na atualização dos ângulos. Essa escolha de $\beta$ contribui para que a estabilidade do sistema seja atingida quando os ângulos estão corretamente agrupados.

\subsection{Algoritmo de clusterização de dados}

A seção anterior descreveu a regra de atualização de ângulos capaz de formar grupos de nós com ângulos similares. Essa seção define então um algoritmo hierárquico divisivo que identifica os clusters através da observação da formação ou não de agrupamentos de ângulos nas séries temporais. O funcionamento do algoritmo é descrito a seguir.

Inicialmente, a rede toda é considerada como um grande cluster e é adicionada ao conjunto de clusters denotado por CSet. A cada iteração, um cluster de CSet é escolhido para ser dividido. Para decidir qual cluster será dividido, a regra de atualização de ângulos descrita pela Equação 5.2 é aplicada para todos os clusters $C_{k} \in C$ Set que com mais de um elemento $\left(n_{C_{k}}>1\right)$. Quando o processo de atualização de ângulos termina, os ângulos de todos os nós de $C_{k}$ são organizados em ordem decrescente. Esse conjunto ordenado de ângulos é chamado $V O_{C_{k}}$.

$\mathrm{O}$ próximo passo é identificar a maior diferença entre dois ângulos, chamada maxDif $f_{C_{k}}$. Essa diferença é dada pelo valor máximo de $\left(V O_{C_{k}}[j]-V O_{C_{k}}[j+1]\right), \forall j \in\left[1, n_{C_{k}}\right)$. A localização dos ângulos de $V O_{C_{k}}$ que possuem a maior diferença entre si, $i d_{C_{k}}$, é definida como $\underset{j}{\operatorname{argmax}}\left(V O_{C_{k}}[j]-V O_{C_{k}}[j+1]\right)$.

Se um cluster possui mais de um sub-cluster (conjunto de nós densamente conectados), os nós de cada sub-cluster serão rapidamente agrupados. Consequentemente, nós de sub-clusters diferentes irão afastar-se, resultando em um alto valor de $\max D i f f_{C_{k}}$. Então, a localização dada por $i d_{C_{k}}$ pode indicar uma boa localização para dividir esse cluster. Por outro lado, se maxDif $f_{C_{k}}$ possui um valor pequeno, significa que os nós do cluster são densamente conectados e que foram rapidamente agrupados pela regra de atualização de ângulo. Isso pode indicar que este cluster não se divide em sub-clusters, não sendo um bom candidato à divisão. 


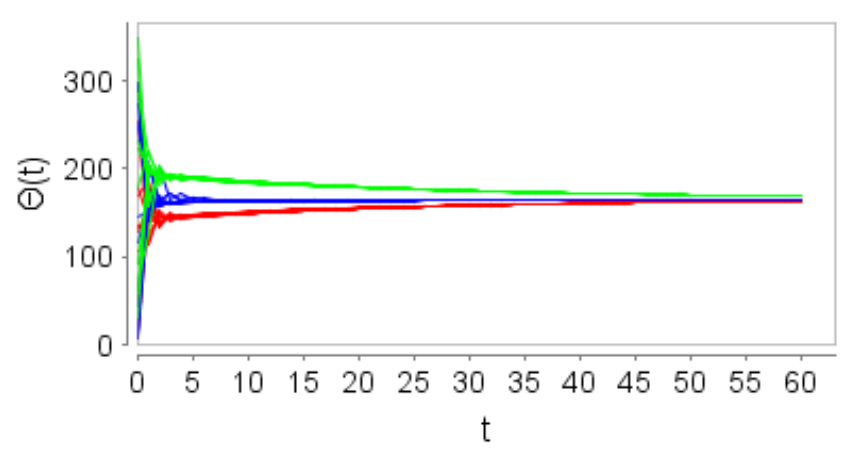

(a)

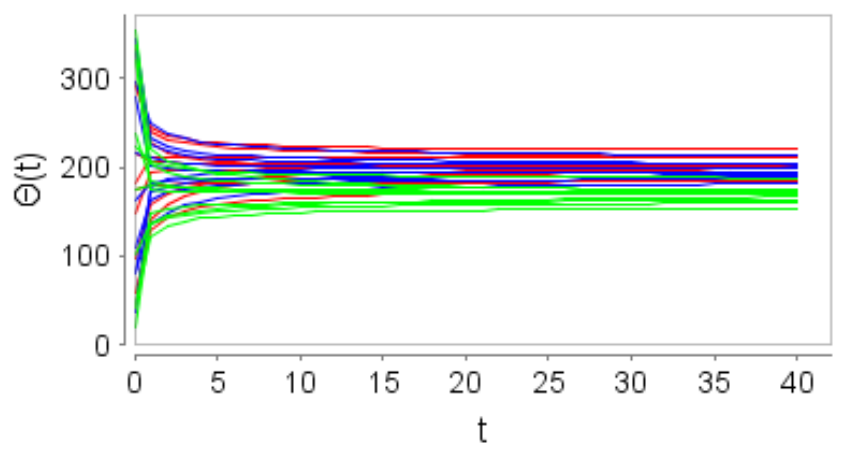

(b)

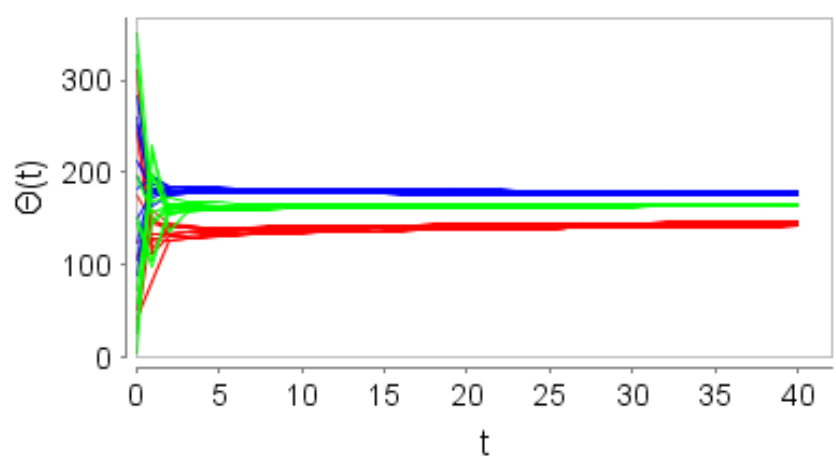

(c)

Figura 5.10: Influência da escolha de $\beta$ na eficiência do algoritmo. (a) Quando $\beta=0.5$ o sistema atinge a estabilidade com os ângulos formando um único grupo; (b) Quando $\beta=50$, a atualização dos ângulos é muito lenta, resultando em nenhum agrupamento dos ângulos; (c) Quando $\beta=5$, o sistema atinge a estabilidade quando os ângulos de nós de um mesmo cluster encontram-se agrupados.

O cluster com maior valor para $\max D i f f_{C_{k}}$, chamado $C_{\text {max }}$, é escolhido para ser dividido. Dois novos clusters são criados pela divisão do conjunto ordenado de ângulos $V O_{C_{\max }}$ na loca- 
lização indicada por $i d_{C_{\max }}$. O processo de divisão dos clusters continua até que cada cluster de $C$ Set seja formado por apenas um elemento.

O algoritmo de clusterização e a regra de atualização de ângulos são descritos formalmente em Algoritmo 2 e Algoritmo 3, respectivamente.
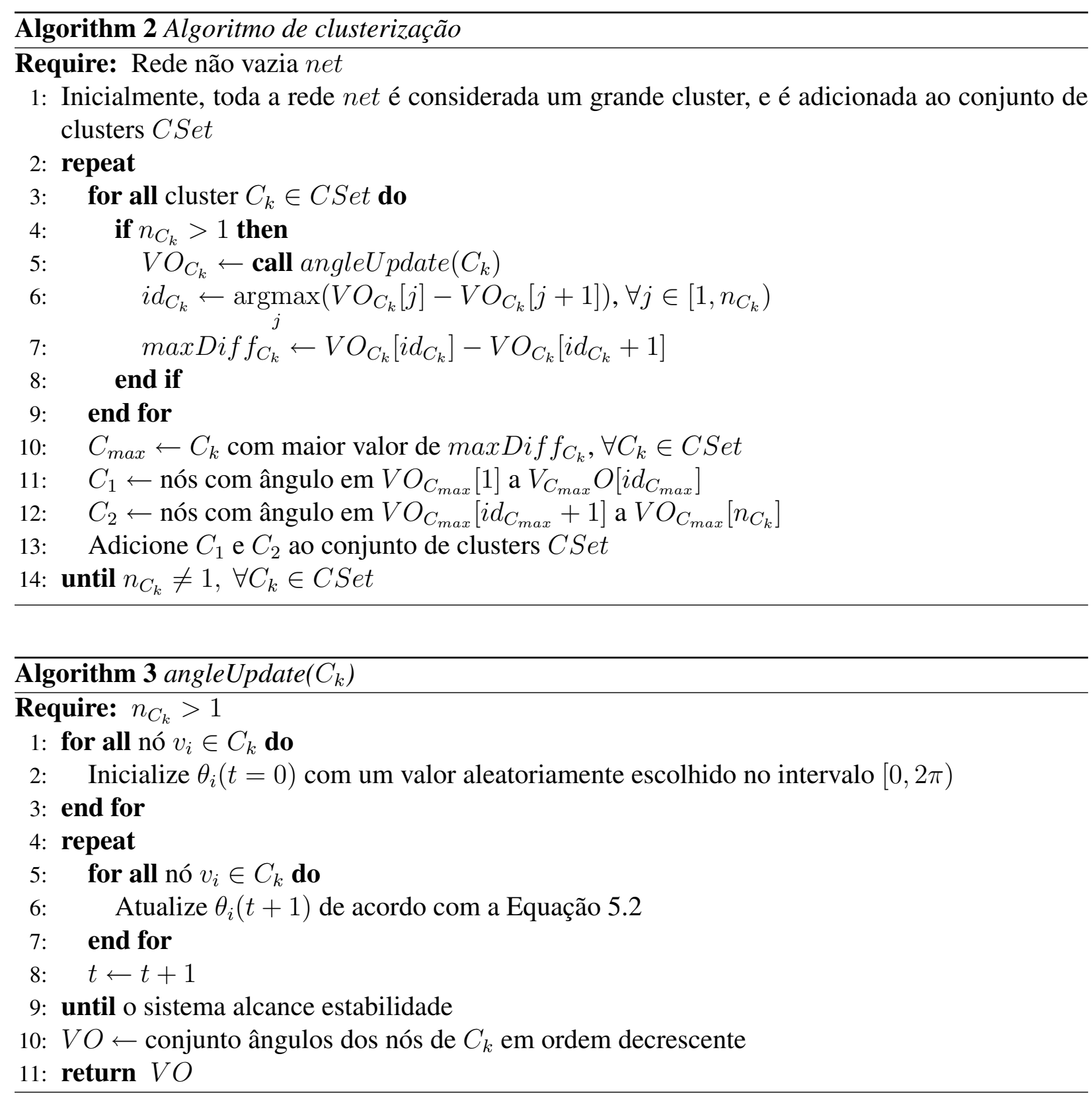

\subsubsection{Exemplo de execução}

O objetivo desse seção é exemplificar a execução do algoritmo passo a passo. Para isso, a rede artificial da Figura 5.2 é usada como entrada do algoritmo. Inicialmente, a rede toda é considerada um cluster chamado $C 1$. O próximo passo é decidir qual cluster será dividido. Isso é feito aplicando a regra de atualização de ângulos em todos os clusters de $C$ Set, nessa etapa apenas $C 1$. O 
cluster $C 1$ é então dividido na posição em que ocorreu a maior diferença entre os ângulos, indicada na Figura 5.11 (b). A divisão de $C 1$ dá origem à dois novos clusters, $C 2$ e $C 3$, que são adicionados ao conjunto de clusters $C$ Set, como mostra a Figura 5.12 (a).

Com a adição de $C 2$ e $C 3$ à $C S e t$, o processo repete-se, e um novo cluster deve ser escolhido para divisão. Para isso, a regra de atualização de ângulos é aplicada a todos os clusters de CSet: $C 2$ e $C 3$. O cluster $C 2$ é então escolhido para ser dividido, pois possui maior diferença entre os ângulos como mostra a Figura 5.12 (b). Sua divisão dá origem à dois novos clusters, $C 4$ e $C 5$. Agora $C$ Set é formado pelos clusters que correspondem às comunidades originais da rede, como mostra a Figura 5.13 (a).

A partir desse ponto, as divisões obtidas pelo algoritmo não revelam qualquer estrutura de comunidades da rede. A Figura 5.13 (b) mostra o resultado da regra de atualização de ângulos nos clusters $C 3, C 4$ e $C 5$, revelando que nenhum cluster possui sub-clusters significativos. O processo de divisão de clusters continua até que cada cluster seja formado por apenas um vértice da rede.

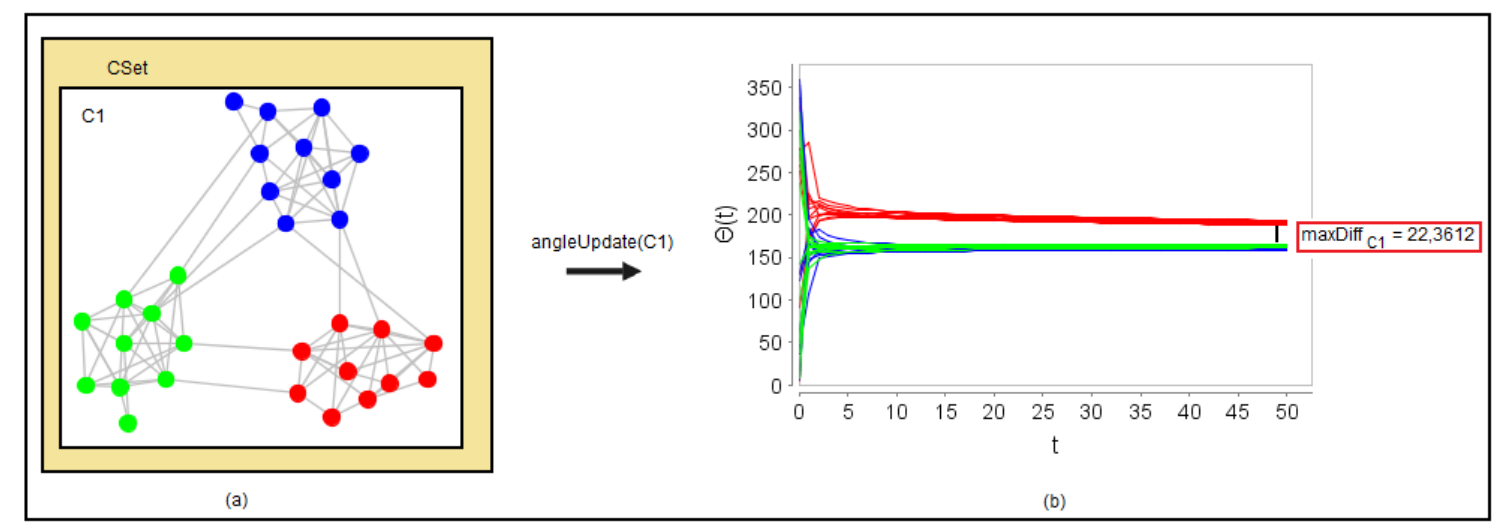

Figura 5.11: Divisão do cluster $C 1$ através da regra de atualização de ângulos. O cluster é dividido na posição em que ocorreu a maior diferença entre ângulos.

\subsection{Considerações Finais}

Neste capítulo as três áreas da computação descritas nos capítulos anteriores foram utilizadas em conjunto para resolver o problema de clusterização de dados. Inicialmente, a própria área de clusterização de dados, contribuindo na definição das medidas de similaridade entre os dados (e na validação dos resultados, que serão apresentados no Capítulo 6). Conforme descrito, algoritmos baseados em grafos possuem boa capacidade de identificar clusters de formas e tamanhos arbitrários, com a desvantagem de oferecerem baixa performance quando lidam com um grande número de dados. A área de redes complexas é então utilizada por modelar sistemas reais formados por muitos dados. Além disso, o conceito de comunidades é naturalmente relacionado ao conceito de cluster. Dessa maneira, a computação bioinspirada é utilizada para auxiliar na detecção de comunidades em redes complexas. 


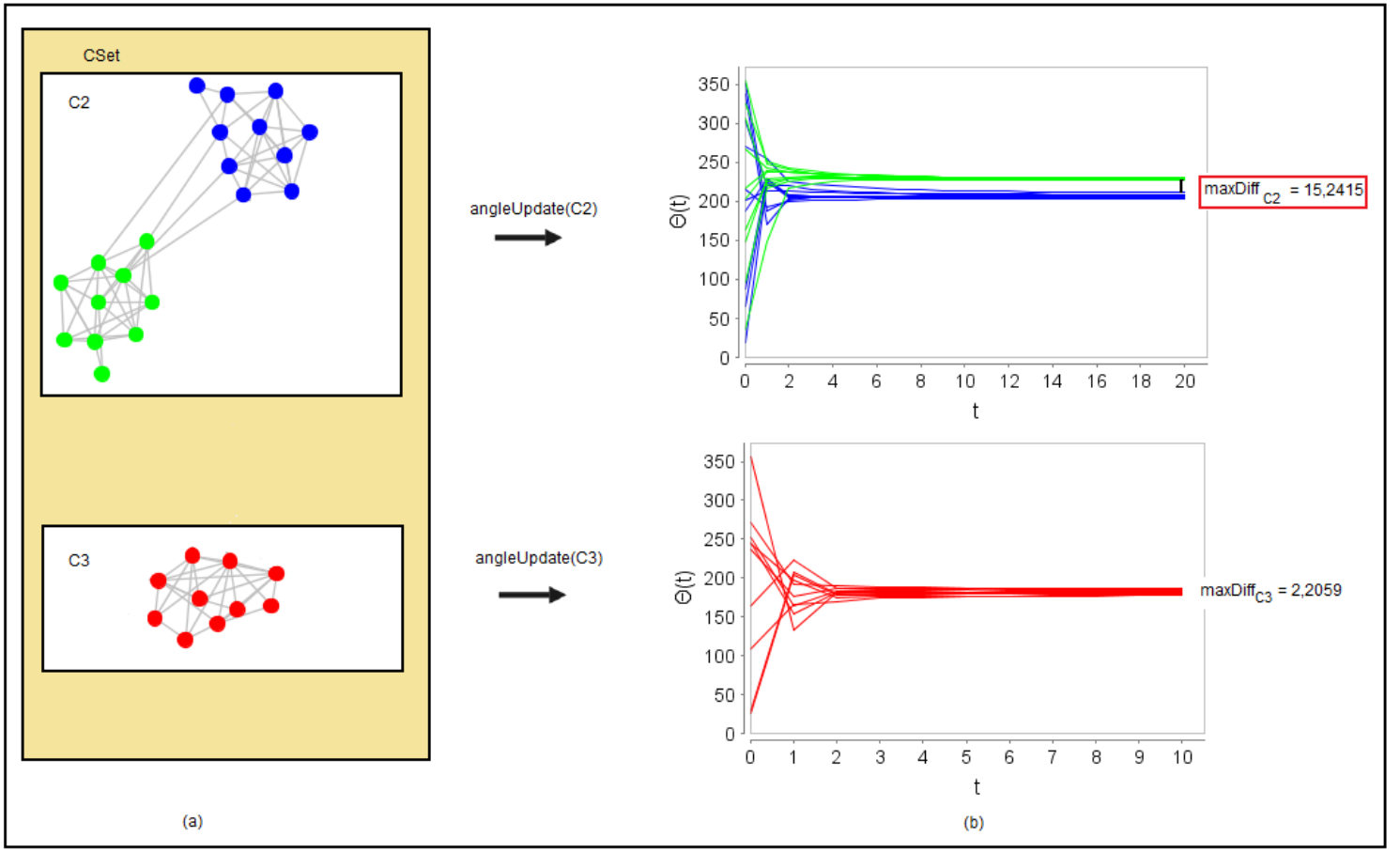

Figura 5.12: $\mathrm{O}$ cluster $C 2$ apresenta a maior diferença entre ângulos, após a aplicação da regra de atualização de ângulos a todos os clusters de CSet.

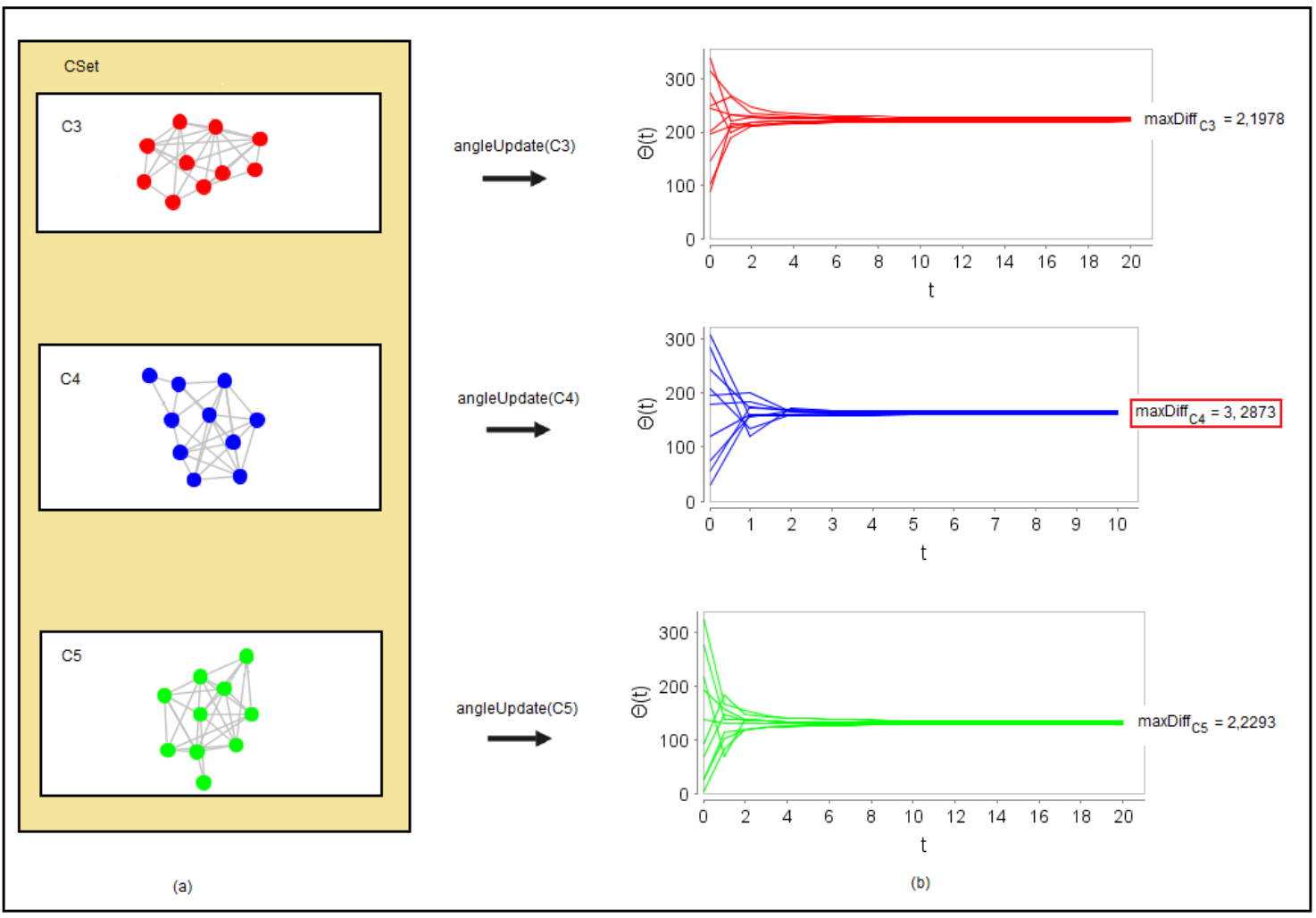

Figura 5.13: Os três clusters em CSet correspondem às comunidades da rede original. A partir desse ponto, a divisão dos clusters não revela qualquer estrutura de comunidades da rede original. 
O algoritmo desenvolvido é composto por duas etapas: na primeira, os dados são modelados em um grafo, onde a similaridade entre dois itens é dada pela distância euclidiana entre eles; na segunda, os clusters são identificados através do particionamento do grafo em sub-grafos. A identificação dos clusters é feita através de um processo biológico adaptativo, onde a cada nó é atribuído um ângulo. Através da atualização desses ângulos, o algoritmo busca agrupar nós de um mesmo cluster. A regra de atualização de ângulos, aproximando nós de um mesmo cluster, foi influenciada pela otimização por nuvem de partículas com velocidade adaptativa de (Li \& Wang, 2007).

Neste capítulo foi apresentada também a influência de cada parâmetro utilizado pelo algoritmo na qualidade da partição obtida. Como exemplo de tais parâmetros pode-se citar a taxa de atualização de ângulo e o parâmetro $\alpha$ na identificação de clusters com diferentes graus de refinamento. Além disso, foi realizada a execução do algoritmo, tomando como entrada uma rede artificial simples, permitindo a visualização passo a passo do processo de identificação dos clusters.

O Capítulo 6 apresenta os resultados obtidos pelo algoritmo proposto. São utilizados como entrada conjuntos de dados reais e artificiais, bem como redes complexas reais e artificiais. A performance do algoritmo é avaliada de acordo com o índice CR, comparando a partição obtida pelo algoritmo com a divisão original dos dados em clusters. Para as simulações que utilizam conjuntos de dados reais como entrada, os resultados do algoritmo são comparados com os resultados obtidos por algotitmos clássicos de clusterização. 


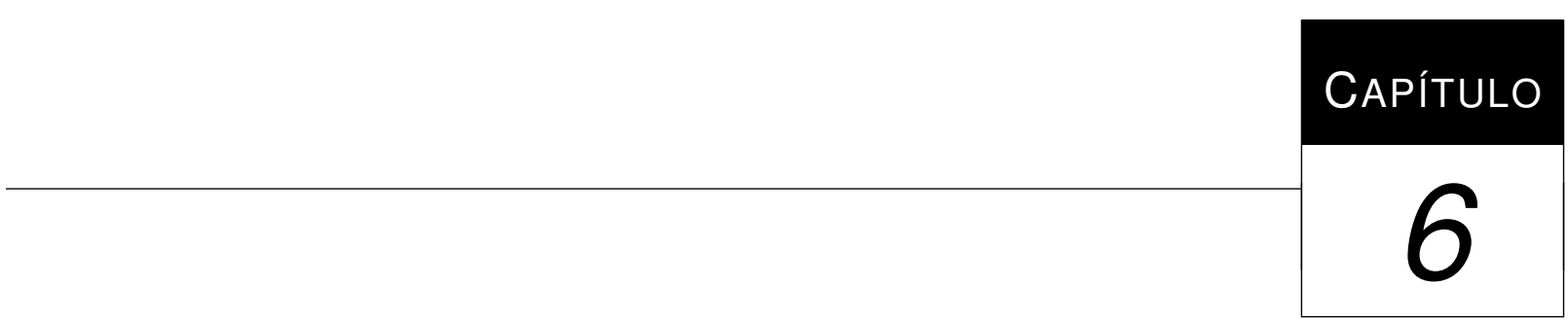

\section{Experimentos}

No Capítulo 5 foi apresentada a técnica de clusterização desenvolvida no trabalho, bem como uma visão geral do seu funcionamento através de um exemplo simples. Nesse capítulo serão detalhados os experimentos realizados para testar a eficiência do algoritmo na identificação de clusters. A Seção 6.1 descreve a metodologia usada na avaliação dos resultados. A Seção 6.2 descreve os resultados obtidos pelo algoritmo em dados artificiais: redes geradas artificialmente e conjuntos de dados bidimensionais. Na Seção 6.3 são descritos os resultados obtidos com redes reais com estrutura de comunidades conhecidas e conjuntos de dados reais.

\subsection{Metodologia de avaliação}

A qualidade de uma partição gerada por um algoritmo de clusterização é dada geralmente por índices estatísticos, como os índices descritos na Seção 2.4. Neste trabalho, a qualidade das soluções foi avaliada com o índice CR, descrito pela Equação 2.16, por tratar-se de um índice muito utilizado na avaliação de algoritmo de clusterização (Jain \& Dubes, 1988).

Os resultados da simulação foram analisados de acordo com o mesmo procedimento adotado em (Julia Handl \& Knowles, 2007), para avaliar a capacidade do algoritmo em gerar boas partições do conjunto de dados. Como o algoritmo proposto é não-determinístico, foram realizadas 30 execuções com os mesmos valores para os parâmetros $K$ (para formação da rede) e $\alpha$ (para o peso de vizinhos na atualização dos ângulos). Para cada uma das 30 execuções, foi calculado o índice CR para partições com diferentes números de clusters. Por tratar-se de um algoritmo hierárquico, uma execução pode ser representada por um dendrograma. Cada nível do dendrograma representa uma partição do conjunto de dados, com diferentes números de clusters. Então, a partição $P$ 
com melhor valor de $\mathrm{CR}$ foi usada para avaliar a qualidade da execução. O número de clusters na partição $P$ é dado por $k_{P}$. Após as 30 execuções, a média e o desvio padrão de $\mathrm{CR}$ foram calculados para avaliar o algoritmo com os valores específicos de $K$ e $\alpha$. Foi calculado também a média e desvio padrão de $k_{P}$. Os parâmetros $K$ e $\alpha$ foram variados, e para cada combinação de $K$ e $\alpha$ foi realizado o mesmo procedimento de avaliação (30 execuções e cálculo da média e desvio padrão para $\mathrm{CR}$ e $k_{P}$ ). Os valores de $K$ e $\alpha$ que apresentaram os melhores valores de CR médio foram escolhidos. Maiores detalhes sobre o procedimento adotado podem ser obtidos em (Julia Handl \& Knowles, 2007).

\subsection{Dados artificiais}

O comportamento do algoritmo foi avaliado inicialmente em dados artificiais. Foram utilizadas redes geradas artificialmente com divisão em comunidades já conhecida, e um conjunto de dados bidimensional, onde a visualização dos clusters é facilitada.

\subsubsection{Redes artificiais}

Como um primeiro exemplo do funcionamento do algoritmo, foram geradas redes artificiais com estruturas de comunidades pré-determinadas. A probabilidade de criar uma aresta entre dois vértices $v_{i}$ e $v_{j}$ depende da comunidade a qual eles pertencem. Se $v_{i}$ e $v_{j}$ pertencem a mesma comunidade, a probabilidade de criar uma aresta entre eles é alta, denotada por Ps. Se $v_{i}$ e $v_{j}$ pertencem a comunidades diferentes, a probabilidade de conectá-los é pequena, denotada por $P l$. Com base em $P s$ e $P l$, a rede artificial é gerada da seguinte maneira:

1. Criar $c$ comunidades com $n_{c}$ vértices cada, formando o conjunto de vértices $V=\left\{v_{0}, \ldots, v_{n-1}\right\}$, onde $n=n_{c} \times c$.

2. Adicionar as arestas que ligam os vértices. Inicialmente, é necessário garantir que cada comunidade forme uma componente conexa. Para isso, os vértices de uma mesma comunidade são inicialmente conectados em "círculo". O mesmo é feito para conectar cada comunidade, formando então uma rede conexa. Nessa etapa não são utilizadas as probabilidades $P s$ e $P l$, o único objetivo é obter uma rede conexa.

3. Arestas são adicionadas à rede de acordo com as probabilidades $P s$ e $P l$. Dois vértices $v_{i}$ e $v_{j}$ são escolhidos aleatoriamente. A probabilidade de conectá-los é $P s$ se pertencerem a mesma comunidade, e $P l$ caso contrário. A adição de arestas é feita até que a média de graus dos vértices atinja o valor desejado $\langle k\rangle$, dada por: $\frac{1}{|V|} \sum_{v_{i} \in V} k_{i}$, onde $V$ é o conjunto de vértices da rede e $k_{i}$ é o grau do vértice $v_{i}$.

As redes artificiais geradas possuem 4 comunidades com 32 vértices em cada comunidade. A média de graus dos vértices da rede escolhida é $\langle k\rangle=16$. As simulações foram realizadas ad- 
mitindo $\beta=0.1$ para controlar o decaimento da taxa de atualização dos ângulos. A Figura 6.1 mostra a eficiência do algoritmo, medida pelo índice $\mathrm{CR}$, em relação à quantidade de arestas entre comunidades, dada por $\mathrm{Pl}$. Na figura, é possível notar que o algoritmo identifica corretamente as comunidades de redes geradas com valores de $P l$ até 0.15 . Em redes geradas com $P l=0.15$, os vértices têm em média 5.7 conexões com vértices de outras comunidades. Conforme a probabilidade de conectar vértices de comunidades diferentes aumenta, a capacidade do algoritmo em identificar as comunidades corretamente diminui. Quando $P l=0.2$, os vértices da rede artificial têm em média 6.9 conexões com vértices de outra comunidade. Nesse caso, o algoritmo atinge em média $C R=0.47$. Essa queda no desempenho explica-se pelo aumento significativo na quantidade de arestas entre comunidades. Como $\langle k\rangle=16$, uma média de 6.9 conexões com vértices de outras comunidades (como ocorre quando $P l=0.2$ ) corresponde à quase metade das conexões do vértice. As simulações realizadas mostram que o algoritmo obtém valores satisfatórios para CR na detecção de comunidades.

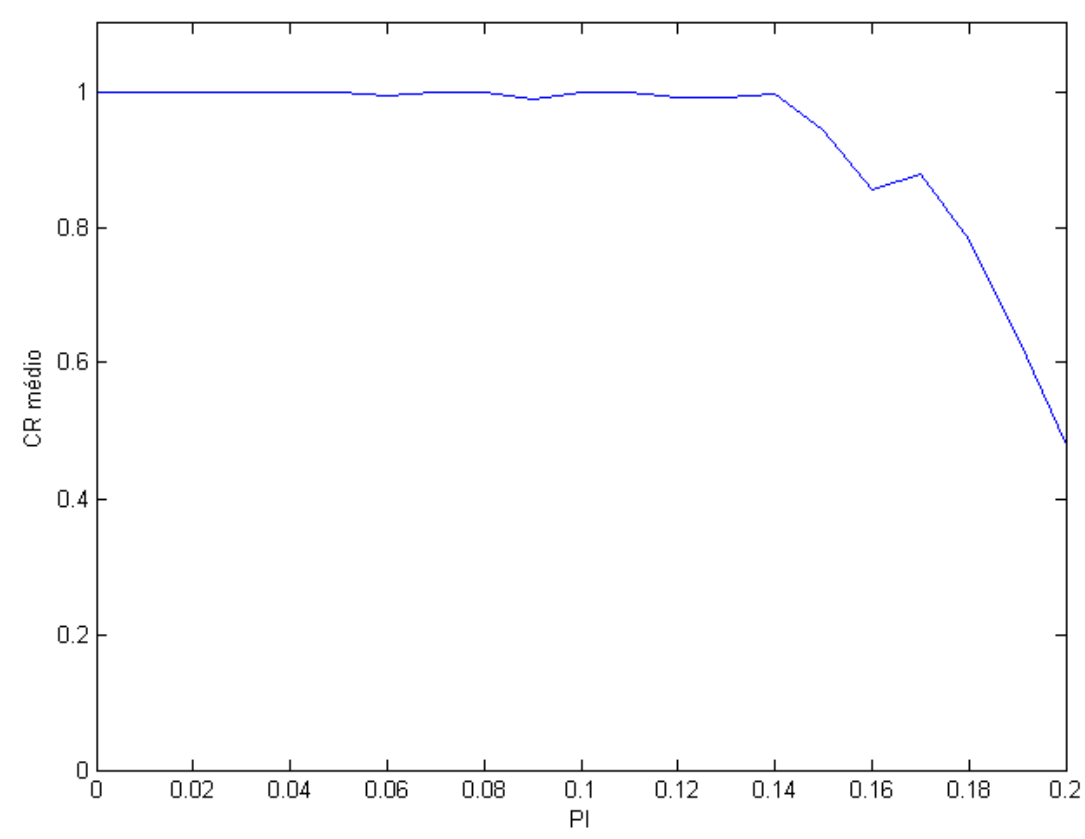

Figura 6.1: Relação entre o índice $C R$ e a probabilidade de conectar vértices de comunidades diferentes, dada por $P l$, em rede artificial formada por 4 comunidades com 32 vértices cada.

\subsubsection{Conjunto de dados artificiais}

Para avaliar a capacidade do algoritmo em detectar clusters de diferentes densidades, formas e tamanhos foi utilizado um conjunto de dados bidimensionais, tornando mais fácil a visualização dos resultados da clusterização.

O conjunto de dados utilizado é mostrado na Figura 6.2. Para esse experimento foi utilizado $K=10$ para formação da rede, conectando cada vértice aos seus $K$ vizinhos mais próximos. A 
rede resultante possui 2123 nós e 12095 arestas. Foi utilizado $\beta=0.01$ para controle da taxa de atualização dos ângulos.

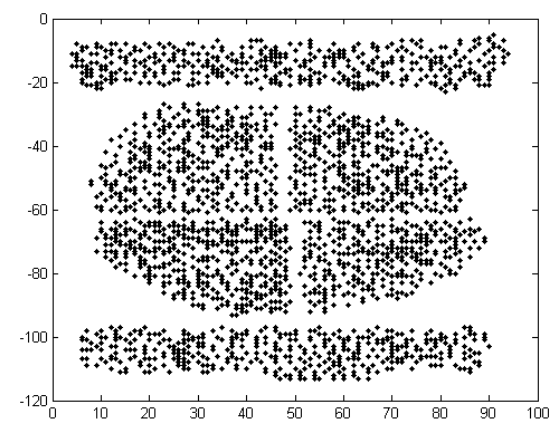

Figura 6.2: Conjunto de dados com 2123 pontos.

Intuitivamente, esse conjunto de dados apresenta duas estruturas. A primeira estrutura $E 1$ divide o conjunto de dados em três clusters: duas "barras" e um "círculo". Usando $\alpha=0.4$ o algoritmo proposto é capaz de detectar corretamente essa divisão de clusters, como mostra a Figura 6.3. A segunda estrutura E2 divide os dados em seis clusters: duas "barras" e quatro quartos de "círculo", um refinamento do "círculo" de E1. Aumentando o valor de $\alpha$, o número de arestas que contribuem para a atualização do ângulo de um nó diminui, aumentando assim o número de clusters identificados. Assim, quando $\alpha=0.5$, os seis clusters de $E 2$ são corretamente identificados, como mostra a Figura 6.4.

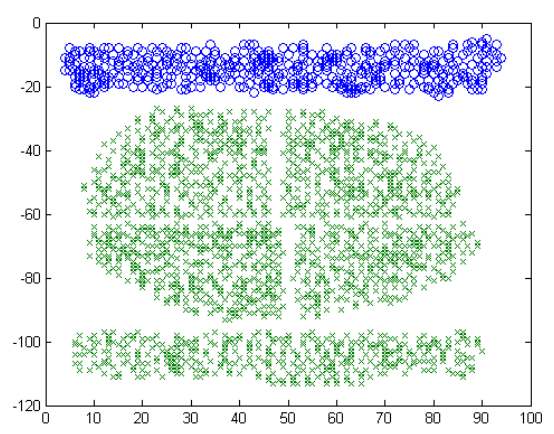

(a)

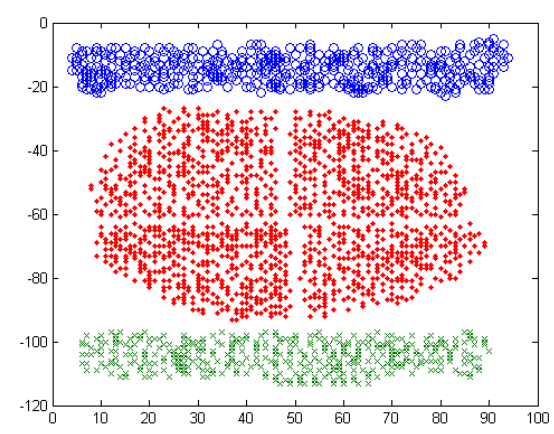

(b)

Figura 6.3: Resultado da clusterização dos dados da Figura 6.2, $\operatorname{com} \alpha=0.4$. (a) Divisão do conjunto de dados em 2 clusters. (b) Estrutura $E 1$, formada por 3 clusters.

\subsection{Dados reais}

Dados reais também foram utilizados como entrada para avaliar a eficiência do algoritmo de clusterização proposto. Foram escolhidas duas redes complexas reais: a primeira modela a in- 


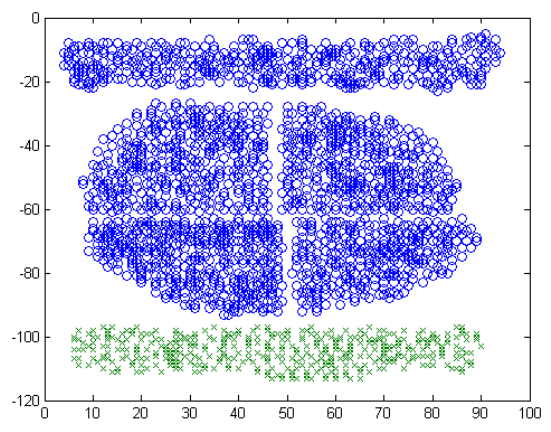

(a)

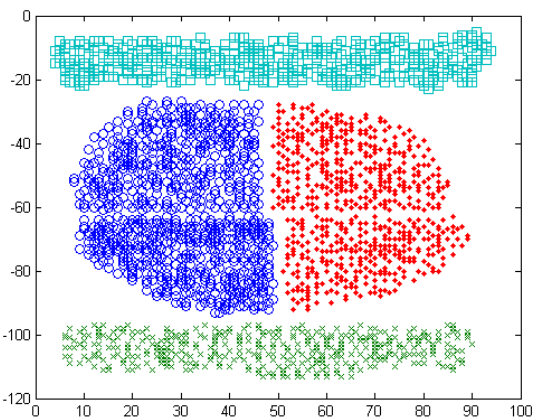

(c)

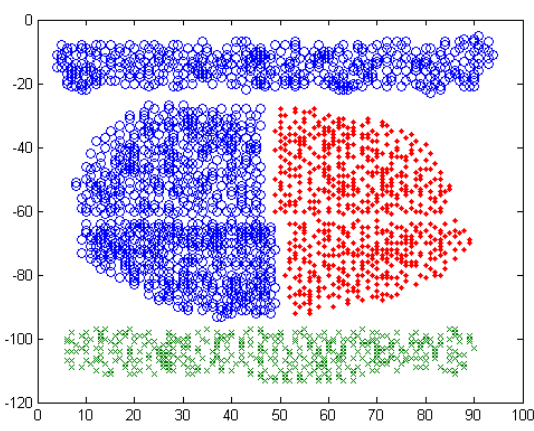

(b)

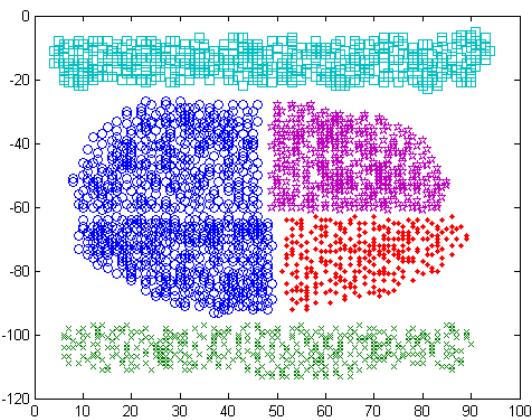

(d)

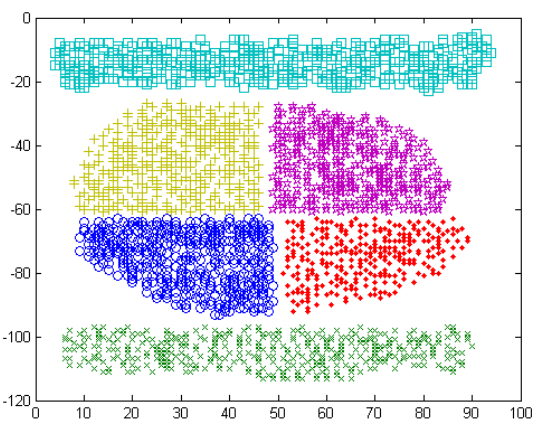

(e)

Figura 6.4: Resultado da clusterização dos dados da Figura 6.2, $\operatorname{com} \alpha=0.5$. (a) Divisão do conjunto de dados em 2 clusters. (b) Divisão dos dados em 3 clusters, onde a estrutura $E 1$ não é mais identificada. (c) Divisão dos dados em 4 clusters. (d) Divisão dos dados em 5 clusters. (e) Estrutura E2, formada por 6 clusters.

teração social entre golfinhos; e a segunda descreve os jogos entre times de futebol americano. Também foram usados dois conjuntos de dados reais: o primeiro divide em grupos espécies da planta íris; e o segundo descreve expressões de genes de pacientes com diferentes tipos de leucemia. 


\subsubsection{Redes complexas reais}

Foram utilizadas duas redes complexas reais como entrada para o algoritmo proposto, com estrutura de comunidades já conhecida. A primeira é uma rede social de 62 golfinhos descrevendo a associação (interação) entre eles (Lusseau et al., 2003). Essa rede possui 62 nós e 159 arestas sem pesos, e apresenta duas comunidades conhecidas, formadas por 21 e 41 elementos. Como a rede não foi gerada a partir de um conjunto de pontos, a simulação foi realizada considerando $C N(i, j)=1$. Através do gráfico de atualização de ângulos da Figura 6.5, é possível identificar dois agrupamentos distintos de ângulos, para $\beta=3$. A cor de cada série temporal indica a comunidade a que o nó pertence originalmente. Na Figura 6.6 é possível visualizar o resultado da simulação através de um dendrograma, onde a cor de cada nó indica a comunidade à qual pertence originalmente. Adotando o procedimento descrito na Seção 6.1, o algoritmo obteve na média $C R=1.0$, identificando corretamente os dois clusters em todas as execuções do procedimento de avaliação.

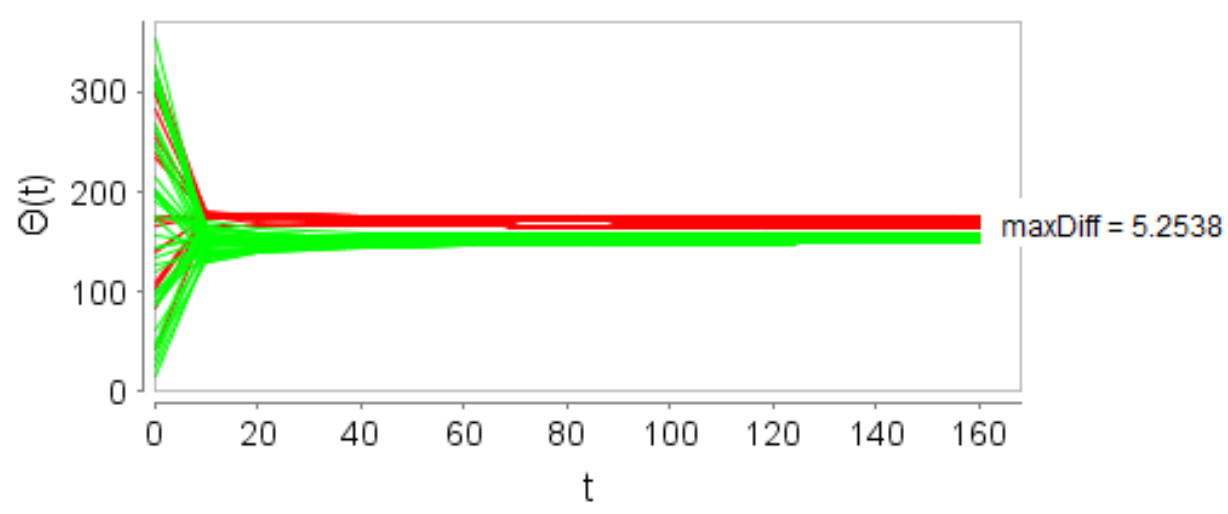

Figura 6.5: Evolução do processo de atualização dos ângulos para a rede social de (Lusseau et al., 2003). As duas comunidades reais podem ser identificadas pelos agrupamentos presentes na série temporal.

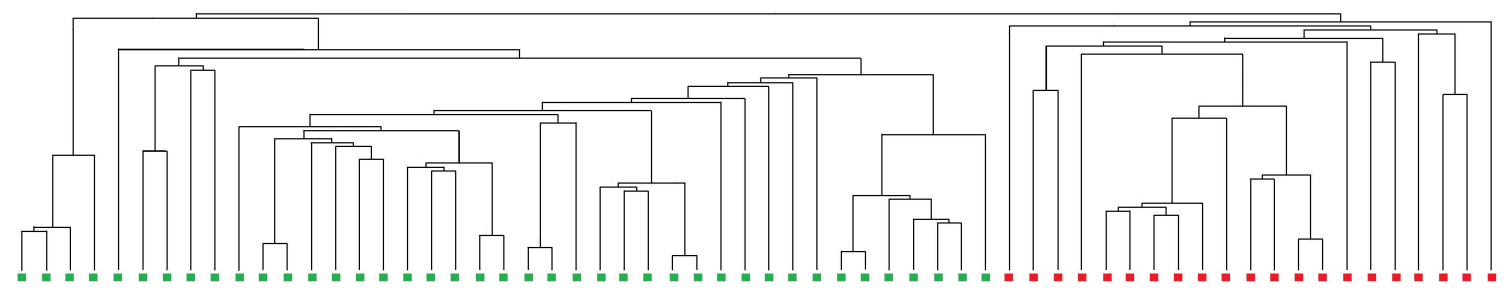

Figura 6.6: Dendrograma do resultado da simulação para a rede social de (Lusseau et al., 2003). O dendrograma revela a divisão dos dados nas duas comunidades originais, indicadas pelos itens em verde (41 elementos) e itens em vermelho (21 elementos).

A segunda rede complexa é a que descreve uma tabela de jogos de um campeonato de futebol americano, compilada em (Girvan \& Newman, 2002). Essa rede é usada na literatura como teste para novos algoritmos de detecção de comunidades, como (Zhou, 2003b) e (Newman, 2004b). A rede é formada por 115 times (nós) divididos em 12 grupos pelos organizadores do evento, e 
616 arestas indicando a existência de um jogo entre os dois times. Uma característica interessante nessa rede é a presença de nós instáveis. Como já foi descrito na Seção 3.2, um nó é considerado instável se a interação total com nós de outra comunidade é maior que a interação total nós de sua própria comunidade. Nessa simulação foi usado $\beta=0.01$ e $C N(i, j)=1$. A Figura 6.7 mostra a divisão em 12 grupos encontrada pelo algoritmo em uma execução. Na figura, os grupos reais são representados pelas cores dos nós, e os grupos identificados pelo algoritmo encontramse espacialmente agrupados. Em geral, para essa rede, o algoritmo classifica um nó em uma comunidade diferente da comunidade original caso o nó seja instável ou tenha igual interação com nós de outra comunidade e com nós de sua própria comunidade. Nessa simulação, o algoritmo obteve na média $C R=0.8017$ quando a partição possui exatamente 12 grupos. Esse resultado demonstra que o algoritmo é capaz de identificar clusters próximos aos reais.

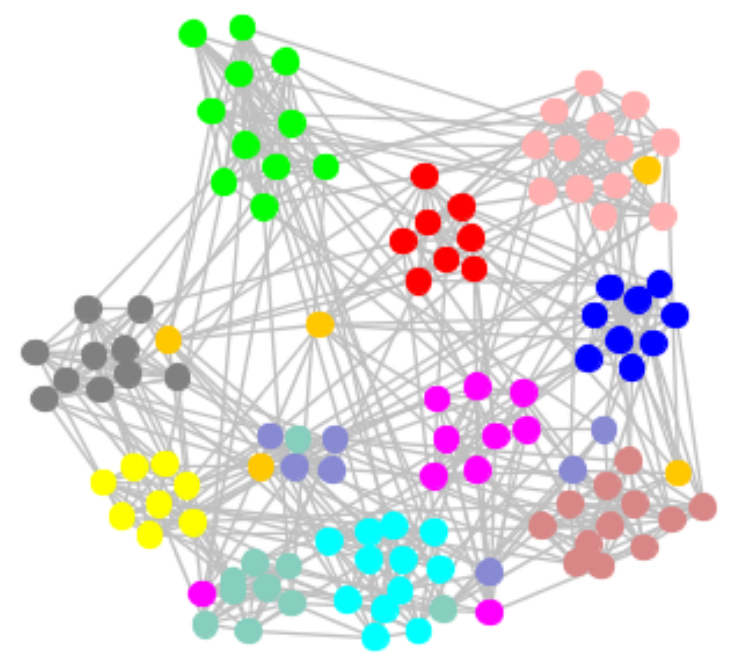

Figura 6.7: Estrutura de comunidades encontrada pelo algoritmo proposto no conjunto de dados de (Girvan \& Newman, 2002). Os nós são coloridos de acordo com as comunidades reais, e a localização espacial indica as comunidades identificadas pelo algoritmo. $\mathrm{O}$ algoritmo apresenta média de $C R=0.8017$, tendo melhores resultados de $C R$ quando a partição tem exatemente 12 grupos. Grande parte dos nós classificados erradamente pelo algoritmo trata-se de nós instáveis.

\subsubsection{Conjuntos de dados reais}

Dois conjuntos de dados reais foram utilizados como entrada para o algoritmo proposto. Para melhor avaliar a eficiência do algoritmo, os resultados obtidos foram comparados com os resultados de alguns algoritmos de clusterização clássicos: dois algorimtos hierárquicos, Single Linkage (SL) e Average Linkage (AL), e o algoritmo por particionamento K-Means (KM). Os resultados dos algoritmos clássicos foram obtidos em (Faceli et al., 2007b) e (Faceli et al., 2007a).

O primeiro conjunto de dados reais utilizado é chamado iris e é geralmente usado para testar algoritmos de aprendizado de máquina. Esse conjunto de dados pode ser obtido em (A. Asuncion, 2007) e divide-se em três grupos de espécies da planta íris: Iris Setosa, Iris Versicolor e Iris 
Verginica. Cada grupo possui 50 elementos e os atributos representam características das espécies de íris, como comprimento e largura de pétalas e sépalas.

Para essa simulação, os atributos do conjunto de dados foram normalizados apresentando média zero e variância unitária. A rede foi gerada conectando cada vértice aos seus $K=10$ vértices mais próximos. Foram adotados $\alpha=1$ para alterar o peso de vizinhos distantes, e $\beta=0.01$ para controlar o decaimento da taxa de atualização de ângulo.

Os resultados da simulação, juntamente com os resultados obtidos pelos algoritmos clássicos de clusterização são mostrados na Tabela 6.1. O valor de $k_{P}$ indica o número de clusters da partição que obteve melhor valor de CR. Através da comparação, é possível notar que o algoritmo proposto possui $C R=0.903$ na média, valor superior aos obtidos pelos algoritmos comparados. O algoritmo proposto atinge melhores valores de CR com partição de tamanho 3 (isso é indicado pelo valor de $D P=0$ para $k_{P}$ ), o mesmo número de grupos em que o conjunto de dados divide-se originalmente. Já o algoritmo hierárquico AL consegue seu melhor resultado dividindo o conjunto de dados em 6 grupos.

Tabela 6.1: Resultados da simulação para o conjunto de dados IRIS (3 clusters originais)

\begin{tabular}{|c||c|c|c|c|}
\hline \multicolumn{1}{|c||}{} & \multicolumn{2}{c|}{ CR } & \multicolumn{2}{c|}{$k_{P}$} \\
\cline { 2 - 5 } Algoritmo & Média & DP & Média & DP \\
\hline AL & 0.586 & - & 6 & - \\
\hline SL & 0.564 & - & 3 & - \\
\hline KM & 0.723 & 0.0071 & 3 & 0 \\
\hline \hline Algoritmo Proposto & $\mathbf{0 . 9 0 3}$ & 0 & 3 & 0 \\
\hline
\end{tabular}

O segundo conjunto de dados reais descreve expressões de genes de pacientes com leucemia (Golub et al., 1999), aqui chamado de golub. Classificar tipos de câncer é uma tarefa muito importante no tratamento da doença, permitindo escolher o tratamento mais eficiente e menos invasivo para os pacientes. Esse conjunto de dados é formado por 72 elementos com 3571 atributos, e apresenta duas estruturas conhecidas, como mostra a Tabela 6.2. A primeira estrutura $E 1$ divide os dados em dois grupos, um de pacientes com ALL (Acute Lymphoblastic Leukemia) e o segundo grupo de pacientes com AML (Acute Myeloid Leukemia). Essa é uma divisão importante para os pacientes de leucemia, pois cada tipo de leucemia envolve um tipo diferente de quimioterapia. Quando um paciente é tratado para o tipo errado de leucemia, as chances de sucesso do tratamento diminuem drasticamente (Golub et al., 1999). A segunda estrutura, chamada $E 2$, é um refinamento do grupo de pacientes $A L L$, que divide-se em dois sub-grupos de amostras: $T$ - $A L L$ e $B$-ALL.

A rede foi gerada conectando cada vértice aos seus $K=10$ vértices mais próximos, e para composição da taxa de atualização de ângulo foi adotado $\beta=0.01$. Para identificar a estrutura $E 1$ foi usado $\alpha=0.45$ e $\alpha=0.5$ para a estrutura E2. As Tabelas 6.3 e 6.4 mostram uma comparação entre os resultados dos algoritmos de clusterização clássicos e o algoritmo proposto. $\mathrm{O}$ melhor valor de CR dentre todos os algoritmos comparados encontra-se em negrito. Como 
Tabela 6.2: Número de elementos dos clusters das duas estruturas conhecidas do conjunto de dados GOLUB (Golub et al., 1999)

\begin{tabular}{|c|c|c|c|}
\hline Estrutura & B-ALL & $T$ - $A L L$ & $A M L$ \\
\hline E1 & \multicolumn{2}{|c|}{47} & 25 \\
\hline E2 & 38 & 9 & 25 \\
\hline
\end{tabular}

aconteceu para o conjunto de dados iris, o melhor resultado obtido pelo algoritmo proposto foi obtido por partições com número de clusters igual ao do conjunto original ( 2 clusters para $E 1 \mathrm{e}$ 3 clusters para E2). Levando em consideração esse critério, os algoritmos clássicos variam muito em relação ao número de clusters da partição que apresentou melhor valor para $C R$. Por exemplo, o algoritmo AL obtém melhor valor de $C R$ para partição de tamanho 6 e 8 para as estruturas $E 1$ e $E 2$ respectivamente, levando a crer que o algoritmo dividiu clusters maiores equivocadamente.

Tabela 6.3: Resultados da simulação para o conjunto de dados GOLUB - E1 (2 clusters originais)

\begin{tabular}{|c||c|c|c|c|}
\hline \multicolumn{1}{|c||}{\multirow{2}{*}{ Algoritmo }} & \multicolumn{2}{c|}{ CR } & \multicolumn{2}{c|}{$k_{P}$} \\
\cline { 2 - 5 } AL & Media & DP & Media & DP \\
\hline SL & 0.876 & - & 6 & - \\
\hline KM & 0.078 & - & 8 & - \\
\hline \hline Algoritmo Proposto & 0.507 & 0.211 & 3 & 0.9 \\
\hline
\end{tabular}

Tabela 6.4: Resultados da simulação para o conjunto de dados GOLUB - E2 (3 clusters originais)

\begin{tabular}{|c||c|c|c|c|}
\hline \multirow{2}{*}{\multicolumn{1}{|c||}{}} & \multicolumn{2}{c|}{ CR } & \multicolumn{2}{c|}{$k_{P}$} \\
\cline { 2 - 5 } Algoritmo & Media & DP & Media & DP \\
\hline AL & 0.798 & - & 8 & - \\
\hline SL & 0.003 & - & 8 & - \\
\hline KM & 0.502 & 0.127 & 3 & 1.2 \\
\hline \hline Algoritmo Proposto & $\mathbf{0 . 8 2 5}$ & 0.149 & 3 & 0 \\
\hline
\end{tabular}

Para ilustrar o resultado obtido pelo algoritmo proposto, a Figura 6.8 mostra um dendrograma com o resultado da simulação para a estrutura $E 1$.

\subsection{Considerações Finais}

Neste capítulo foram descritos os experimentos realizados para avaliar a capacidade do algoritmo proposto na identificação de clusters. Os resultados obtidos foram avaliados segundo a metodologia adotada em (Julia Handl \& Knowles, 2007). 


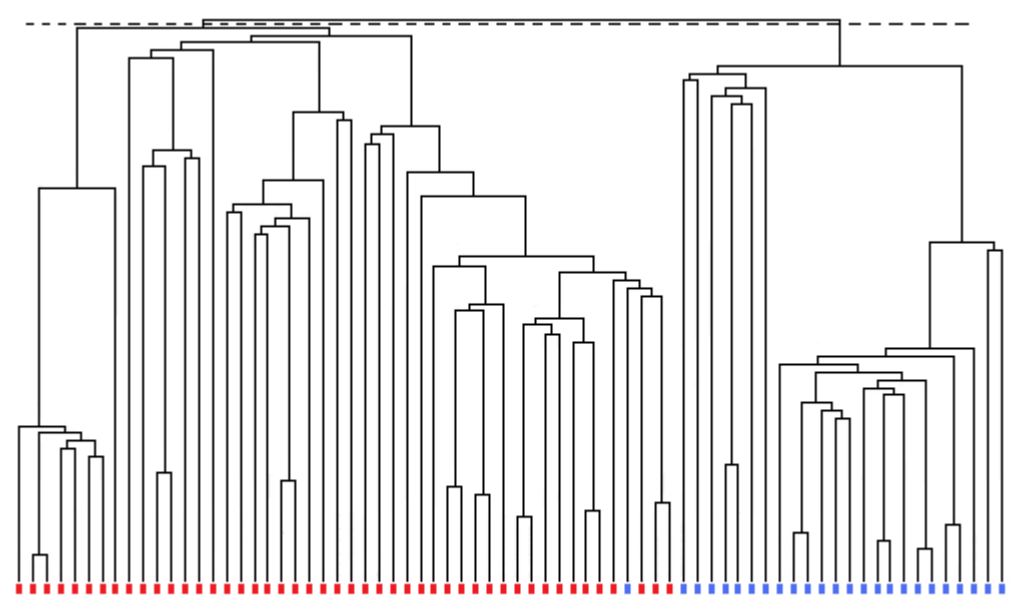

Figura 6.8: Dendrograma do resultado da simulação para a estrutura $E 1$ do conjunto de dados golub. A linha pontilhada corta o dendrograma em dois clusters, representando dois tipos de leucemia: $A L L$ (itens em vermelho) and $A M L$ (itens em $a z u l$ ).

Primeiramente, foram realizados testes com redes geradas artificialmente e estruturas de comunidades pré-definidas. Através das simulações mostradas, foi possível notar que quanto maior era o número de arestas que conectavam um nó a nós de comunidades diferentes, pior era a performance do algoritmo.

Para avaliar a capacidade do algoritmo em identificar clusters de diferentes formas e tamanhos, foram realizadas simulações com conjuntos dados artificiais bidimensionais, facilitando a visualização dos resultados. As simulações mostraram também que o algoritmo é capaz de identificar clusters com diferentes graus de refinamento, através do ajuste do parâmetro $\alpha$ usado pelo algoritmo.

Foram escolhidas duas redes complexas reais, que modelam interações sociais, para avaliar a performance do algoritmo proposto na detecção de comunidades. A aplicação do algoritmo em redes que modelam interações sociais obtiveram bons resultados.

$\mathrm{O}$ algoritmo foi aplicado também tomando como entrada dois conjuntos de dados reais. $\mathrm{O}$ primeiro conjunto, iris, é amplamente utilizado como benchmark para algoritmos de aprendizado de máquina. Na comparação entre os resultados obtidos pelo algoritmo proposto e algoritmos clássicos, o primeiro mostrou um desempenho superior aos demais. O segundo conjunto de dados, golub, representa expressões de genes de pacientes portadores de leucemia. Também para esse conjunto de dados, os resultados obtidos pelo algoritmo proposto atingiram a melhor média para o índice de validação CR dentre todos os algoritmos comparados.

Através dos resultados satisfatórios obtidos pelas simulações, mostrou-se que o algoritmo proposto é capaz de identificar clusters com diferentes formas e tamanhos. Além disso, é capaz de detectar clusters com diferentes graus de refinamento, através do ajuste de poucos parâmetros. 


\section{CAPÍTULO}

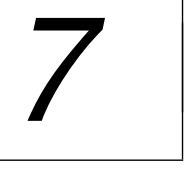

Conclusão

É possível notar a semelhança entre clusterização de dados e deteç̧ão de comunidades em redes complexas: ambos buscam o agrupamento de dados semelhantes de alguma forma. Com base nessa semelhança, este trabalho propõe uma nova abordagem para clusterização de dados envolvendo redes complexas e computação bioinspirada.

O objetivo do trabalho é o desenvolvimento de um algoritmo de clusterização com duas características principais:

- identificação de clusters com diferentes formas, tamanhos e densidades;

- detecção de clusters com diferentes níveis de refinamento.

O algoritmo proposto é composto por duas etapas: modelagem dos dados em um grafo e identificação dos clusters a partir do grafo gerado. As etapas do algoritmo são definidas a fim de que o algoritmo apresente as características estabelecidas anteriormente.

Na primeira etapa, a modelagem dos dados em grafo é feita usando a abordagem KNN, onde cada vértice é ligado aos seus $K$ vizinhos mais próximos. Entretanto, para privilegiar vizinhos mais próximos de um nó em detrimento dos mais distantes, as arestas do grafo possuem um peso correspondente à distância euclidiana entre os dados. A proximidade entre os dados será considerada pelo algoritmo proposto na etapa seguinte, durante a identificação dos clusters. É através da modelagem dos dados em um grafo que o algoritmo proposto adquire a característica de detectar clusters com diferentes formas, tamanhos e densidades. Outra vantagem obtida ao incorporar a distância entre os dados no grafo, já discutida anteriormente, é contornar uma deficiência da abordagem KNN, que tende a unir clusters distintos caso seja usado um valor muito alto para $K$. 
Na segunda etapa, a identificação dos clusters é feita usando a técnica bioinspirada de otimização por nuvem de partículas para detectar comunidades em redes complexas. Na técnica desenvolvida, cada nó da rede possui um ângulo inicial, que é atualizado iterativamente de acordo com o ângulo de seus vizinhos, ou seja, cada nó comporta-se como uma partícula em um sistema adaptativo. O objetivo é que, após a estabilização do sistema, nós de um mesmo cluster encontremse agrupados em torno de um mesmo ângulo. Nessa etapa, a proximidade entre os dados é usada na identificação de clusters com diferentes níveis de refinamento. A alteração do parâmetro $\alpha$ é responsável pelo peso que será dado a cada vizinho pela regra de atualização do ângulo de um nó. Como já foi discutido no Capítulo 5, quanto maior o valor de $\alpha$, maior o número de clusters identificados, e consequentemente maior é o nível de refinamento dos clusters no conjunto de dados.

Os experimentos realizados no Capítulo 6, confirmam que o algoritmo proposto cumpre o objetivo inicial de maneira robusta. Isso foi verificado essencialmente pelos valores do índice de validação CR obtidos pelo algoritmo nas simulações executadas e, em alguns casos, através da comparação com os resultados obtidos por algoritmos clássicos de clusterização.

\subsection{Contribuições}

Entre as principais contribuições oferecidas com a execução desse trabalho destacam-se:

- Detecção de clusters com formas, tamanhos e densidades arbitrários.

- Identificação de clusters com diferentes níveis de refinamento, revelando a decomposição de conjuntos de dados em grupos em subgrupos relevantes.

- Extensão da abordagem KNN para modelagem dos dados em grafos, permitindo que o algoritmo de clusterização tire vantagem da similaridade entre os dados.

- Possibilidade de aplicação do algoritmo em redes com ou sem peso.

Além disso, os resultados do método desenvolvido resultaram na elaboração de um artigo submetido para o IEEE World Congress on Computational Intelligence.

\subsection{Conclusões}

Neste trabalho foi desenvolvido um algoritmo de clusterização baseado em redes, que busca tirar vantagem da estrutura de comunidades presente em redes complexas. A utilização de redes complexas, em conjunto com a técnica de otimização por nuvem de partículas resultou em um algoritmo robusto e eficiente no tratamento de grandes conjunto de dados. 
Assim, podemos concluir que redes complexas consiste em uma nova área de pesquisa, que possui como vantagem a capacidade de representar grandes conjuntos de dados. Além disso, essa representação revela a estrutura topológica dos dados de entrada.

O estudo de redes complexas não só considera estruturas mas também dinâmicas, modelando sistemas que evoluem ao longo do tempo. Essa propriedade é uma das diferenças entre estudo de redes complexas e teoria dos grafos. O uso de rede complexa em conjunto com o processo de evolução é capaz de revelar não apenas a divisão dos dados em clusters, mas também as etapas do processo de clusterização como um todo.

Redes complexas são capazes de adicionar maior dinâmica à estrutura da rede, modelando sistemas que evoluem ao longo do tempo. Essa propriedade é uma das diferenças entre redes complexas e teoria dos grafos. O uso de rede complexa em conjunto com o processo de evolução é capaz de revelar não apenas a divisão dos dados em clusters, mas também as etapas do processo de clusterização como um todo.

Enquanto isso, técnicas bioinspiradas oferecem soluções eficientes e robustas à problemas de otimização. Assim, é viável a aplicação dessas técnicas no processamento de grandes conjuntos de dados, por exemplo, representados por redes complexas.

Portanto, a união de redes complexas e sistemas inspirados biologicamente constitui uma abordagem promissora para análise de dados em geral.

Apesar de já existirem muitos estudos e técnicas abordando a área de clusterização de dados, cada técnica apresenta vantagens e desvantagens. Desse modo, ainda há muito espaço para exploração na área, como por exemplo, a aplicação de técnicas de clusterização na resolução de problemas de bioinformática.

\subsection{Trabalhos Futuros}

Entre os trabalhos futuros a serem realizados com base na técnica desenvolvida encontram-se:

- Investigar a possibilidade de aplicação de outras técnicas bioinspiradas para auxiliar a detecção de comunidades em redes complexas. Como métodos de detecção de comunidades baseiam-se na distância topológica entre dois nós, sistema de colônia de formigas parece ser um método promissor nesse aspecto, podendo ser utilizado para definir a distância entre dois nós.

- Aplicar o método de clusterização em conjuntos de dados semelhantes ao usado em (Golub et al., 1999), investigando a existência de novos grupos em dados biológicos.

- Adaptar e estender o método desenvolvido para classificação de dados.

- Investigar redes complexas representadas por sistemas dinâmicos acoplados, observando novos fenômenos, analisando sua dinâmica e buscando novas aplicações na análise de dados. 
- Analisar as distâncias entre os agrupamentos gerados pela regra de atualização de ângulo da técnica proposta, considerando a sobreposição de ângulos dos dados originais. Essa análise pode ser utilizada para desenvolver uma medida de avaliação do processo de clusterização de dados. 


\section{Referências Bibliográficas}

A. Asuncion, D. N. UCI machine learning repository. Acessado em 06 de novembro de 2007, 2007.

Disponível em http://www.ics.uci.edu/ mlearn/MLRepository.html

ABIDo, M. A. Optimal power flow using particle swarm optimization. International Journal of Electrical Power and Energy Systems, v. 24, n. 07, p. 563-571, 2002.

Albert, R.; BARABAsi, A. L. Statistical mechanics of complex networks. Reviews of Modern Physics, v. 74, n. 1, 2002.

Barabasi, A. L.; Albert, R. Emergence of scaling in random networks. Science, v. 286, p. 509, 1999.

Bellman, R. E. Dynamic Programming. Princeton University Press, Princeton, NJ., 1957.

Bertsekas, D. P.; Tsitsiklis, J. N. Neuro-dynamic programming. Athena Scientific, 1996.

BISHOP, C. M. Pattern recognition and machine learning (information science and statistics). Springer, 2006.

Blum, C. Ant colony optimization: Introduction and recent trends. Physics of Life Reviews, v. 2, n. 4, p. 353-373, 2005.

Boley, D.; Gini, M.; Gross, R.; Han, E.-H.; Karypis, G.; Kumar, V.; Mobasher, B.; Moore, J.; Hastings, K. Partitioning-based clustering for web document categorization. Decis. Support Syst., v. 27, n. 3, p. 329-341, 1999.

Celenk, M. A color clustering technique for image segmentation. Comput. Vision Graph. Image Process., v. 52, n. 2, p. 145-170, 1990.

Chung, F. R. K. Spectral graph theory (cbms regional conference series in mathematics, no. 92) (cbms regional conference series in mathematics). American Mathematical Society, 1997. 
Cormen, T. H.; Leiserson, C. E.; Rivest, R. L.; Stein, C. Introduction to algorithms. Cambridge Mass.: MIT Press, 2001.

Dorigo, M.; Maniezzo, V.; Colorni, A. The Ant System: Optimization by a colony of cooperating agents. IEEE Transactions on Systems, Man, and Cybernetics Part B: Cybernetics, v. 26, n. 1, p. 29-41, 1996.

Eberhart, R. C.; Kennedy, J. A new optimizer using particle swarm theory. 6th Int. Symp. Micro Machine and Human Science, p. 39-43, 1995.

ERdös, P.; RÉNYI, A. On random graphs. Publ. Math. Debrecen, v. 6, p. 290-297, 1959.

Ester, M.; Kriegel, H. P.; SAnder, J.; Xu, X. A density-based algorithm for discovering clusters in large spatial databases with noise. In: Proceedings of 2 nd International Conference on Knowledge Discovery and Data Mining, 1996, p. 226-231.

Everitt, B. S.; Landau, S.; Leese, M. Cluster analysis. Arnold Publishers, 2001.

Faceli, K.; Carvalho, A. C. P. L. F.; Souto, M. C. P. Cluster ensemble and multi-objective clustering methods. to appear in: B. verma and m. blumenstein (eds.) pattern recognition technologies and applications: Recent advances IGI Global Press, USA, 2007a.

Faceli, K.; Carvalho, A. C. P. L. F.; Souto, M. C. P. Multi-objective clustering ensemble. International Journal of Hybrid Intelligent Systems, Special Issue: Ensemble and Integration Approaches, Selected papers contributed to the HIS-NCEI.06 conference, v. 4, n. 3, p. 145-156, 2007b.

FACElli, K.; Carvalho, A.; Souto, M. Validação de algoritmo de agrupamento. Relatório técnico 254, Instituto de Ciências Matemáticas e de Computação, Universidade de São Paulo, acessado em 07 de outubro de 2007, 2005.

Disponível em http://www.icmc.usp.br/ biblio/relatorios_tecnicos. php

Filippone, M.; Camastra, F.; Masulli, F.; Rovetta, S. A survey of kernel and spectral methods for clustering. Pattern Recognition, v. 41, n. 1, p. 176-190, 2008.

Girvan, M.; Newman, M. E. J. Community structure in social and biological networks. Proc. the National Academy of Science, v. 99, p. 7821-7826, 2002.

Glover, F.; Laguna, M. Tabu search. In: Reeves, C., ed. Modern Heuristic Techniques for Combinatorial Problems, Oxford, England: Blackwell Scientific Publishing, 1993.

GoldberG, D. E. Genetic algorithms in search, optimization, and machine learning. AddisonWesley Professional, 1989. 
Golub, T.; Slonim, D.; Tamayo, P.; Huard, C.; GaAsenbeek, M.; Mesirov, J.; ColLer, H.; Loh, M.; Downing, J.; Caligiuri, M.; Bloomfield, C.; LAnder, E. Molecular classification of cancer: Class discovery and class prediction by gene expression monitoring. Science, v. 286, n. 5439, p. 531-537, 1999.

HAYKIn, S. Neural Networks: A Comprehensive Foundation. McMaster University Halmiton, Ontario, Canada, 1999.

JAIN, A.; Dubes, R. Algorithms for clustering data. Prentice-Hall, 1988.

Jain, A. K.; Murty, M. N.; Flynn, P. J. Data clustering: a review. ACM Comput. Surv., v. 31, n. 3, p. 264-323, 1999.

JiAng, D.; TANG, C.; ZHANG, A. Cluster analysis for gene expression data: a survey. IEEE Transactions on Knowledge and Data Engineering, v. 16, n. 11, p. 1370-1386, 2004.

Julia Handl, D. K.; KNOWles, J. Multiobjective optimization in computational biology and bioinformatics. IEEE Transactions on Evolutionary Computation, v. 11, p. 56-76, 2007.

KARYPIS, G. hmetis - hypergraph and circuit partitioning. Acessado em 12 de fevereiro de 2007, 1998.

Disponível em http://glaros.dtc.umn.edu/gkhome/metis/hmetis/ overview

KARYPIS, G.; HAN, E.-H.; KUMAR, V. Chameleon: Hierarchical clustering using dynamic modeling. IEEE Computer, v. 32, n. 8, p. 68-75, 1999.

Kennedy, J.; Eberhart, R. Particle swarm optimization. Proceedings of the IEEE International Conference on Neural Networks, v. 4, p. 1942-1948 vol.4, 1995.

KIRKPATRICK, S.; Gelatt, C. D.; VeCCHI, M. Optimization by simulated annealing. Science, v. 220, n. 4598, p. 671-680, 1983.

KoHONEn, T. Self-organized formation of topologically correct feature maps. Biological Cybernetics, v. 43, p. 59-69, 1982.

LI, W.; WAng, X. Adaptive velocity strategy for swarm aggregation. Physical Review E, v. 75, n. 1, p. 021917-1 - 021917-7, 2007.

Lusseau, D.; Schneider, K.; Boisseau, O. J.; HaAse, P.; Slooten, E.; Dawson, S. M. The bottlenose dolphin community of doubtful sound features a large proportion of long-lasting associations. Behavioral Ecology and Sociobiology, v. 54, p. 396-405, 2003.

Mitchell, T. M. Machine learning. McGraw-Hill Science/Engineering/Math, 1997. 
Newman, M. E. J. The structure and function of complex networks. SIAM Review, v. 45, p. 167 $-256,2003$.

Newman, M. E. J. Detecting community structure in networks. The European Physical Journal $B$, v. 38, n. 2, p. 321-330, 2004a.

Newman, M. E. J. Fast algorithm for detecting community structure in networks. Physical Review E, v. 69, p. 066133-1 - 066133-5, 2004b.

Newman, M. E. J.; Girvan, M. Finding and evaluating community structure in networks. Physical Review E, v. 69, p. 026113-1 - 026113-15, 2004.

Salman, A.; Imtiaz, A.; Al-Madani, S. Particle swarm optimization for task assignment problem. Microprocessors and Microsystems, v. 26, p. 363-371, 2002.

SCHAEFFER, S. E. Graph clustering. Computer Science Review, v. I, p. 27 - 64, 2007.

Strogatz, S. H. Exploring complex networks. Nature, v. 410, n. 6825, p. 268-276, 2001.

Sutton, R. S.; BARto, A. G. Reinforcement learning: An introduction (adaptive computation and machine learning). The MIT Press, 1998.

Tan, P.-N.; Steinbach, M.; Kumar, V. Introduction to data mining. 1 ed. Addison Wesley, 2005.

The MathWorks, I. Rastrigin's function. Acessado em 12 de fevereiro de 2007, 2006.

Disponível em http://www.mathworks.com.au/access/helpdesk/help/ toolbox/gads/index.html?/access/helpdesk/help/toolbox/gads/ f10136.html

VAndenBergh, F.; Engelbrecht, A. P. A cooperative approach to particle swarm optimization. IEEE Trans. Evolutionary Computation, v. 8, n. 3, p. 225-239, 2004.

Vicsek, T.; Czirók, A.; Ben-Jacob, E.; Cohen, I.; Shochet, O. Novel type of phase transition in a system of self-driven particles. Physical Review Letters, v. 75, n. 6, p. 12261229, 1995.

WATKIns, C. Learning from delayed rewards. Tese de Doutoramento, University of Cambridge, England, 1989.

Watts, D. J.; Strogatz, S. H. Collective dynamics of 'small-world' networks. Nature, v. 393, n. 6684, p. 440-442, 1998.

YiP, A. M.; Ding, C.; Chan, T. F. Dynamic cluster formation using level set methods. IEEE Trans. Pattern Anal. Mach. Intell., v. 28, n. 6, p. 877-889, 2006. 
ZACHARY, W. W. An information flow model for conflict and fission in small groups. J. Anthropol. Res., v. 33, p. 452, 1977.

Zhou, H. Distance, dissimilarity index, and network community structure. Physical Review E, v. 67, p. 061901-1 - 061901-8, 2003a.

Zhou, H. Network landscape from a brownian particle's perspective. Physical Review E, v. 67, p. 041908-1 - 041908-5, 2003b. 